\title{
Disentangling factors that assemble New Zealand's ant communities
}

\author{
by
}

Rafael Forti Barbieri

A thesis submitted to Victoria University of Wellington in fulfilment of the requirements for the degree of Doctor of Philosophy in Ecology and Biodiversity.

Victoria University of Wellington

2014 
This thesis was conducted under the supervision of:

Prof. Philip J. Lester (Primary Supervisor)

Victoria University of Wellington,

Wellington, New Zealand

and

Dr. Julien Grangier (Secondary Supervisor)

Université Claude Bernard

Lyon, France 


\section{General abstract}

Several biotic and abiotic stressors can influence community assembly. The negative co-occurrence patterns observed within many communities, for example, may derive either from behavioural similarities (e.g. species displaying high aggression levels towards each other) or habitat preference. I evaluated the role of several stressors that may shape New Zealand's ant communities. First, I investigated (in chapter 2) the co-occurrence patterns of two native ant communities located within transitional grassland-forest habitats. I also monitored the temperature variation in these habitats over a one-year period. I found that grasslands are exposed to higher temperature variation than forest habitats. I also found that some ants are mostly associated with forest habitats and others with grasslands. Using null models to examine these communities, I found evidence that two ant species (Monomorium antarcticum and Prolasius advenus) exhibit negative co-occurrence patterns. In the reminder of my thesis I developed a series of laboratory-based experiments to examine the processes that could explain the co-occurrence patterns that I observed in these ant communities.

In chapter 3, I subjected heterospecific groups of ants to interactions in controlled conditions. I asked if interspecific aggression predict the survival probability and co-occurrence patterns described in chapter 2. My results demonstrated that aggression predicted the survival probability of interacting ant species and their co-occurrence patterns. I argued that aggressive behaviour might reflect the risks imposed by competitors. Differences in aggression may thus be a key factor influencing sympatric and allopatric cooccurrence patterns of these ant communities.

In chapter 4, I tested the hypotheses that arrival sequence and diet influence the strength of interactions between colonies of two species that exhibited negative co-occurrence patterns ( $P$. advenus and $M$. antarcticum). 
When arriving first, $P$. advenus displayed increased aggression and $M$. antarcticum a defensive reaction. The adoption of a defensive reaction by $M$. antarcticum increased their colony survival probability. Changes in carbohydrate and protein availability modulated colony activity rates of both species. These results indicate that arrival sequence can modulate the territorial behaviour displayed by interacting species in situations of conflict. Also, I showed that these ant species adjust their foraging activity rates in according to their diet, but different species do so differently.

In chapter 5, I expanded the scope of chapter 4 and asked if aggression and foraging behaviour of $P$. advenus and $M$. antarcticum change in different conditions of temperature, diet and group size. For both ant species, changes in temperature had stronger effects on small than large colonies. Small groups of $M$. antarcticum displayed higher foraging activity at lower temperatures. Conversely, small groups of $P$. advenus displayed higher foraging activity at high temperatures. Also, small M. antarcticum colonies displayed increased aggression and significantly reduced the size of large $P$. advenus colonies, regardless of temperature and diet. These results suggest that $P$. advenus and M. antarcticum perform differently at different temperatures. Furthermore, I demonstrated that the persistence of these small colonies might be related to their ability to modulate foraging activities and interspecific aggression according to the environment.

I also investigated (in chapter 6 ) the effects of a neurotoxic pesticide (neonicotinoid) on a native $(M$. antarcticum) and an invasive ant (Linepithema humile). I tested whether sublethal contamination with a neonicotinoid affects foraging, fitness and the outcome of interspecific interactions between these ants. Overall, pesticide exposure increased aggression of the invasive ant and reduced the aggression of the native species. Importantly, non-exposed individuals of the invasive species subjected to interactions against exposed natives were less aggressive, but more likely to survive. These results suggest 
that the modification of the physicochemical environment by pesticide contamination could change the dynamics of communities and influence invasion success.

Overall, this thesis highlights that synergistic effects between several biotic and abiotic factors influence community assembly. My results suggest that non-random allopatric patterns of niche occupancy observed in these ant communities are better explained by high levels of aggression displayed between pairs of species that seldom co-occur, though I was unable to falsify the hypothesis that habitat preference also plays a role in determining their distribution and co-occurrence patterns. The modification of behaviour by external factors - either natural (e.g. temperature) or human mediated (e.g. pesticide exposure) - likely has broad effects on population and community dynamics and on patterns of species co-existence. 


\section{Acknowledgments}

Firstly, I would like to thank my supervisor Professor Phil Lester for his support and patience throughout this degree. I also thank to my secondary supervisor Dr Julien Grangier for his assistance and helpful comments on chapters two, four and five.

I am grateful to my colleagues Monica Gruber, Meghan Cooling, Fabian Westermann, Davide Santoro and Alexandra Sébastien for their helpful comments on my work throughout. I also extend my acknowledgments to my office mates Mark Heath and Patrick Kavanagh for their support, friendship, and the uncountable times they read my stuff. I have learned from all of these people and it has been great to have them around to discuss ideas, seek advice and drink coffee, or a beer with.

I thank Ken Ryan and Alexander Miller for their collaboration on chapter six. I would also like to thank Evan Brenton-Rule, Chris McGrannachan and Clement Chevallier for all their assistance in the field. I thank Evan, in particular, for his assistance in the lab and the very useful insights on chapter three.

I express my gratitude to the technicians and administrators at VIC. Mary Murray, Sandra Taylor, Paul Marsden, Mark Stephen, Patricia Stein and Lesley Thompson for their help and promptness to solve administrative problems. Neville Higgison, Craig Doney, Tristam Price and Shaun Graham for their assistance on running the temperature-controlled room and equipment support.

Thanks to the ones who participated of Bug Club and Ant Club for helpful comments on various drafts and presentations. This is a great opportunity to thank Stephen Hartley for his support and encouragement to explore the world of $\mathrm{R}$. 
I thank to the staff of the DOC and Greater Wellington for granting access to land in Nelson Lakes National Park and Kaitoke Regional Park. I also thank AgResearch for authorize the use of their area on the surroundings of Kaitoke. In particular, I thank Denis (farm manager) for his support and promptness throughout the last three years.

I would like to thank Victoria University of Wellington for the financial support throughout this degree without which the whole thing would not have been impossible.

I would like to thank my mother Marcia, my father Marco and my brother Samuel for their support and encouragement throughout this degree.

Finally, I would like to thank my wife Amanda for her support, encouragement and the lovely nicknames she came up with for some ants. She has put up with a lot and helped me keep this degree in focus. 


\section{Publications from this thesis}

\section{Journal articles from this thesis}

Barbieri R.F., Grangier J. \& Lester P.J. (2013) Arrival sequence and diet mediate interspecific competition in an ant community. Insectes Sociaux 60: 463-473.

- Author contribution: RFB designed and performed the experiment, analyzed the data and wrote the manuscript; JG and PJL edited the manuscript

Barbieri R.F., Lester P.J., Miller A.S. \& Ryan K.G. (2013) A neurotoxic pesticide changes the outcome of aggressive interactions between native and invasive ants. Proceedings of the Royal Society B doi:10.1098/rspb.2013.2157

- Author contribution: RFB designed and performed the experiment, analyzed the data and wrote the manuscript; PJL wrote the first draft of the introduction and edited the manuscript; ASM wrote the first draft of methods and performed the experiment; KGR edited the manuscript

Barbieri R.F., Grangier J. \& Lester P.J. (In review) Synergistic effects of temperature, diet and colony size on the competitive ability of two ant species. Austral Ecology.

- Author contribution: RFB designed and performed the experiment, analyzed the data and wrote the manuscript; JG and PJL edited the manuscript 
Barbieri R.F., Grangier J. \& Lester P.J. (In prep.) Interspecific aggression predicts co-occurrence patterns in native ant communities.

- Author contribution: RFB designed and performed the experiment, analyzed the data and wrote the manuscript; JG and PJL edited the manuscript

Barbieri R.F., Brenton-Rule E.C. \& Lester P.J. (In prep.) Argentine ants vs. native ants: interspecific aggression and survival.

- Author contribution: RFB designed and performed the experiment, analyzed the data and wrote the manuscript; ECB designed and performed the experiment; PJL edited the manuscript 


\section{Table of Contents}

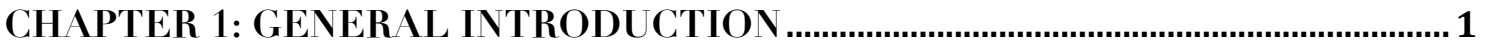

CHAPTER 2: CO-OCCURRENCE PATTERNS OF TWO NATIVE ANT

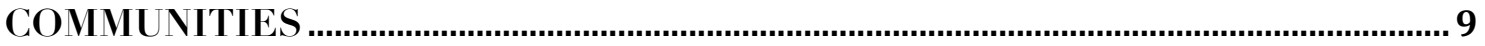

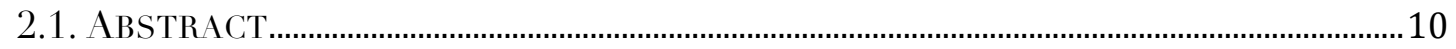

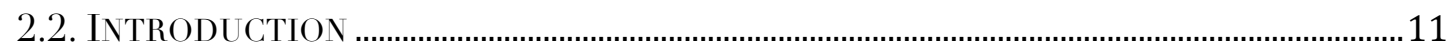

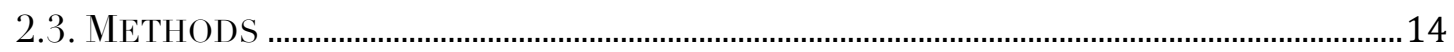

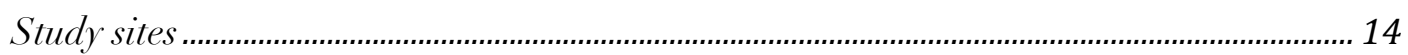

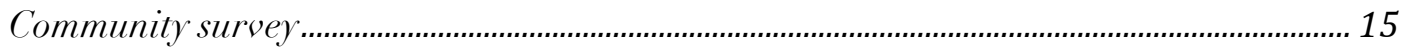

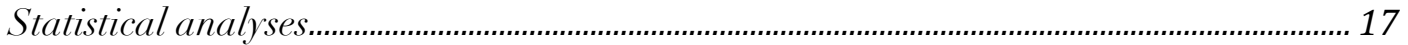

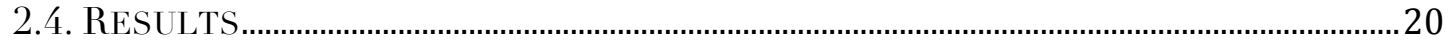

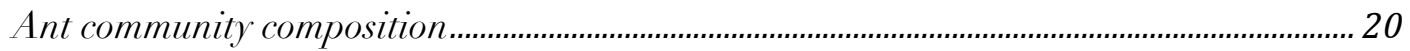

Co-occurrence patterns …………………………............................................................. 21

Temperature

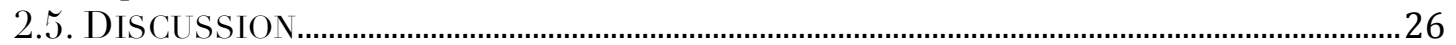

CHAPTER 3: INTERSPECIFIC ENCOUNTERS: AGGRESSION LEVELS

PREDICT SURVIVAL PROBABILITY AND OCCURRENCE PATTERNS .............29

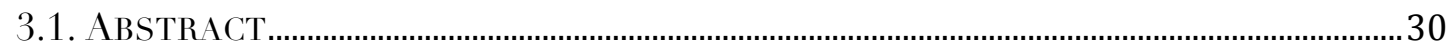

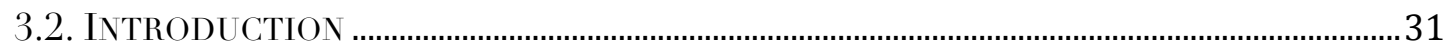

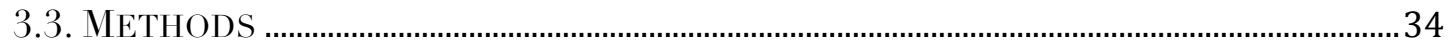

Experimental setup and design ........................................................................................... 34

Statistical analyses

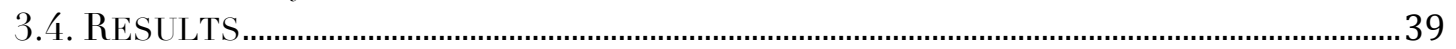

Effects of opponents' identity and body size on survival probability ................................... 39

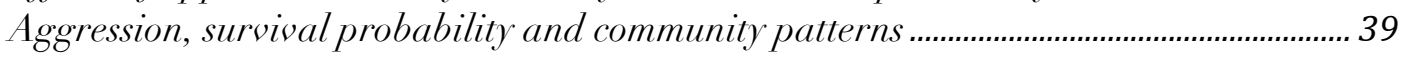

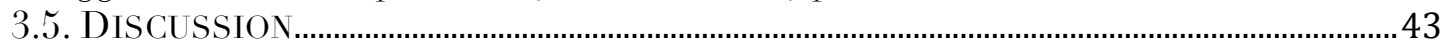

CHAPTER 4: ARRIVAL SEQUENCE AND DIET MEDIATE INTERSPECIFIC

COMPETITION

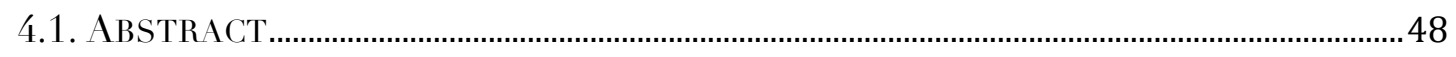

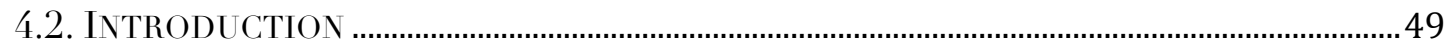

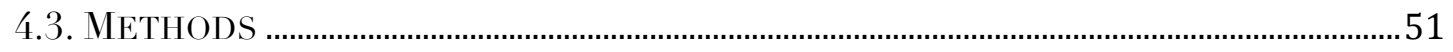

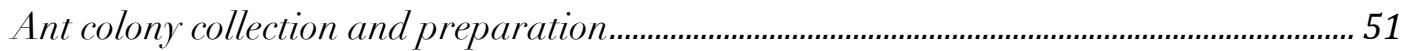

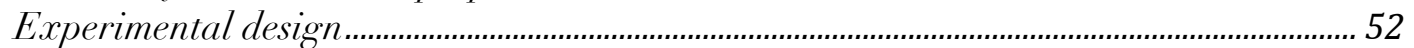

Interspecific aggression level.......................................................................................... 53

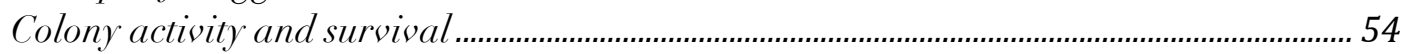

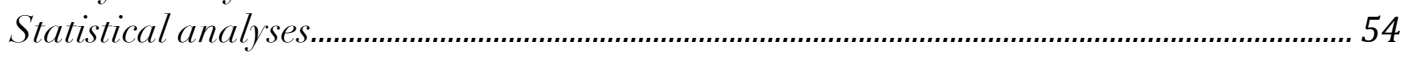

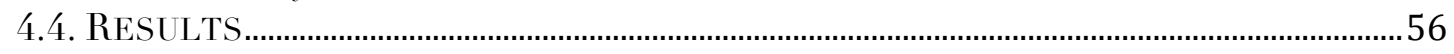

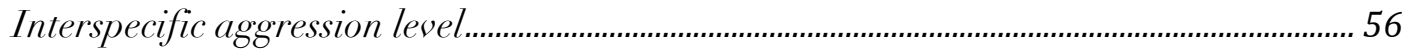

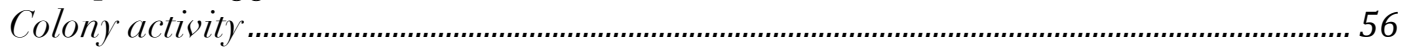

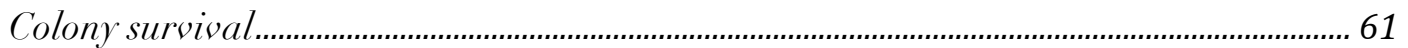

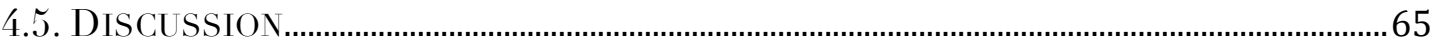




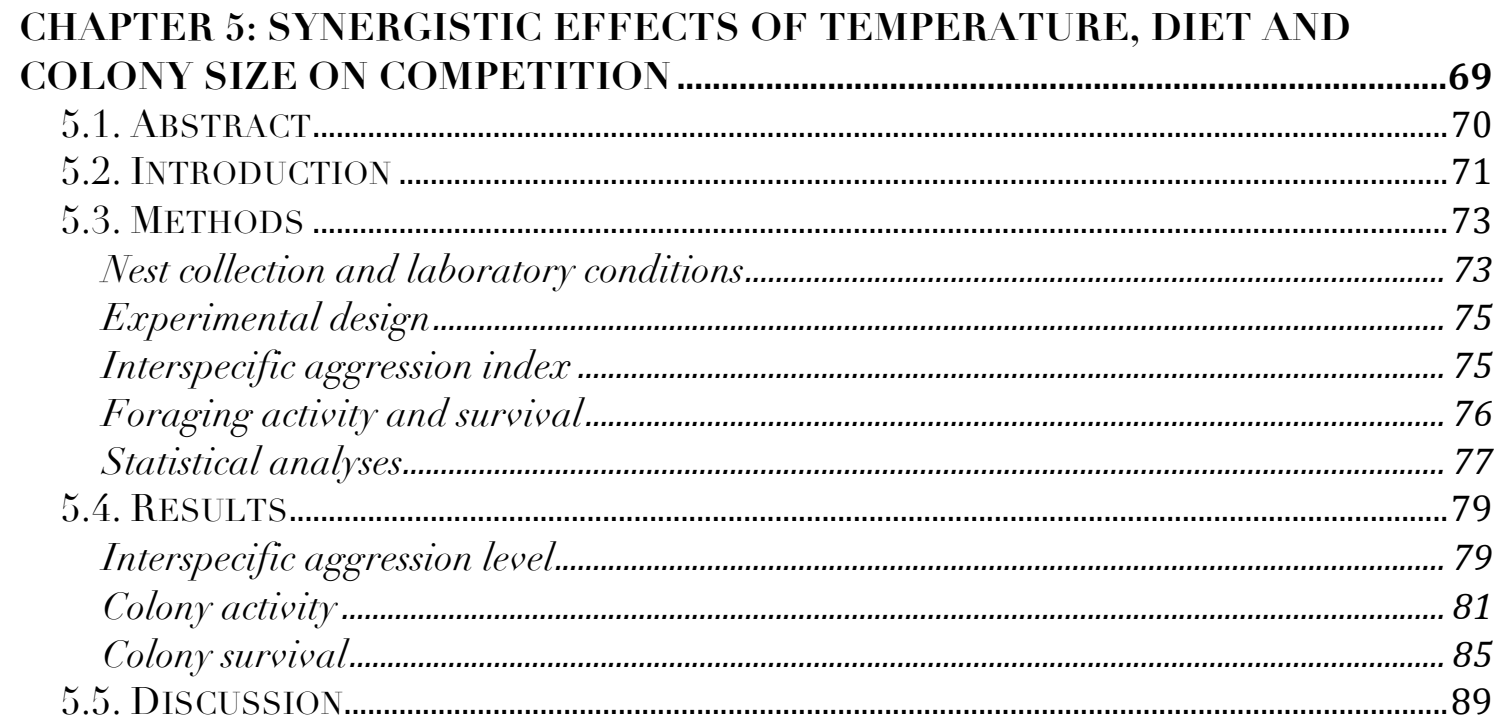

\section{CHAPTER 6: HUMAN MEDIATED STRESSOR: A NEUROTOXIC PESTICIDE} CHANGES THE OUTCOME OF AGGRESSIVE INTERACTIONS .........................93

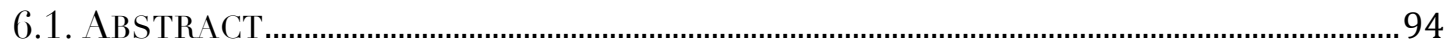

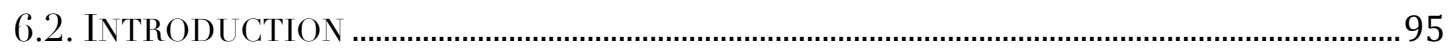

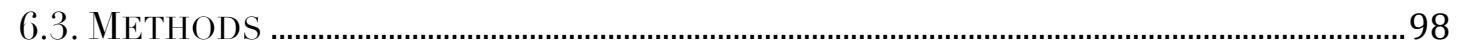

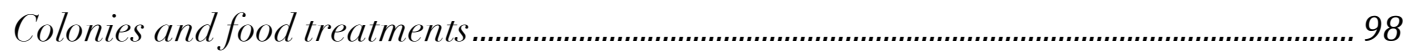

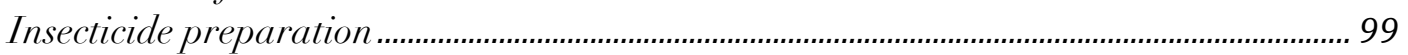

Feeding treatments ............................................................................................................. 99

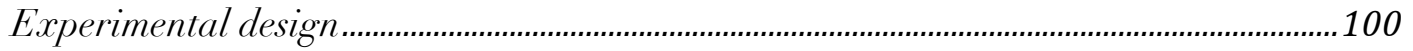

Agonistic interaction and worker survival probability .......................................................103

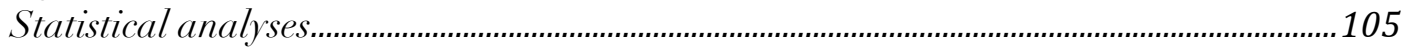

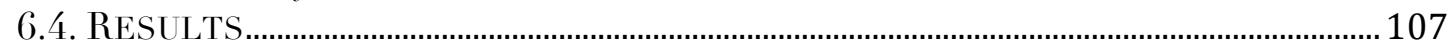

Effects of sublethal doses of the neonicotinoid on workers and colony fitness...................107

Effects of sublethal doses of the neonicotinoid on interspecific interaction and survival

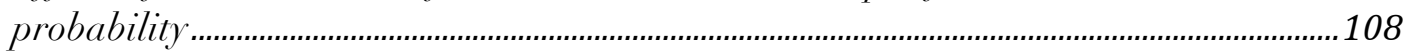

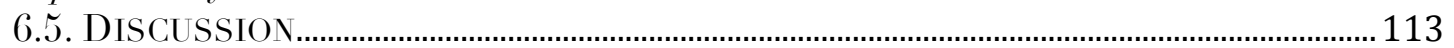

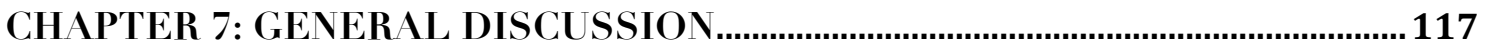

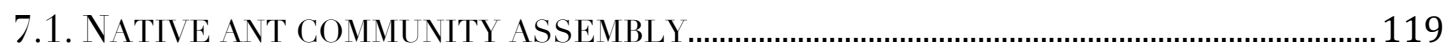

The role of aggression ..............................................................................................................119

The role of arrival sequence and colony size ……..............................................................121

The role of temperature ............................................................................................................122

The role of food sources ......................................................................................................124

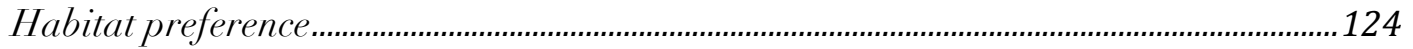

7.2. DIFFERENCES IN CO-OCCURRENCE PATTERNS BETWEEN SITES …………………...126

7.3. ANTHROPOGENIC IMPACTS AND BIOLOGICAL INVASIONS .........................................127

7.4. CONTRIBUTIONS OF THIS STUDY AND FUTURE DIRECTIONS .......................................128

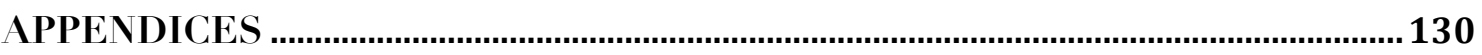

Appendix A - The foraging patterns of Prolasius advenus and Monomorium antarcticum and additional information regarding statistical models................................131

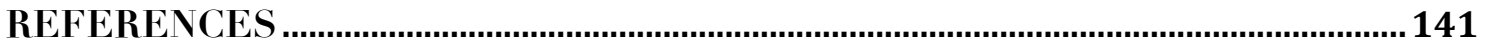




\section{Chapter 1: General introduction}


How do communities assemble? Several theories have attempted to provide an answer to this question (Elton 1949, Hutchinson 1959, Abrams 1983, Chesson and Case 1986). The neutral theory (Hubbell 2001), for example, proposes that community patterns originate from a "zero-sum", where sympatric species have equal probabilities to colonize and compete for resources. Diamond (1975), in contrast with Hubbell's neutral theory, suggests that community assembly derives from non-random processes, which are typically regulated by the physical and biological environment. According Diamond, competition is one of the main factors determining community assembly and regulating species abundances. Diamond (1975) used a checkerboard distribution map of two species of fruit doves (Ptilinopus) to test for non-random patterns of species co-occurrence in the Bismarck Archipelago. Interestingly, he found that these two species of fruit doves never co-occur and thus argued that competitive exclusion was the main factors assembling these communities.

Since Diamons's assembly rules were first proposed, there have been several controversial arguments for and against the role of competition in determining community assembly and composition. Connor and Simberloff (1979), for example, strongly opposed to Diamond's hypothesis that interspecific competition as a major organizing force. Connor and Simberloff (1979) suggested that the patterns of co-occurrence of Diamond's avian communities could be derived from differences in dispersal abilities. Furthermore, they argue that robust observations of species are needed to detect competition, but competition may not be apparent from simple spatially based null models. Diamond's (1975) assembly rules suggest that species living in sympatry should be less similar than species that seldom cooccur. According to Connell (1980), such limits to similarity would be only possible in communities with low species diversity. 
An increasingly common approach is to assume that biotic and abiotic 'filtering' processes assemble communities (Leibold et al. 2004, Moritz et al. 2013). The metacommunity theory provides an integrative framework for ecological studies as it incorporates dispersal constraints (Hubbell 2001) and the context-dependence of ecological interactions (Diamond 1975, Abrams 1983). Local communities are frequently composed by multiple species that often interact and affect each other. In a metacommunity, however, patchy communities are connected by dispersal (mass effects) and at risk of extinction (Leibold et al. 2004). Invasion processes, for example, follow metacommunity dynamics but at macro-ecological scales (Puth and Post 2005) and the mechanisms promoting dispersion of invaders are frequently human mediated (Mack et al. 2000).

In any community, several deterministic and stochastic stressors thus filter the abundance of resident species and establishment of newcomers (Grime 1977, Southwood 1977, Chase and Myers 2011). The presences of highly aggressive competitors, extreme temperature conditions, or the lack suitable food sources are examples of deterministic drivers of extinctions. Environmental change - such as the effects of seasonal temperature variation on the availability of food sources, animal physiology, and behaviour - are examples of stochastic mechanisms that could influence community assembly (Tilman 2004, Chase and Myers 2011, Dante et al. 2013, Stegen et al. 2013). It is unlikely though that different species follow similar conventions of ecological engagement. Species living in sympatry may respond differently to environmental changes and exhibit differences in fitness, food preferences and competitive ability (Abrams 1983, Pacala and Tilman 1994, Leibold et al. 2004).

There is evidence that competition and aggression are major forces assembling ant communities (Hölldobler and Wilson 1990; Andersen 1992, 1995, Cerdá et al. 2013). Several studies have shown that ants are territorial 
organisms and often deploy strategic behaviours and high levels of aggression during encounters with their opponents (Hölldobler and Wilson 1978, Hölldobler and Lumsden 1980, Barton et al. 2002, Heuts et al. 2003). Enemy specification, for example, appears to be an extreme case of aggression and territoriality. Enemy specification is described as an evolved defensive action directed to identify and react against the most dangerous opponents in a precise way (Hölldobler and Wilson 1990). Such a reaction was first described when the fire ant Solenopsis invicta invades the territory of the ant Pheidole dendata (Wilson 1975, 1976). As soon as P. dendata detects S. invicta workers, scouts of the ant $P$. dendata trigger massive recruitment to fight against the fire ant. The presence of a single fire ant worker activates such strong reaction. It seems that the evolved enemy-specific response described by Wilson (1975) is genus-specific (Feener 1986, 1987), and, as far as is known, displayed by Pheidole only in the presence of fire ants.

Negative patterns of co-occurrence have been described in ant communities at local (Czechowski and Marko 2005) and regional scale (Gotelli and Ellison 2002). In these examples, ant communities are continuously distributed across broad landscapes. One may argue that such patterns are not typical of metacommunities - which assumes that discrete communities are associated with isolated habitats. However, ant communities showing negative co-occurrence patterns at local or regional scales are typically assembled by metacommunity dynamics (Leibold et al. 2004; Spiesman and Cumming 2008).

In ant communities, multiple factors, such as temperature, adequate food sources, numerical dominance, physicochemical characteristics of the environment, or even the time of arrival into the community could modulate aggression and influence population dynamics and community assembly. Diurnal and seasonal temperature variation, for example, were reported to influence dominance hierarchy (Cerdá et al. 1997) and niche partitioning of ant communities (Albrecht and Gotelli 2001). Furthermore, changes in 
temperature can affect walking speed and the probability of ants to discover food resources (McGrannachan and Lester 2013). Adequate food availability is crucial to ensure species existence and fitness (Wagner et al. 2013). Changes in diet may compromise the ability of ants to compete for resources (Davidson 1997) and even alter the encounter ratio between competitiors (Oster and Wilson 1978). Numerical dominance is another important factor that directly affects both the establishment of newcomers into local communities and the competitive ability of already established groups (Andersen 2008, Rice and Silverman 2013). Ants frequently adopt differential behaviours in response to group size. In large groups, ants may either display higher levels of aggression towards their opponents or adopt different strategies to defend the colony (Sagata and Lester 2009; Tanner 2006). The ability of ant colonies to persist is largely determined during the establishment process (Andersen 2008). As the colony grows, so do its foraging abilities, resource needs and capacity to monopolize resources. Thus, the arrival sequence of species during colonization events often favours the species that arrives first, with a reduction in both the fitness and establishment success of subsequent species (Cole $1983 \mathrm{a}, \mathrm{b})$.

New Zealand's native ant community is composed by 11 species, all of which are endemic (Don 2007). A total of 37 ant species are known to have become established (Don 2007), including the invasive Argentine ant Linepithema humile (Ward et al. 2010). However, some forest and open habitats throughout New Zealand still exhibit a native ant community composition (Don 2007). The factors structuring these ant communities and determining the establishment success of newcomers, such as the Argentine ant, may include habitat preference, tolerance for abiotic conditions, anthropogenic influence, and interspecific competition (Roura-Pascual et al. 2011, Cooling et al. 2012). For example, New Zealand's native forests are mainly composed by several broad-leaved tree species, conifers and beech trees (Nothofagus spp.) 
(Leathwick 2011; Leathwick and Whitehead 2001). In New Zealand beech forests, sooty beech scale insects (Ultracoelostoma spp.) are ubiquitous and offer abundant supply of honeydew (Dhami et al. 2011). Honeydew is an important energetic food source for several invertebrates, including ants, and may modulate ecological interactions in these communities Morales et al. 1988, Duthie and Lester 2013).

In this thesis, I investigated the co-occurrence patterns within two native ant communities. I then used an experimental approach to evaluate the effects of several stressors that may determine the occurrence patterns in these ant communities. I also assessed (in Chapter 3 and 6 ) certain aspects of interspecific interactions between a native ant (Monomorium antarcticum) and the invasive Argentine ant L. Humile. Each chapter of this thesis was written as a stand-alone paper. Therefore, there is some repetition in the information I presented in the introduction and methods of some chapters.

In chapter 2, I firstly describe the co-occurrence patterns of two native ant communities located within transitional forest-grasslands in New Zealand. I use null models to examine if two native ant communities show evidence for deterministic assembly rules. In the remainder of my thesis, I develop a series of laboratory-based experiments to examine the processes for these cooccurrence patterns.

In chapter 3, I subject groups of native ant species and Argentine ants to pairwise interspecific interactions under controlled laboratory conditions. I investigate the role of interespecific aggression on the survival probability and patterns of co-occurrence described in chapter 2.

In chapter 4, I subject two ant species that displayed negative cooccurrence patterns (Prolasius advenus and M. antarcticum) to interspecific interactions in controlled conditions to test the hypothesis that arrival sequence and diet modulate the outcome of behavioural interactions. I 
investigated whether the primary species (the species that arrives first) deploys strategic behaviours that enhance their ability to secure resources and persist in the presence of a competitor arriving later in the territory.

In chapter 5, I expanded the scope of chapter 4 and tested if interspecific aggression and foraging behaviour of $P$. advenus and $M$. antarcticum change in different conditions of temperature, diet and group size. Then, I asked if behavioural changes affect the probability of colonies with different sizes to persist.

In chapter 6 , I evaluated the effects of a neurotoxic pesticide (a humanmediated stressor) on the native $M$. antarcticum and the invasive Argentine ant. I tested if sublethal contamination with a neonicotinoid pesticide affects foraging, colony fitness, and the outcome of interspecific interactions between these ant species.

In chapter 7, I synthesised my results. Overall, this thesis suggests that interspecific aggression is an important factor determining the co-occurrence patterns of the ant communities I investigated. I discussed that several factors such as temperature, food sources and anthropogenic stressors (e.g. pesticides) can modulate interspecific aggression and foraging activities and potentially affect community assembly. 


\section{Chapter 2: Co-occurrence patterns of two native ant communities}




\subsection{Abstract}

Species coexistence is strongly influenced by the physicochemical environment and its inhabitants. Diurnal and seasonal temperature cycles, for example, can up and down regulate animal fitness. Competition has also been hypothesized to be one of the major forces shaping communities. The goals of this chapter are: i) to examine the co-occurrence patterns of two native ant communities that are located in transitional forest-grassland environments in New Zealand; and ii) investigate the temperature range in forest and grassland habitats of each site. I surveyed ant communities in both field sites on two occasions over a two-year period. Additionally, I monitored the temperature of forest and grasslands for a one-year period. I used null model analyses to quantify the co-occurrence patterns observed in both communities. I found that sites differed in their degree of co-occurrence, as well as in their temperature ranges. Two ant species - Prolasius advenus and Monomorium antarcticum - typically had an allopatric distribution. I suggest that interspecific interactions and temperature are important factors determining co-occurrence patterns in these ant communities. I argue that ant community assembly in these areas may derive from the modulation of behaviours by temperature and several factors such as food sources - which will be further explored in the next chapters of this thesis. 


\subsection{Introduction}

An ongoing debate in ecology is the role of competition and habitat preference in community assembly (Diamond 1975; Connor and Simberloff 1979; Hubbell 2001). Despite decades of empirical research, the importance of random and predictable assembly is unresolved. There is evidence that habitat harshness filters for species expressing evolved traits (Gotelli \& Ellison 2002, Dante et al. 2013, Donoso 2013). Temperature variation, for example, can impose severe pressure that may overcome species' physiological boundaries and hinder the ability of individuals to occupy particular niches (Kearney et al. 2009, Amarasekare and Sifuentes 2012). Competition has also been hypothesized to be one of the major forces shaping communities (Diamond 1975, 1978). For example, processes that generate communities where the similarity among coexisting species is limited (e.g. interspecific competition) could increase trait and phylogenetic dispersion among coexisting species (Hutchinson 1959). However, studies have demonstrated that both habitat and competitive constraints operate simultaneously to determine community assembly (Vespäläinen \& Pisarski 1982, Fox \& Brown 1993, Leibold et al. 2004, Decanës et al. 2008, Lester et al. 2009, Manson et al. 2011, Moritz et al. 2013).

In ants, aggressive behaviours are common in situations of interspecific competition (Cerdá et al. 2013). Furthermore, it has been shown that individuals can modulate their interspecific behaviour according to the identity and abundance of their opponents (Wilson 1975, Tanner and Adler 2009, Batchelor and Briffa 2011, Grangier and Lester 2012). The modification of behaviour likely reflects the risks imposed by competitors to individuals overall fitness of individuals, as reported in other animals (Pulliam et al. 1982). Interspecific aggression displayed by individuals of an established and abundant ant colony towards newcomers could potentially reduce the establishment success of these newcomers and influence community cooccurrence patterns. Thus, the presence of aggressive competitors may 
structure ant community patterns and generate discontinuous species mosaics.

Many ant communities are typically assembled by metacommunity dynamics (Leibold et al. 2004, Andersen 2008). Such communities, as with any ecological community, are dynamic systems constantly influenced by biotic and abiotic stressors are thought to influence the ability of species to compete and co-exist with each other (Leibold et al. 2004, Moritz et al. 2013). Furthermore, the majority of ant species are modular organisms. After the establishment process, either via independent or swarming founding, the colony typically remains in their original territory. As soon as the colony reaches maturity, a process that varies from species to species, it produces new reproductive winged queens and males, which disperse, mate and colonize new habitats (Hölldobler and Wilson 1990). Once established in a new territory, the colony often becomes less susceptible to environmental stress (Kaspari and Vargo 1995). However, mechanical disturbance, changes in light and air currents, and the presence of antagonists can promote colony movement. Diurnal and seasonal temperature cycles can up- and downregulate ants' physiology, fitness and behaviour (Killen et al. 2013). Changes from warm to cold temperatures, for example, have been reported to reduce reproduction rate (Porter 1988) and the probability of different ant species to find and dominate food sources (Stringer et al. 2007, McGrannachan and Lester 2013). The thermal modulation of population dynamics and animal behaviour likely creates temporal hierarchies in ant communities (Cerdá et al. 1997, Bestelmeyer 2000, Albrecht and Gotelli 2001) and may also drive patterns of species co-occurrence.

In New Zealand, some native ant communities appear to exhibit negative co-occurrence patterns. For example, two endemic ant species Prolasius advenus and Monomorium antarcticum - have similar food preferences and nesting habits (Brown 1958, Don 2007). The ant P. advenus is frequently 
found in forests areas (Burne 2012), and M. antarcticum is ubiquitous in open habitats throughout the country (Don 2007). However, these two ant species have been previously observed to co-occur (Taylor 1959). The factors structuring this distribution pattern may derive from several factors, including habitat preference, tolerance for abiotic conditions and interspecific competition. Differences in microclimatic conditions (e.g. temperature) between forest and open habitats may modulate behaviour and fitness of ant species occurring in these communities. Therefore, transitional forestgrasslands habitats within New Zealand provide a suitable model to explore the mechanisms shaping community structure and determining species coexistence.

In this chapter, I first assessed the co-occurrence patterns within two native ant communities that are located in transitional forest-grasslands environments. Secondly, I used null models to test the hypothesis that these ant communities are competitively structured. Finally, I attempted to explain the observed patterns by discussing the effects of temperature on physiology and behaviour, and how these factors could influence the probability of ants to co-occur. 


\subsection{Methods}

\section{Study sites}

I studied the ant communities of two areas of New Zealand (Figure 2.1). Located in the North Island, Kaitoke Regional Park (41 $\left.4^{\prime} \mathrm{S}, 175^{\circ} 11^{\prime} \mathrm{E}\right)$ is a 2,860 hectares reserve predominantly covered by podocarp and beech (Nothofagus spp.) forests. Located in the South Island, Nelson Lakes National Park (St. Arnaud) $\left(41^{\circ} 48^{\prime} \mathrm{S}, 172^{\circ} 38^{\prime} \mathrm{E}\right)$ is a 102,000 hectares reserve mostly covered by beech forest. In both Kaitoke and St. Arnaud, grasslands occur along the margins of forest patches. In St. Arnaud's beech forests, the sooty beech scale insects (Ultracoelostoma spp.) are ubiquitous and offers abundant supply of honeydew (Duthie and Lester 2013). In Kaitoke, however, scale insects are not as abundant as in St. Arnaud. Honeydew is an important energetic food source for several invertebrates and may modulate ecological interactions in these communities (Morales et al. 1988, Moller and Tilley 1989, Dhami et al. 2011).

Figure 2.1. Location of Kaitoke Regional Park and Nelson Lakes National Park (St. Arnaud) in New Zealand.

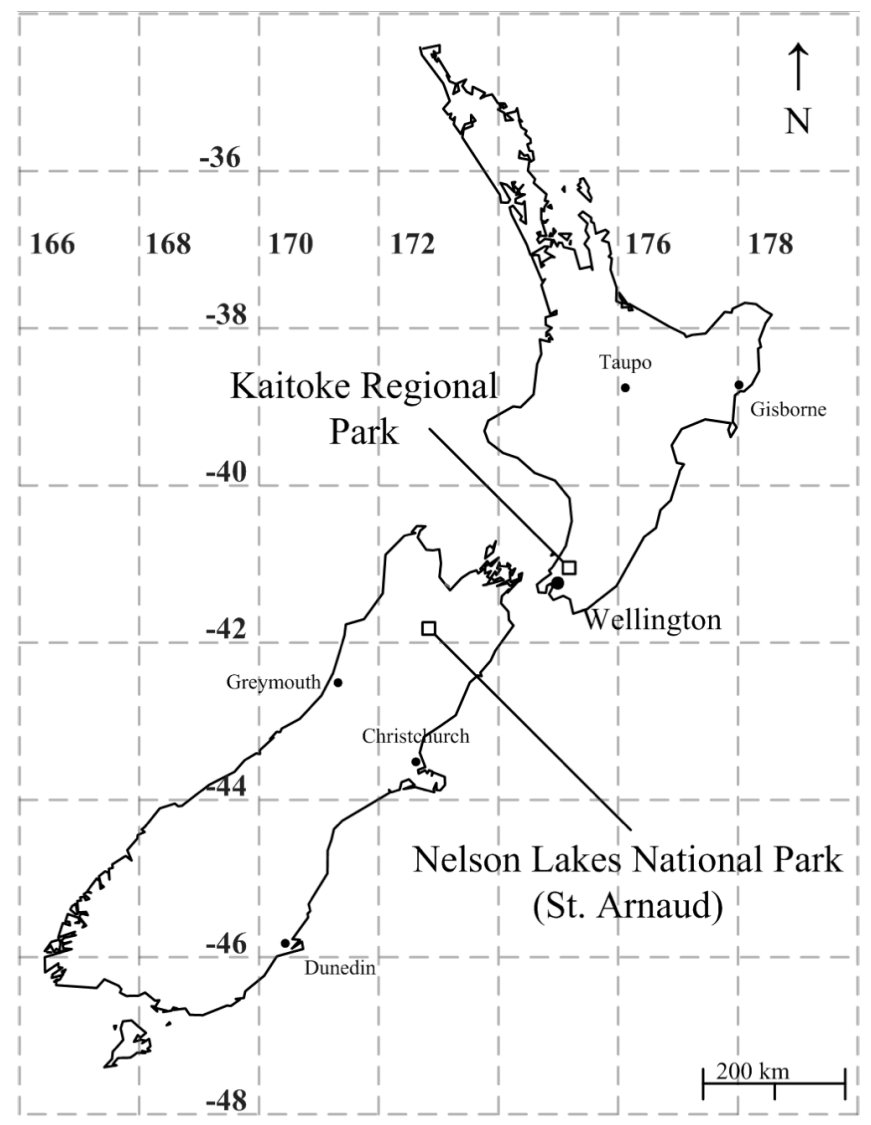




\section{Community survey}

During the summer of 2011 and 2012, I sampled a $1 \times 1 \mathrm{Km}$ grid (100 hectare) covering a grassland-forest transition in Kaitoke and St. Arnaud. Each grid was subdivided into 25 plots of $200 \times 200 \mathrm{~m}$ (Figure 2.2). I generated the grid design of both study sites using Google Earth@ v.7.1.1.1888. Then, I imported the coordinates into a GPS device (Garmin GPS60).

The ant communities were sampled twice, first from February to March 2011 and then during the same months in 2012. In 2011, I surveyed ants by using pitfall traps and tuna-honey baits. Both methods are widely used to assess ant communities (Bestelmeyer et al. 2000). In 2012, I randomly selected three out of five lanes $(1000 \times 200 \mathrm{~m}$ each $)$ crossing from grasslands to forest areas in each grid (each lane was composed of five $200 \times 200 \mathrm{~m}$ blocks). These lanes were only assessed using pitfall traps. In Kaitoke, I could not sample 10 hectares in the forest habitat due to difficulties to access these areas (Figure 2.2a). In St. Arnaud, I could not sample $\sim 12$ hectares in the grassland - which was a swamp (Figure 2.2b).

In each $200 \mathrm{~m}^{2}$ plot, I haphazardly placed pitfall traps (a maximum of ten per plot) and five bait stations of each tuna and honey (Figure 2.2). Pitfall traps were plastic cups $(7 \mathrm{~cm} \varnothing)$ containing $50 \mathrm{~mL}$ of water/ethylene glycol (volume/volume) solution (50/50\%) and a few drops of neutral liquid soap. Pitfall traps were left for seven days. Tuna and honey baits were offered simultaneously on two separated bait stations (plastic dish; $10 \mathrm{~cm} \varnothing$ ), which were placed approximately a meter apart at the soil levels. This approach is appropriate since different ant species may have different food preferences (Cerdá et al. 2013). For tuna baits, I used canned water-based tuna. For honey baits, I used a cotton wool soaked with honey/water (v/v) (20/80\%) solution. Baiting was performed for a three-hour period, always between 10am and $3 \mathrm{pm}$. Ants observed on each bait station were collected with an aspirator. 

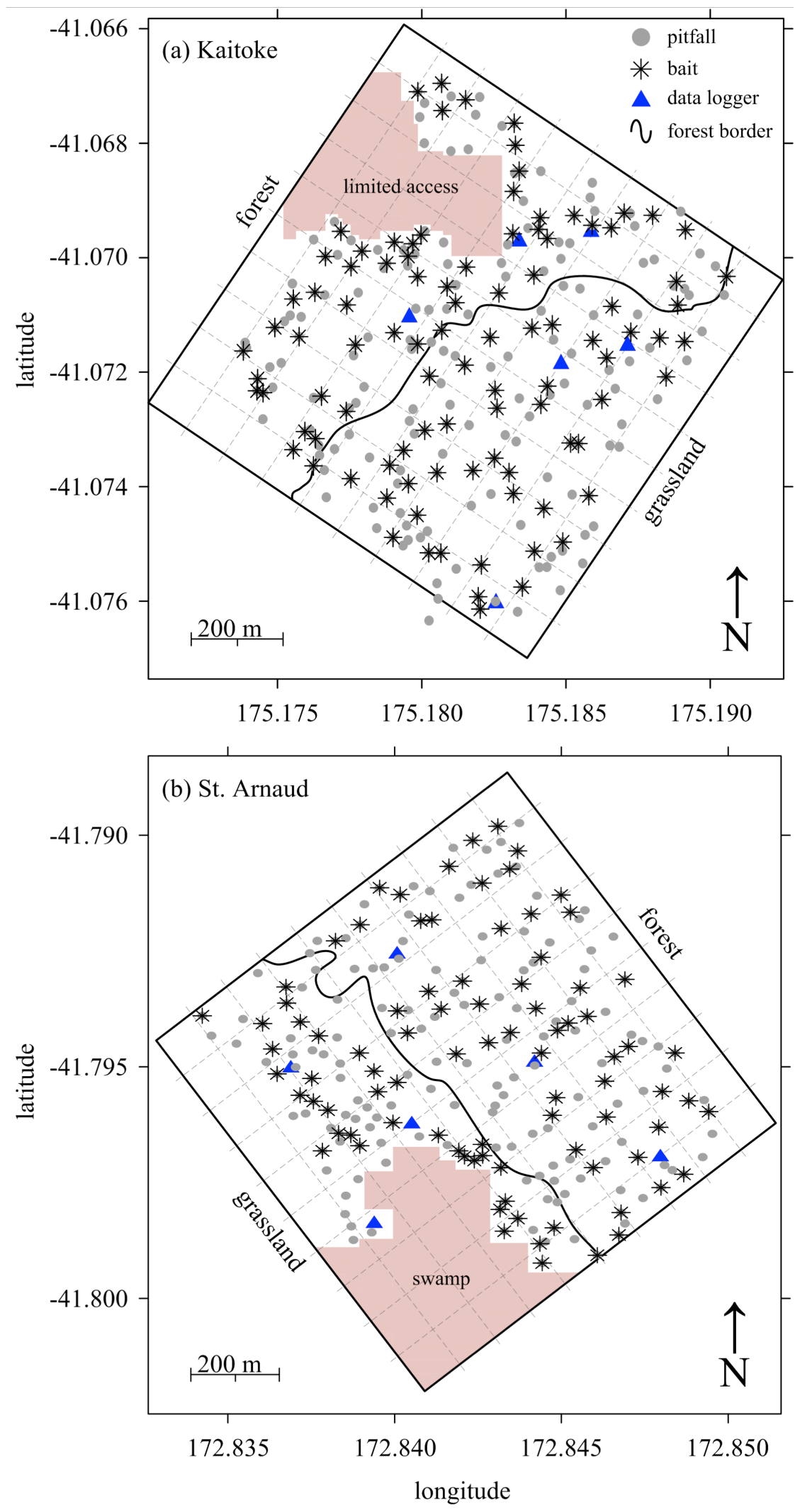

Figure 2.2. The $1 \times 1 \mathrm{Km}$ grid design and the sampling effort to assess ant communities in (a) Kaitoke and (b) St. Arnaud. Zones highlighted in the grid could not be sampled. The solid lines across the grids indicate the forest border. 
At each site, I monitored the temperature from March 2012 to April 2013. I placed six data loggers (TidbiTv2; UTBI-001; onset ${ }^{\circledR}$ ) at the soil level and at least $60 \mathrm{~m}$ away from the forest border in both directions. Three loggers were placed in the forest and three in the grassland (Figure 2.2). This approach provided detailed information about temperature conditions faced by ants in forests and grasslands.

\section{Statistical analyses}

\section{Spatial patterns}

To test for non-random patterns of co-occurrence I used the C-score analysis implemented in EcoSim v. 7.0 (Gotelli and Entsminger 2004). The Cscore is the average value of all possible checkerboards between all pairs of species (Stone and Roberts 1990). Each checkerboard unit is calculated by $\left(r_{\mathrm{a}}\right.$ $-S)\left(r_{\mathrm{b}}-S\right)$ where $S$ is the total number of 'sampling unities' (e.g. pitfall traps) shared by the species pair, and $r_{\mathrm{a}}$ and $r_{\mathrm{b}}$ are the row totals for species "a" and "b", respectively. If the community exhibits an allopatric pattern of cooccurrence, the observed C-score should be significantly larger than expected by chance. A C-score of zero indicates that species always co-occur (Stone and Roberts 1990). For all C-score analyses I present below, observed C-scores were compared to average C-scores generated from 5000 randomized matrices. I used only ant species detected at least 10 times in the C-score analysis. This was considered appropriate given that rare species were unlikely influence the overall patterns of co-occurrence.

Firstly, I used the "guild structure" option in EcoSim to compare the ant community assemblage between sites. This analysis preserves the structure of the matrix but shuffles the position of the locations (columns) to test for differences in the variance of the observed C-score. A significantly small variance indicates similar degrees of co-occurrence between sites. 
Conversely, a significantly large variance indicates different degrees of cooccurrence between sites.

Then, I asked if ant communities of each Kaitoke and St. Arnaud present sympatric or allopatric patterns of co-occurrence. For these two series of analysis, I adopted a fixed-equiprobable model structure in EcoSim. This model structure preserves rows (total species) but gives species an equal probability to occur in all columns (sampling points). For each site, separately, I also performed a series of null models (fixed-equiprobable model structure) for each pair of species to extract the standard effect sizes (SES) values for each species pair. The SES value represents the number of standard deviation of the observed C-scores compared with the expected mean value. A SES greater than 2, or lower than -2 , is statistically significantly with a tail probability of 0.05 (Gurevitch et al. 1992).

\section{Habitat preference and community composition}

Additionally, to assess the role of habitat type and ant community composition on the occurrence patterns of each ant species, I used a series of generalized mixed effect models (GLMM) with a binomial response function (presence/absence). Site (Kaitoke/St. Arnaud) was set as a random effect term in the model structure. This approach was appropriate given that I aimed to assess the likelihood of each ant species to occupy different habitats (forest or grassland) and co-occur with each other.

\section{Temperature variation}

Temperature variation between habitats (forest $\times$ grassland) and between sites (Kaiotke $\times$ St. Arnaud) was compared using generalized estimating equations (GEE) with a Gaussian response function. I selected an autoregressive correlation structure, where the correlation between observations is modelled as a function of time. I ran two sets of analysis, one 
for the minimum and one for the maximum temperature registered over a one-year period. This design was appropriate given that the occurrence patterns observed within habitats and in different sites may derive from differences in temperature.

Statistical analyses were performed in $\mathrm{R}$ version 2.15 .3 ( $\mathrm{R}$ Development Core Team 2013). I used the GLMM model function implemented in the package lme4 (Bates et al. 2012). For GEE models, I used the package geepack (Højsgaard et al. 2006). Significance for all tests was assumed at $P<0.05$. 


\subsection{Results}

\section{Ant community composition}

In both Kaitoke and St. Arnaud, I recorded the presence of seven ant species: Prolasius advenus Fr. Smith 1862, Huberia striata Fr. Smith 1876, Huberia brounii Forel 1895, Monomorium antarcticum Fr. Smith 1858 and Pachycondyla sp., Discothyrea antarctica Emery 1895, and Amblyopone saundersi Forel 1982. Prolasius advenus and M. antarcticum were regularly detected in Kaitoke and St. Arnaud (Figure 2.3). The occurrence of three other ant species - H. striata, H. brounï and Pachycondyla sp. - showed clear differences between sites. Huberia brounii and Pachycondyla sp. were abundant in Kaitoke (Figure 3a) but only occasionally observed in St. Arnaud (Figure 2.3b). Conversely, H. striata was abundant in St Arnaud (Figure 2.3b) but only observed in five sampling points in Kaitoke (Figure 2.3a).

Habitat type significantly affected the probability of these five ant species to occur (Table $2.1 ; P<0.007)$. Three ant species $-P$. advenus, $H$. striata and H. brounii - had high occurrence rate in the forest habitat. Conversely, two ant species - M. antarcticum and Pachycondyla sp. - had high occurrence in grasslands. However, P. advenus (Figure 2.3a) and H. striata (Figure 2.3b) were also observed in grasslands, and $M$. antarcticum occasionally occurred in forest habitats in both sites (Figure 2.3), indicating that they could tolerate the abiotic environments. The occurrence patterns of $P$. advenus and H. brounii were positively associated (Table $2.1 ; P<0.001$ ), as well as the occurrence patterns of $H$. striata and $M$. antarcticum (Table $2.1 ; P<0.044$ ). Interestingly, the ant Pachycondyla sp. was not significantly affected by the presence of any ant species (Table $2.1 ; P>0.454)$.

The two other ant species - D. antarctica and A. saundersi - were occasionally observed during the sampling seasons. They were always observed in the forest and only in pitfall traps. In Kaitoke, D. antarctica was a 
singleton and A. saundersi trapped seven times. In St. Arnaud, D. antarctica was trapped eight times and A. saundersi in three occasions.

\section{Co-occurrence patterns}

The between-site analysis (using the "guild structure" in EcoSim) indicated that the average C-score between sites is not significantly larger than expected by change (observed C-score $=508.1$, simulated C-score $=629.2, P_{\text {obs } \geq}$ $\exp =1.000 ; \mathrm{SES}=-11.069)$. Therefore, ant species do not co-occur less than expected by chance between sites. The variance of the C-score index, however, was significantly larger than that expected $\left(\right.$ observed $=1.396 \times 10^{-4}$, simulated $=$ $\left.2.361 \times 10^{8}, P_{\mathrm{obs} \geq \exp }=0.026 ; \mathrm{SES}=-1.536 \times 10^{4}\right)$. This indicates that ant community assemblages differed in the degree of co-occurrence between sites.

For the C-score analyses performed for each site, I analysed only species that I detected at least 10 times. Kaitoke was mainly composed by $P$. advenus, H. brounï, M. antarcticum and Pachycondyla sp.. St. Arnaud was mainly composed by $P$. advenus, H. striata, H. brounii and M. antarcticum. The ant community assemblage of Kaitoke had significantly less co-occurrence than expected by chance (large C-score) (observed C-score $=2040$, simulated C-score $\left.=1809.8, P_{\text {obs } \geq \exp }=0.016 ; \mathrm{SES}=2.102\right)$. Conversely, the ant community of St. Arnaud exhibited a random co-occurrence pattern (observed C-score $=905.5$, simulated C-score $\left.=998.1, P_{\text {obs } \geq \exp }=0.911 ; \mathrm{SES}=-1.359\right)$.

The pairwise analysis indicated that only two ant species, $P$. advenus and M. antarcticum, had less co-occurrence than expected by chance in both sites (Table 2.2; $P<0.001)$. Interestingly, in Kaitoke there was a significant separation between species occurring in forest and grasslands. Both $P$. advenus and $H$. brounii had less co-occurrence with $M$. antarcticum and Pachycondyla sp. than expected by chance (Table $2.2 ; P<0.001)$. 

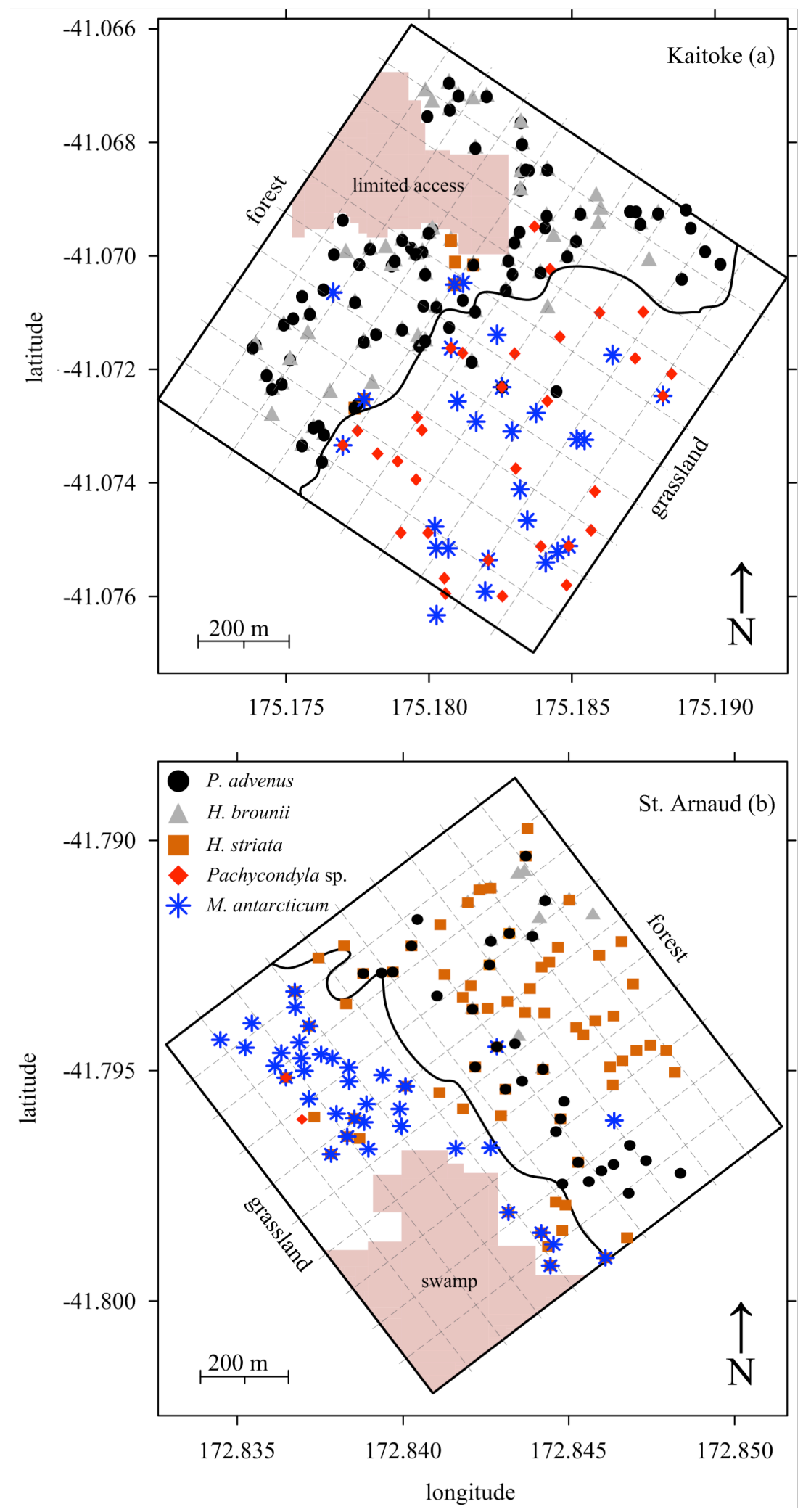

Figure 2.3. The occurrence patterns of the five most abundant ant species encountered in the $1 \times 1 \mathrm{Km}$ grid in (a) Kaitoke and (b) St. Arnaud. Painted zones in the grid could not be sampled. The solid lines across the grids represent the forest border. 
Table 2.1. Results of the generalized mixed effect models evaluating the effects of habitat (forest/grassland) and the presence of the other four ant species on the occurrence patterns of each ant species. The reference category for all the five models is forest habitat.

\begin{tabular}{llrccc}
\hline \multicolumn{1}{c}{ species } & \multicolumn{1}{c}{ predictors } & \multicolumn{2}{c}{$\beta( \pm \mathrm{sem})$} & $z$ & $P$ \\
\hline P. advenus & habitat & -3.628 & $(0.64)$ & -5.629 & $<\mathbf{0 . 0 0 1}$ \\
& H. striata & 0.098 & $(0.38)$ & 0.261 & 0.794 \\
& H. brounii & 1.290 & $(0.32)$ & 3.992 & $<\mathbf{0 . 0 0 1}$ \\
& M. antarcticum & -0.924 & $(0.75)$ & -1.227 & 0.220 \\
& Pachycondyla sp. & 0.677 & $(0.81)$ & 0.836 & 0.403 \\
H. striata & habitat & -1.153 & $(0.42)$ & -2.715 & $\mathbf{0 . 0 0 7}$ \\
& P. advenus & 0.160 & $(0.38)$ & 0.420 & 0.674 \\
& H. brounii & 0.269 & $(0.41)$ & 0.651 & 0.515 \\
& M. antarcticum & 0.940 & $(0.47)$ & 2.011 & $\mathbf{0 . 0 4 4}$ \\
& Pachycondyla sp. & -0.448 & $(1.11)$ & -0.402 & 0.688 \\
& habitat & -2.259 & $(0.60)$ & -3.781 & $<\mathbf{0 . 0 0 1}$ \\
& P. advenus & 1.334 & $(0.32)$ & 4.173 & $<\mathbf{0 . 0 0 1}$ \\
& H. striata & 0.148 & $(0.41)$ & 0.363 & 0.716 \\
& M. antarcticum & -0.392 & $(0.73)$ & -0.533 & 0.594 \\
& Pachycondyla sp. & -0.284 & $(0.86)$ & -0.329 & 0.742 \\
& habitat & 3.160 & $(0.53)$ & 5.946 & $<\mathbf{0 . 0 0 1}$ \\
& P. advenus & -0.542 & $(0.74)$ & -0.730 & 0.466 \\
& H. striata & 0.971 & $(0.41)$ & 2.352 & $\mathbf{0 . 0 1 9}$ \\
& H. brounii & -0.203 & $(0.75)$ & -0.272 & 0.786 \\
& Pachycondyla sp. & -0.038 & $(0.38)$ & -0.099 & 0.921 \\
& habchycondyla sp. & 3.854 & $(0.99)$ & 3.905 & $<\mathbf{0 . 0 0 1}$ \\
& P. advenus & 0.675 & $(0.90)$ & 0.749 & 0.454 \\
& H. striata brounii & 0.078 & $(1.21)$ & 0.064 & 0.949 \\
& M. antarcticum & -0.484 & $(1.01)$ & -0.478 & 0.633 \\
& 0.191 & $(0.42)$ & 0.458 & 0.647 \\
\hline & & & & &
\end{tabular}

Significant $P$-values are highlighted in bold.

\section{Temperature}

In Kaitoke (Figure 2.4a), the minimum temperature registered over oneyear period did not significantly differ between habitats (GEE: $b=-1.10 \pm$ 0.78, $W=1.98, P=0.160)$. However, the maximum temperature was significantly higher in the grasslands than into the forest (GEE: $b=6.03 \pm$ 1.04, $W=33.5, P<0.001$ ). In St. Arnaud (Figure 2.4b), the minimum 
temperature was significantly lower (GEE: $b=-3.62 \pm 0.78, W=21.5, P<$ 0.001 ) and the maximum temperature significantly higher (GEE: $b=4.89 \pm$ $1.45, W=11.4, P<0.001)$ in grasslands than into the forest.

Table 2.2. The observed and expected C-scores for the species pairs that compose each Kaitoke and St. Arnaud ant communities. Negative standard effect size (SES) indicates that species co-occur and positive SES that ant species do not co-occur. Empty cells are species combinations with less than 10 detections.

\begin{tabular}{|c|c|c|c|c|c|}
\hline \multirow{2}{*}{\multicolumn{2}{|c|}{ species pairs }} & \multicolumn{4}{|c|}{ Kaitoke } \\
\hline & & \multirow{2}{*}{$\frac{\text { C-score }(\mathrm{obs})}{-}$} & \multirow{2}{*}{$\frac{\text { C-score }(\exp )}{-}$} & \multirow{2}{*}{$\frac{P(\text { obs } \geq \exp )}{-}$} & \multirow{2}{*}{$\frac{\text { SES }}{-}$} \\
\hline P. advenus & H. striata & & & & \\
\hline P. advenus & H. brounii & 432 & 2938.1 & 1.000 & -6.491 \\
\hline P. advenus & M. antarcticum & 2852 & 1706.2 & $<0.001$ & 4.301 \\
\hline P. advenus & Pachycondyla sp. & 3367 & 1990.9 & $<\mathbf{0 . 0 0 1}$ & 4.660 \\
\hline H. striata & H. brounii & - & - & - & - \\
\hline H. striata & M. antarcticum & - & - & - & - \\
\hline H. striata & Pachycondyla sp. & - & - & - & - \\
\hline H. brounï & M. antarcticum & 2310 & 1484.7 & $<\mathbf{0 . 0 0 1}$ & 3.980 \\
\hline H. brounii & Pachycondyla sp. & 2691 & 1724.5 & $<\mathbf{0 . 0 0 1}$ & 4.131 \\
\hline Pachycondyla sp. & M. antarcticum & 588 & 1001.5 & 1.000 & -3.230 \\
\hline \multirow{2}{*}{\multicolumn{2}{|c|}{ species pairs }} & \multicolumn{4}{|c|}{ St. Arnaud } \\
\hline & & C-score (obs) & C-score $(\exp )$ & $P($ obs $\geq \exp )$ & SES \\
\hline P. advenus & H. striata & 1024 & 1394.9 & 0.971 & -1.686 \\
\hline P. advenus & H. brounii & 288 & 499.5 & 1.000 & -3.089 \\
\hline P. advenus & M. antarcticum & 1312 & 916.1 & $<0.001$ & 3.158 \\
\hline P. advenus & Pachycondyla sp. & & & & \\
\hline H. striata & H. brounii & 621 & 929.6 & 0.979 & -1.756 \\
\hline H. striata & M. antarcticum & 1512 & 1706.8 & 0.823 & -0.765 \\
\hline H. striata & Pachycondyla sp. & & & & \\
\hline H. brounii & M. antarcticum & 702 & 609.1 & 0.239 & 1.047 \\
\hline H. brounï & Pachycondyla sp. & - & - & - & - \\
\hline Pachycondyla sp. & M. antarcticum & - & - & - & - \\
\hline
\end{tabular}

Significant $P$-values are reported in bold

Results showed that Kaitoke and St. Arnaud exhibited differences in ant community assembly. It is possible that ant community patterns are driven by differences in temperature between sites. The "between-site-analysis" indicates that the minimum temperature differed between sites. In St. Arnaud, the minimum temperature was significantly lower in both forest (GEE: $b=-3.65 \pm 0.68, W=28.5, P<0.001)$ and grasslands $($ GEE: $b=-6.0 \pm$ 0.82, $W=53.1, P<0.001)$. Conversely, the maximum temperature did not 
significantly differ between sites, neither in forest (GEE: $b=-0.42 \pm 1.26, W=$ $0.11, P=0.740)$ nor in grasslands (GEE: $b=-1.51 \pm 1.27, W=1.42, P=0.230)$.
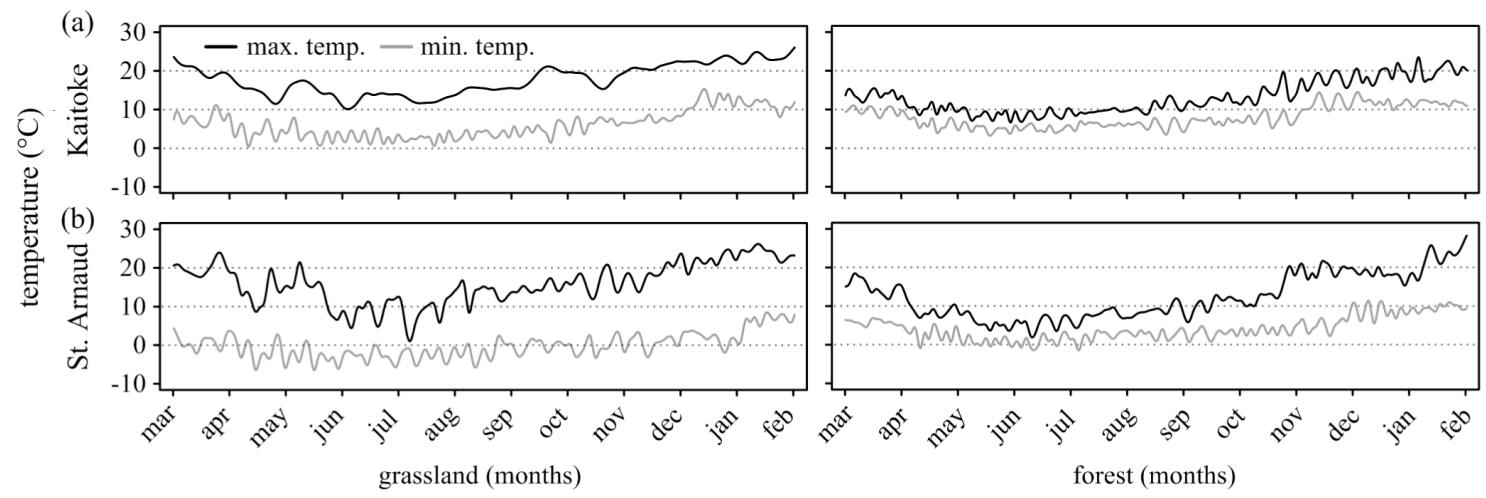

Figure 2.4. The minimum (grey lines) and maximum (black lines) temperature registered in Kaitoke (a) and St. Arnaud (b); grasslands (left panels) and forests (right panels) over a one-year period (March 2012 - February 2013). Lines are the smooth lines $(\mathbf{n}=3)$. 


\subsection{Discussion}

My results show that two ant species $-P$. advenus and $M$. antarcticumexhibited consistent negative co-occurrence patterns in both field sites. Overall, $P$. advenus and $H$. brounii were frequently observed in the forest habitat while $M$. antarcticum and Pachycondyla sp. were often detected in grasslands. Prolasius advenus and M. antarcticum occasionally occurred out of their typical habitats, as well as H. striata, which occurred in both forest and grasslands in St. Arnaud. The differences observed in the ant community assembly between Kaitoke and St. Arnaud may be related to differences in temperature variation. The lower temperatures registered in St. Arnaud may favour species that perform better in such conditions. It is also possible that differences in temperature variation between grasslands and forest habitats, in each site, influenced the observed occurrence patterns.

The influence of temperature on ecological success is well known (Gaston 2000, Amarasekare and Sifuentes 2012), including in ant communities. For example, Rice and Silverman (2013) found that a broad thermal tolerance favoured both establishment and expansion of Asian needle ant colonies (Pachycondyla chinensis), even though Argentine ants (Linepithema humile) were dominant at food sources. Cerdá et al. (1997) demonstrated that temperature variation could create temporal niches in ant communities by adjusting both foraging cycles and the ability of ant species to manipulate food sources. Differences in temperature within habitats may even filter for the occurrence of species with optimum physiological ranges (Amarasekare and Sifuentes 2012). Therefore, the different occurrence patterns observed between Kaitoke and St. Arnaud may derive from the impacts of temperature on foraging activities and behavioural dominance, through species-specific thermal constraints and responses to temperature variations. 
The negative co-occurrence patterns between $P$. advenus and $M$. antarcticum, for example, could be determined by microclimatic conditions. McGrannachan and Lester (2013) found that P. advenus has higher mobility than $M$. antarcticum at $23^{\circ} \mathrm{C}$ and that $P$. advenus was unlikely to recruit under colder temperatures $\left(13^{\circ} \mathrm{C}\right)$. The low temperatures observed in grasslands may reduce the ability of $P$. advenus to locating and using food sources. Conversely, a more stable temperature condition in the forest than in the grassland could potentially favour $P$. advenus. On the other hand, $M$. antarcticum appears to be more tolerant to temperature variation than P. advenus (McGrannachan and Lester 2013), which may explain their ecological success in grasslands but not their absence in forest habitats.

Interspecific aggression and competition are important factors that could determine community assemble (Diamond 1978, Cerdá et al. 2013). Behavioural adaptations and the strength of interspecific aggression appear to enable species to co-exist (Andersen 2008) and generate patchy communities that are usually connected by dispersal (Leibold et al. 2004). Therefore, it is also possible that the tendency of ant species from Kaitoke and St. Arnaud to show allopatric or sympatric occurrence patterns derived from interspecific aggression as a result of antagonistic coevolution.

For Andersen (2008), the ability of ant colonies to persist is largely determined during the establishment process. In a metacommunity, such as the ant communities of Kaitoke and St. Arnaud, winged queens may exhibit a neutral dispersal process, with equal probabilities to reach either forest or grassland. It is important to highlight that dispersal of these species occurs during the warm spring-summer period. Therefore, temperature is unlikely to limit the ability of queens to establish new colonies at this stage. However, it is possible that queens may select optimal temperatures during the colonization process $\mathrm{Yu}$ and Davidson 1997). After about three months - when the first workers appear and the temperature drops - temperature may enhance the 
physiological limitations and modulate both the foraging and aggressive behaviour of ant species.

Changes in the dietary intake have been shown to affect population dynamics and elicit distinct activity rates and behavioural responses in a number of organisms (Oster and Wilson 1978, Davidson 1997, Wagner et al. 2013). Differences in honeydew abundance observed between Kaitoke and St. Arnaud could directly affect fitness, change the outcome of interspecific interactions, modulate the foraging activity of ants and, therefore, influence ant community assembly. It is also possible that variations in the availability of honeydew (Moller and Tilley 1989) directly affect the establishment success of new colonies in forest habitats.

Negative co-occurrence patterns were previously observed in ant communities (Badano et al. 2005; Czechowski and Marko 2005; Sanders et al. 2007). In this study, I demonstrated that at least two ant species (P. advenus and $M$. antarcticum) typically have an allopatric distribution. Though differences in temperature between forest and grasslands may assemble ant communities in Kaitoke and St. Arnaud, several other factors - such as colony size (Sagata and Lester 2009), food preferences (Gaze and Clout 1983, Davidson 1997), presence of parasites (Zhao et al. 2013), the use of evolved fight strategies, morphological characteristics and chemical weapons during interspecific interactions (Hölldobler and Lumsden 1980, Barton et al. 2002, Laforsch and Tollrian 2004, Rajakumar et al. 2012), and even an extreme case of enemy specification (Wilson 1975, Hölldobler and Wilson 1978) - could also influence species co-existence in these areas. Several of these factors will be further explored in the next chapters. 


\section{Chapter 3: Interspecific encounters: aggression levels predict survival probability and occurrence patterns}




\subsection{Abstract}

Is community assembly derived from the outcome of interspecific interactions? In ant communities, for example, aggression is frequently observed. Herein, I asked if aggression influence the survival probability and co-occurrence patterns of ant species. I subjected six ant species (five native species and the invasive Linepithema humile) found within New Zealand to interspecific interactions. First, I assessed the influence of aggression and body size on the survival probability of all ants. Then, I tested the hypothesis that aggression predicts the co-occurrence patterns of two native ant communities previously described in New Zealand. I found that aggressiveness, but not body size, predicted survival probability after interspecific interactions. Furthermore, levels of aggression observed during pairwise interactions predicted the co-occurrence patterns in these two ant communities. Aggressive behaviour likely reflects the risks imposed by competitors and may be the key biotic factor influencing sympatric and allopatric patterns of occurrence in these two native ant communities. 


\subsection{Introduction}

How do interspecific interactions influence species survival and community assembly? A host of studies have examined interspecific behaviours relating to competition (e.g. Wilson 1975, Deitloff et al. 2008, Grangier and Lester 2012, Toms 2013, Harris and Siefferman 2014). The positive and negative influence of interspecific encounters on species cooccurrence patterns is explicit when examining effects of predation (Lima and Dill 1990; Wissinger and McGrady 1993, Louette and Meester 2007, Englund et al. 2009, Colman et al. 2014, Líznarová and Pekár 2013). However, few studies have explicitly tested for the role of direct aggression in species coexistence .(Adler et al. 2007, Wittman and Gotelli 2011).

The responses adopted by interacting individuals can be classified as either aggressive (which would likely inflict direct harm) or nonaggressive (inflict no harm). Aggressive responses may favour the overall fitness of the attacker, but simultaneously expose the attacker to counterattacks from the recipients (Líznarová and Pekár 2013) - if the recipient also adopts an aggressive posture. Conversely, nonaggressive responses, such as avoidance or escape, reduce the odds of a conflict and thus favour the attacker, which does not have to fight to secure resources (Laskowski and Bell 2013). The outcomes of differential responses are likely influenced by a variety of factors. In insects, for example, the presence of evolved morphological characteristics (e.g. larger body size) or chemical weapons likely confer competitive advantages during interspecific interactions (Prestwich 1984; Andersen et al. 1991; Rajakumar et al. 2012). Also, there is evidence that the identity of the interacting species determines the outcome of interspecific interactions (Carlin and Johnston 1984; Scharf et al. 2011) and that individuals interpret risks and learn after frequent encounters with heterospecifics (Dall et al. 2005; Robinson et al. 2009 ). 
In ant communities, for example, interspecific aggression is frequent (Cerdá et al. 2013; Hölldobler 1983; Wilson 1975). The high levels of antagonistic responses displayed by ants have been described by Hölldobler and Wilson (1994) as a "genocidal annihilation" and "if ants had nuclear weapons, they would probably end the world in a week". Once an opponent (e.g. competitors, predators or parasites) is detected in the territory of many ant species, stereotyped responses may considerably vary among taxa, castes and according to recognition cues (Hölldobler and Carlin 1987). Such responses typically involve either resistance or escape. It is important to note, however, that either resisting to or absconding in the presence of an opponent necessarily lowers the fitness of the recipient species (the species interacting with the opponent). Avoidance, for example, could reduce foraging rates (Stephens 2008; Gonzálvez \& Rodríguez-Gironés 2013) or end up with brood, nest and territory loss (Droual 1983; Berghoff et al. 2003; Dahbi et al. 2008). In such situations, the recipient species necessarily avoids any reaction towards the opponent. Therefore, the recipient has its fitness lowered with no further consequences to the opponent.

By imposing resistance, however, recipient species could also deplete the fitness of their opponents (Svensson and Raberg 2010). The nature of the reaction displayed by the recipient species thus determines the impacts on the fitness of their opponents. The recipient could solely prevent fitness loss by using evolved morphological traits. For example, soldiers of the ant Colobopsis spp. (Wilson 1974; Hölldobler and Wilson 1990) and the turtle ant Cephalotes rohsveri (Powell and Dornhaus 2013) have larger heads than their nestmates. The armoured heads of soldier ants are used to block and protect their nest entrances from raids of their enemies. Because the only function of these bigheaded soldiers is to act as living doors (Hölldobler and Wilson 1990), such behaviour may not compromise colony fitness and, conversely, likely maximizes it. The recipient species could alternatively counter attack and 
engage in direct combat against their opponents. Active responses could involve attacks in overwhelming numbers (Hölldobler 1983) or ritualised aggression (Hölldobler 1976). In one-on-one combat interactions, recipients may even sacrifice theirselves to protect their siblings (Jones et al. 2004) or display greatly heightened levels of agonistic behaviour towards specific opponents (Carlin and Johnston 1984; Scharf et al. 2011). Therefore, direct confrontation, where recipients engage in combat with their opponents, could lead to direct impacts on the fitness of both recipients and opponents, and potentially shape community composition.

In this study, I subjected six ant species commonly found in New Zealand to interspecific interactions in laboratory conditions. The levels of aggression displayed by each ant species during pairwise interspecific interactions and their survival probabilities were assessed. Firstly, I asked if the opponent's identity or body size predicts the survival probability of each ant species. Secondly, I verified if the levels of aggression observed during interspecific interactions predict individuals' survival probability. Finally, I tested the hypothesis that the occurrence patterns of the two native ant communities studied in Chapter 2 derive from interspecific aggression. 


\subsection{Methods}

\section{Experimental setup and design}

I collected ant colonies from forest and open field sites located in New Zealand and maintained them in laboratory conditions $\left(20^{\circ} \mathrm{C} \pm 1 ; 12 / 12 \mathrm{~h}\right.$ lightdark cycle). Ants were fed ad libitum with a $20 / 80 \%$ honey/water (v/v) solution and mealworms (Tenebio molitor; larva). Five ant species (Prolasius advenus, Huberia brounii, Huberia striata, Monomorium antarcticum, Pachycondyla sp.) are native, and one is the invasive species (the Argentine ant Linepithema humile). Colonies of M. antarcticum $(\mathrm{n}=10)$ and H. brounii $(\mathrm{n}=3)$ were collected from grasslands and forests, respectively, in Nelson Lakes National Park (St. Arnaud) $\left(41^{\circ} 48^{\prime} \mathrm{S}, 172^{\circ} 38^{\prime} \mathrm{E}\right)$. Colonies of $P$. advenus $(\mathrm{n}=11)$ and $H$. striata $(\mathbf{n}=$ 6) were collected from forests in St. Arnaud and Kaitoke Regional Park $\left(41^{\circ} 4^{\prime} \mathrm{S}, 175^{\circ} 11^{\prime} \mathrm{E}\right)$. Pachycondyla sp. colonies $(\mathrm{n}=12)$ were collected from the gardens of Victoria University of Wellington $\left(41^{\circ} 28^{\prime} \mathrm{S}, 174^{\circ} 77^{\prime} \mathrm{E}\right)$. Argentine ants are unicolonial organisms (Holway et al. 2002), thus we combined colonies collected from invaded areas in North Wellington (Petone) $\left(41^{\circ} 22^{\prime} \mathrm{S}\right.$, $\left.174^{\circ} 91^{\prime} \mathrm{E}\right)$ in one single nesting box.

From these colonies, I haphazardly selected groups of 10 workers and subjected them to interspecific interactions. I adopted a full factorial design with 10 replicates, though only six replicates for all interactions involving $H$. brounii, due to the low number of workers in each colony and the difficulty of finding additional colonies. I subjected each one of the six ant species to interspecific interactions against all of the other five ant species. I adopted the terms "recipient" and "opponent" to designate the role played by each ant species during the trials. It is important to highlight that in any interaction both "recipients" and "opponents" are perpetrators but also receive the reactions displayed by the interacting species. Therefore, the terms "recipient" and "opponent" are herein adopted to describe the role played by the species in 
focus. For example, when I describe the interactions between $P$. advenus with H. brounii. In this situation, P. advenus is the "recipient" and H. Brounï the “opponent". However, when I describe the interaction between H. brounii with P. advenus, the role played by each species switch. Huberia brounï become the "recipient" and P. advenus the "opponent".

I subjected groups of workers to interspecific interactions in a plastic box $(14 \times 10 \times 8 \mathrm{~cm})$ coated with Fluon ${ }^{\mathrm{TM}}$ (Polytetrafluoroethylene PTFE-30; BioQuip Products, Inc.). Inside the plastic box, I placed a ring $(5 \mathrm{~cm} \varnothing ; 5 \mathrm{~cm}$ high) with the inner and outer sides coated with Fluon ${ }^{\mathrm{TM}}$ (Retana and Cerda 1995). Using a coin toss, I randomly placed groups of workers either inside or outside the ring and kept them apart for 20 minutes prior to the start of the trials. I adopted this procedure to isolate the interacting groups of workers and reduce the stress caused by the separation form their nests. To initiate the trial, I then removed the ring and scored the behavioural interactions between pairs of species. Trials were conducted over a year period and a maximum of three replicates of interactions between the same species pair were conducted in the same day (e.g. day one $=P$. advenus vs. $M$. antarcticum $(\mathbf{n}=3) ; H$. brounii vs. H. striata $(\mathbf{n}=3)$; L. humile vs. H. striata $(\mathbf{n}=3))$.

Patterns of interspecific interaction between "recipients" and "opponents" were scored using the following behavioural categories (adapted from Suarez et al. 1999): "ignore" (score 0) - body contact with no reaction; "touch" (score 1) - one ant taps the other with its antennae; "avoid" (score 2) - after contact ants retreat in opposite directions; "aggression" (score 3) - head biting, leg biting, raising up the gaster or spraying acid; and "fighting" (score 4) - prolonged aggression $(>5$ sec) between individuals with one or both ants locking mandibles onto a body part, carrying the other with the mandibles, or gripping and flexing the gaster (usually related to venom use). I scored interspecific interactions for 20 seconds every $2 \mathrm{~min}$ for 20 minutes. Then, I calculated the mean aggression level based on all interactions observed for 
each two-minute period (Table 3.1). The use of aggression scores provided a quantitative estimate of aggression that can be applied for both the "recipient" and the "opponents".

Table 3.1. The body size index (BSI; $n=50$ ) and the aggression levels displayed by each "recipient" during pairwise interactions against different "opponents" $(\mathbf{n}=10)$. The aggression score ranges from 0 (not aggressive) to 4 (highly aggressive).

\begin{tabular}{|c|c|c|c|}
\hline recipient & $\begin{array}{c}\text { body size }(\mathrm{BSI}) \\
\text { mean } \pm \text { sem }\end{array}$ & opponent & $\begin{array}{c}\text { aggression level } \\
\text { mean } \pm \text { sem }\end{array}$ \\
\hline \multirow[t]{5}{*}{ P. advenus } & \multirow{5}{*}{$0.98 \pm 0.013$} & H. striata & $2.35 \pm 0.06$ \\
\hline & & H. brounii & $1.12 \pm 0.05$ \\
\hline & & M. antarcticum & $1.40 \pm 0.06$ \\
\hline & & Pachycondyla sp. & $1.67 \pm 0.11$ \\
\hline & & L. humile & $1.66 \pm 0.22$ \\
\hline \multirow[t]{5}{*}{ H. striata } & \multirow{5}{*}{$2.79 \pm 0.103$} & P. advenus & $1.95 \pm 0.15$ \\
\hline & & H. brounii & $1.56 \pm 0.21$ \\
\hline & & M. antarcticum & $2.27 \pm 0.22$ \\
\hline & & Pachycondyla sp. & $2.42 \pm 0.13$ \\
\hline & & L. humile & $1.62 \pm 0.15$ \\
\hline \multirow[t]{5}{*}{ H. brounii } & \multirow{5}{*}{$1.07 \pm 0.014$} & P. advenus & $0.79 \pm 0.13$ \\
\hline & & H. striata & $1.08 \pm 0.11$ \\
\hline & & M. antarcticum & $1.96 \pm 0.25$ \\
\hline & & Pachycondyla sp. & $1.07 \pm 0.18$ \\
\hline & & L. humile & $1.99 \pm 0.30$ \\
\hline \multirow[t]{5}{*}{ M. antarcticum } & \multirow{5}{*}{$0.93 \pm 0.023$} & P. advenus & $2.32 \pm 0.16$ \\
\hline & & H. striata & $3.06 \pm 0.04$ \\
\hline & & H. brounii & $2.19 \pm 0.13$ \\
\hline & & Pachycondyla sp. & $2.43 \pm 0.09$ \\
\hline & & L. humile & $2.44 \pm 0.19$ \\
\hline \multirow[t]{5}{*}{ Pachycondyla sp. } & \multirow{5}{*}{$9.31 \pm 0.753$} & P. advenus & $1.21 \pm 0.21$ \\
\hline & & H. striata & $2.36 \pm 0.18$ \\
\hline & & H. brounii & $0.55 \pm 0.04$ \\
\hline & & M. antarcticum & $0.79 \pm 0.09$ \\
\hline & & L. humile & $0.57 \pm 0.04$ \\
\hline \multirow[t]{5}{*}{ L. humile } & \multirow{5}{*}{$0.94 \pm 0.008$} & P. advenus & $1.83 \pm 0.09$ \\
\hline & & H. striata & $2.41 \pm 0.10$ \\
\hline & & H. brounï & $2.31 \pm 0.16$ \\
\hline & & M. antarcticum & $2.29 \pm 0.17$ \\
\hline & & Pachycondyla sp. & $2.12 \pm 0.09$ \\
\hline
\end{tabular}


To assess the survival probability of each "recipient" during interspecific interactions against different "opponents", I monitored the number of individuals alive at the set intervals: every two minutes during the first $20 \mathrm{~min}$; then at 25, 30, 40, 50, 60 min; 2, 4, 8, 16, 32 and $64 \mathrm{~h}$. As an external control, I maintained groups containing ten workers of each species $(\mathbf{n}=6)$ under the same experimental conditions, but these groups were not subjected to interspecific interactions.

Additionally, I randomly selected 50 workers from each species and measured their body parts to assess the worker's body size index (BSI; Table 3.1) as follows:

$$
B S I=W l^{(H l+M l) * H w}
$$

where $W l$ is the Weber's length (maximum diagonal distance between the base of anterior slope of the pronotum and the metapleural lobe); $H l$ is the head length (distance from anterior clypeal margin to the midpoint of the occipital margin); $M l$ is the mandible length (length of the mandible at full closure from the mandibular apex to the clypeal margin); $H_{w} w$ is the head width (maximum width of the head behind the eyes). In ants, the head concentrates several morphological adaptations related to defence mechanisms (e.g. larger mandibles) (Hölldobler and Wilson 1990). Therefore, the BSI scales body length as a function of head parts. This value was used as a proxy to assess the effects of body size on the survival probability of ants during interspecific interactions.

\section{Statistical analyses}

To assess the survival probability of interacting species, I first plotted their Kaplan-Maier survival curves and then extracted the final survival probabilities of each "recipients" and "opponents" subjected to interspecific interaction. I compared the effects of each "opponent" on the final survival 
probability of each "recipient" using generalized linear model (GLM) with a Gamma distribution, which was appropriate since data were right skewed towards positive values. I added one to the final survival probabilities as Gamma distribution accepts only values $>0$. I set the identity of the "opponents" as a fixed factor, and their body sizes (BSI) were accounted as a covariate.

I used Spearman's rank correlations to assess the relationship between the aggression displayed by both the "recipient" and the "opponents" during interspecific interactions and the final survival probabilities of the "recipient". I then extracted the standard effect sizes (SES) obtained with the C-score analyses (see Chapter 2; Table 2.2) and correlated with the interspecific aggression observed during pairwise confrontations. This approach is appropriate given that the SES values scale the C-scores in terms of standard deviations, which allows the combined analysis of the data.

All data analyses were performed in $\mathrm{R}$ version 2.15.3 ( $\mathrm{R}$ Development Core Team 2013). I plotted the Kaplan-Maier survival curves using the package "survival" (Therneau 2012). Significance for all tests was assumed at $P<0.05$. 


\subsection{Results}

Effects of opponents' identity and body size on survival probability

All "recipients" had at least one "opponent" that significantly reduced their survival probability by more than $50 \%(P<0.001$; Table 3.2$)$, and one "opponent" that caused no significant loss $(P>0.104$; Table 3) (Figure 3.1). The native ant M. antarcticum was the only "opponent" that significantly reduced the survival probability of all "recipients" $(<40 \% ; P<0.001$; Table 3.2). However, $M$. antarcticum had its survival probability significantly reduced only when interacting against the native H. striata (Figure 3.1d) $(\approx 30 \% ; P<0.001$; Table 3.2). Interestingly, the invasive $L$. humile did not significantly reduce the survival probability of any of the "recipients" $(P>0.104$; Table 3.2) (Figure 3.1). However, H. striata and $M$. antarcticum drastically reduced the survival probability of the invasive $L$. humile $(<20 \% ; P<0.001$; Table 3.2) (Figure 3.1f). I found no significant effects of opponent's body size (BSI) on the final survival probability of any of the "recipients" (Table 3.2; $P>0.470$ ). No ants died in the control groups.

\section{Aggression, survival probability and community patterns}

When "opponents" increased their aggression the survival probability of the "recipients" was significantly reduced (Figure 3.2a; $P=0.032$ ). However, I found no significant relationship between the survivorship of the "recipients" and the levels of aggression they displayed towards different "opponents" (Figure 3.2b; $P=0.100$ ).

I found evidence for the hypothesis that the patterns of co-occurrence observed in two native ant communities significantly scale with the intensity of their interspecific aggression (Figure 3.3; $P=0.016$ ). Pairs of native ant species that displayed higher levels of aggression also exhibited high levels of segregation within the community. 
Table 3.2. Results of the generalized linear models evaluating the final survival probability of each "recipient" after 64 hours of interactions against different "opponents". BSI is the body size of the opponents.

\begin{tabular}{|c|c|c|c|c|c|}
\hline recipients & opponent & \multicolumn{2}{|c|}{$\beta($ sem $)$} & $t$ & $P$-value \\
\hline \multirow[t]{5}{*}{ P. advenus } & H. striata & 0.472 & 0.058 & 8.195 & $<0.001$ \\
\hline & Pachycondyla sp. & 0.070 & 0.101 & 0.692 & 0.493 \\
\hline & M. antarcticum & 0.257 & 0.047 & 5.457 & $<0.001$ \\
\hline & L. humile & 0.066 & 0.041 & 1.607 & 0.116 \\
\hline & opponent BSI & -0.005 & 0.011 & -0.406 & 0.687 \\
\hline \multirow[t]{5}{*}{ H. striata } & P. advenus & 0.002 & 0.024 & 0.089 & 0.930 \\
\hline & Pachycondyla sp. & 0.284 & 0.086 & 3.322 & 0.002 \\
\hline & M. antarcticum & 0.400 & 0.032 & 12.325 & $<0.001$ \\
\hline & L. humile & -0.001 & 0.024 & -0.022 & 0.983 \\
\hline & opponent BSI & -0.004 & 0.010 & -0.402 & 0.690 \\
\hline \multirow[t]{5}{*}{ H. brounii } & P. advenus & 0.003 & 0.070 & 0.040 & 0.969 \\
\hline & H. striata & -0.010 & 0.056 & -0.173 & 0.864 \\
\hline & M. antarcticum & 0.324 & 0.074 & 4.382 & $<0.001$ \\
\hline & L. humile & 0.003 & 0.070 & 0.039 & 0.969 \\
\hline & opponent BSI & -0.001 & 0.008 & -0.103 & 0.919 \\
\hline \multirow[t]{5}{*}{ M. antarcticum } & P. advenus & 0.062 & 0.034 & 1.843 & 0.073 \\
\hline & H. striata & 0.308 & 0.045 & 6.887 & $<0.001$ \\
\hline & Pachycondyla sp. & 0.012 & 0.088 & 0.132 & 0.895 \\
\hline & L. humile & 0.022 & 0.033 & 0.658 & 0.514 \\
\hline & opponent BSI & 0.007 & 0.010 & 0.695 & 0.491 \\
\hline \multirow[t]{5}{*}{ Pachycondyla sp. } & P. advenus & 0.235 & 0.060 & 3.937 & $<0.001$ \\
\hline & H. striata & 0.271 & 0.265 & 1.026 & 0.311 \\
\hline & M. antarcticum & 0.424 & 0.070 & 6.085 & $<0.001$ \\
\hline & L. humile & 0.092 & 0.055 & 1.665 & 0.104 \\
\hline & opponent BSI & 0.021 & 0.149 & 0.138 & 0.891 \\
\hline \multirow[t]{5}{*}{ L. humile } & P. advenus & 0.085 & 0.032 & 2.630 & 0.012 \\
\hline & H. striata & 0.358 & 0.042 & 8.510 & $<0.001$ \\
\hline & M. antarcticum & 0.422 & 0.041 & 10.294 & $<0.001$ \\
\hline & Pachycondyla sp. & -0.044 & 0.074 & -0.591 & 0.558 \\
\hline & opponent BSI & 0.006 & 0.008 & 0.730 & 0.470 \\
\hline
\end{tabular}

The reference category for the analysis was $H$. brounii. For interactions where $H$. brounii was the recipient, Pachycondyla sp. was adopted as the reference category. Significant $P$-values are highlighted in bold 

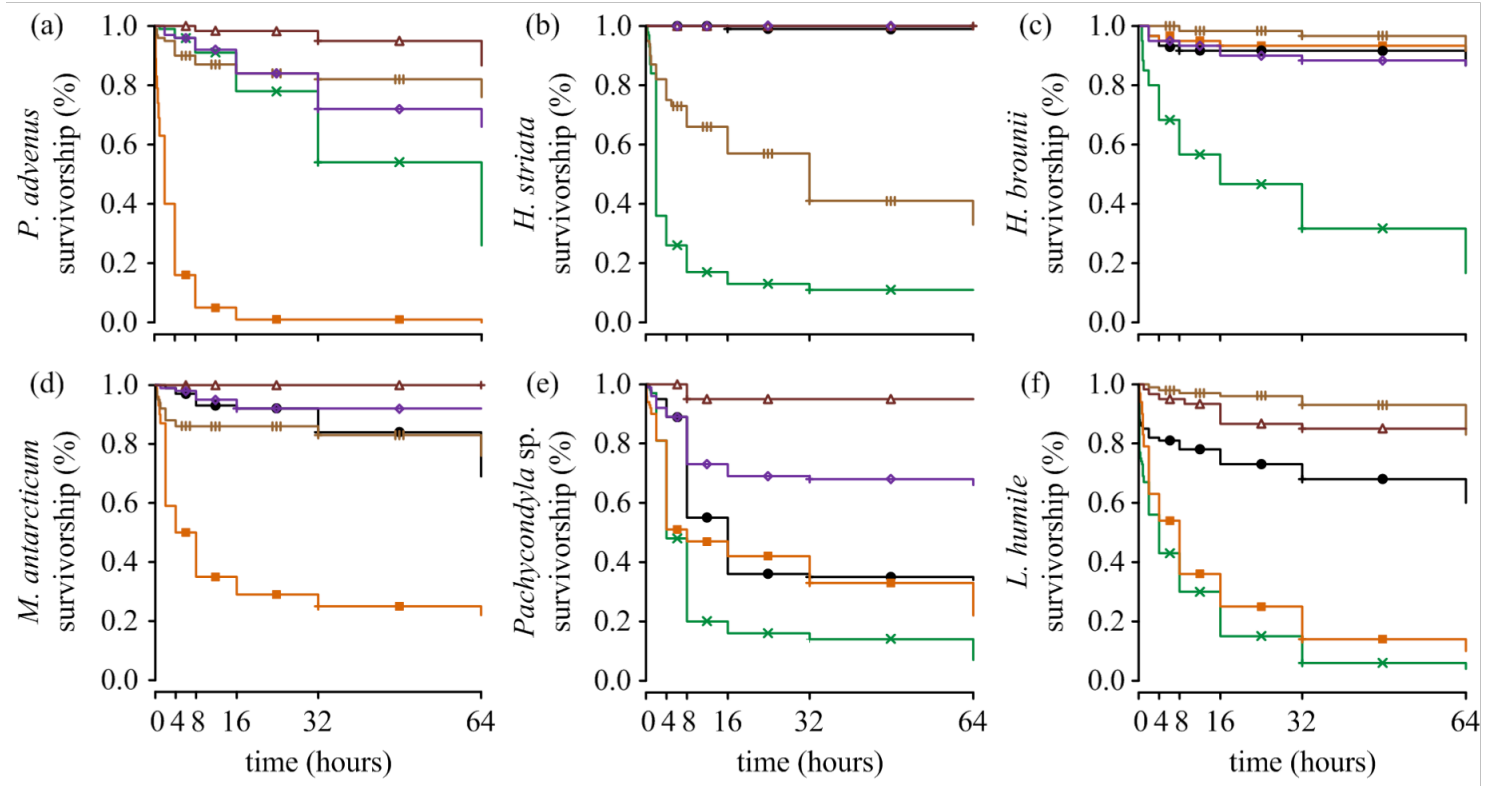

P. advenus

H. striata

- H. brounii $\rightarrow$ M. antarcticum

+1 Pachycondyla sp. $\diamond$ L. humile

Figure 3.1. The survival probability of "recipients" (y-axis on panels a-f) over 64 hours of interspecific interaction with different "opponents" (the Kaplan-Meier survival curves with different colours and elements; see legend underneath panels). The final survival probabilities were compared using a generalized linear model with Gamma distribution (see Table 2.2 for exact $P$-values). Interacting groups $(\mathbf{n}=10)$ contained 10 ants of each species. For experimental sets involving $H$. brounii, $\mathrm{n}=6$.

Figure 3.2. The relationship between the levels of aggression displayed by (a) "opponents" and (b) "recipients", and the survival probability of the "recipients". The solid line indicates the least square slope for the significant relationship $(r \neq 0)$. Statistics are reported in each panel.

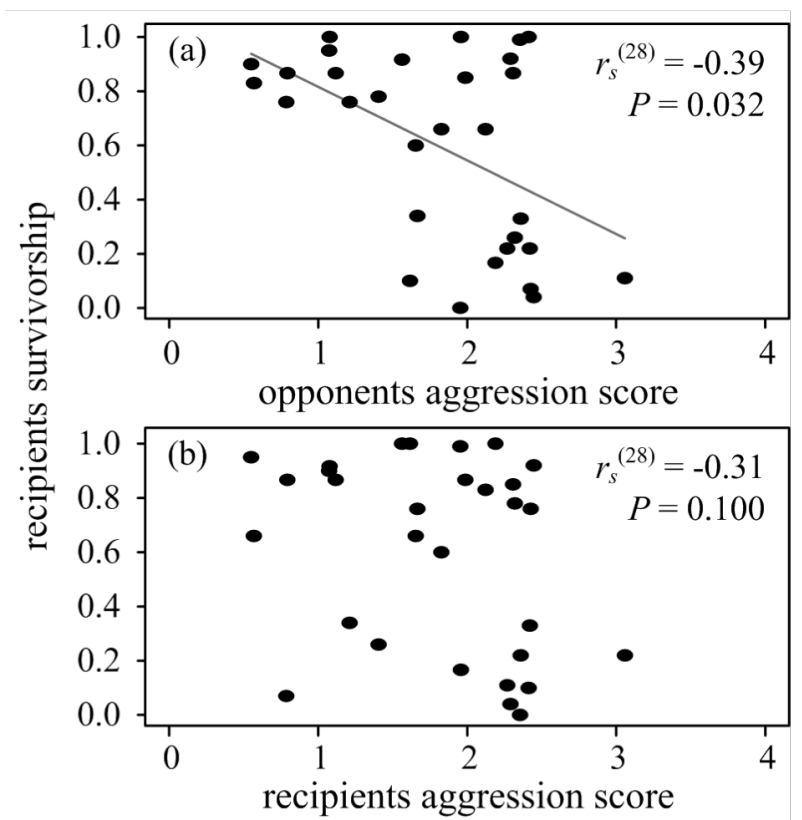


Figure 3.3. The relationship between the levels of aggression observed during pairwise interspecific interactions (native ants only) and the standard effect sizes (SES) obtained with the C-score analysis (see Chapter 2; Table 2.2). The aggression score ranges from 0 (no aggression) to 4 (highly aggressive). Positive SES values indicate species

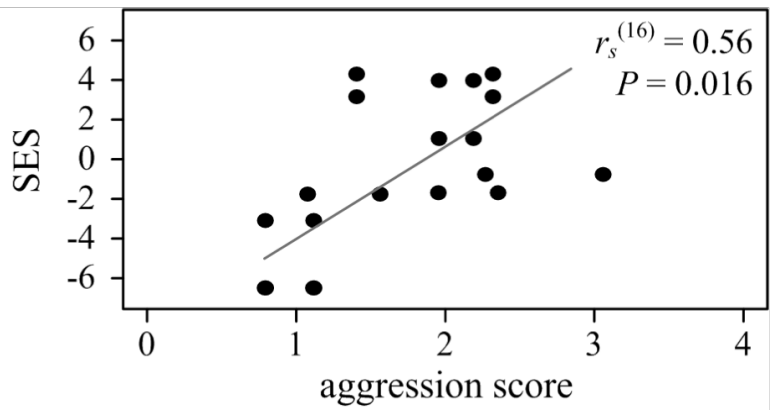
segregation. Negative SES values indicate species aggregation. The solid line indicates the least square slope for the significant relationship $(r \neq 0)$. Statistics are reported in the panel. 


\subsection{Discussion}

My findings are compatible with the hypothesis that high levels of interspecific aggression result in high mortality rates of the "recipients", but not the "opponents". Furthermore, I found that interspecific aggression predicts the co-occurrence patterns of two native ant communities. The decision-making between either an aggressive or nonaggressive response is usually adjusted with increasing familiarity between interacting species (Carlin and Johnston 1984).

The ontogenesis of behavioural responses may be a result of learning, imprint at individual or group level, and subsequent genetic assimilation (Gordon 2013). The tendency herein observed of "recipients" to display higher levels of aggression towards specific "opponents" could be a result of antagonistic coevolution. The low levels of aggression I observed from the native ant species towards the invasive $L$. humile, for instance, may be related to the lack of familiarity between "recipients" and "opponents". However, the differential responses displayed by native "recipients" towards native “opponents" likely reflect the risks imposed by the "opponents". Therefore, learning processes may mediate the expression of differential aggression levels between heterospecific pairs of species in native ant communities.

In natural communities, the strength of aggressive responses probably plays an important role in the patterns of species co-occurrence. For example, non-random allopatric patterns of niche occupancy may be explained by high levels of aggression displayed between pairs of species that seldom co-occur (Diamond 1975). These patterns may potentially derive from survival probabilities resulting from interspecific conflicts. The understanding of how the community components behave during interspecific interactions is a requirement for agent-based studies exploring the influence of aggressive behaviour on community patterns. 
When a new species arrives into the community, local species may display behavioural responses that unlikely reflect the level of risk imposed by the newcomer, due to the lack of coevolutionary history (Le Breton et al. 2007). Adaptation of native species to an invader has been observed in other systems. For example, there is strong evidence demonstrating that fence lizards (Sceloporus undulatus) evolved longer limbs and flee behaviour as a defensive mechanism against the red imported fire ant (Solenopsis invicta) (Langkilde 2009). A valuable extension of this work would be to observe the behavioural changes of native ants after several generations, in areas invaded by L. humile throughout New Zealand. Thus, these results offer a valuable contribution for future studies evaluating the importance of interspecific behaviours on community structure and the evolution of antagonistic responses.

Herein, "opponents" body size did not predict survivorship of the "recipients", possibly because variations in body size and morphology are relatively limited in ant species used in this study (Don 2007). The use of venoms could also modulate the outcome of interspecific interactions (Casewell et al. 2013). For example, M. antarcticum has ant-repellent venom alkaloids (Andersen et al. 1991; Don and Jones 1993) and P. advenus frequently spray formic acid during aggressive interactions (Grangier and Lester 2011). The use of these chemical weapons likely favours these ants during interspecific interactions. Furthermore, the influence of social insects, such as ants, and other gregarious organisms on community assembly is often densitydependent (Sagata and Lester 2009; Walters and Mackay 2005). Therefore, it is also possible that a higher relative abundance could modulate the behavioural responses between "recipients" and "opponents" and, consequently, change the outcome of interspecific interactions.

Aggressive behaviour may be the key biotic factor mediating the outcome of ecological interactions, including biological invasions (Holway and Suarez 1999). Only two studies (Adler et al. 2007; Wittman and Gotelli 2011), 
as far as I know, used dominance indices to predict community assembly. Both were unable to predict the likelihood of species to co-exist, probably because the behavioural responses of ants in their study may be influenced by other factors such as group size or lack of familiarity. Here, I demonstrated that variation in interspecific aggression likely determine the co-occurrence patterns observed in two native ant communities and could potentially explains community assembly of many coevolved communities. 


\section{Chapter 4: Arrival sequence and diet mediate interspecific competition}

Publication: Barbieri RF, Grangier J and Lester PJ (2013) Arrival sequence and diet mediate interspecific competition in an ant community. Insectes Sociaux 60: 463-473 (Appendix B) 


\subsection{Abstract}

The arrival sequence of organisms in a habitat and their diet are two factors that are thought to modulate animal performance, affect the outcome of behavioural interactions, and shape communities. In New Zealand, two species that seldom co-occur in field populations are Prolasius advenus and Monomorium antarcticum. Herein I tested the hypotheses that arrival sequence and diet influence the strength of interactions between these two species. These ant species showed asymmetric responses to arrival sequence and diet variation. When arriving first $P$. advenus displayed increased aggression and M. antarcticum a defensive reaction. Changes in carbohydrate and protein availability modulated colony activity rates of both species. Colonies of $M$. antarcticum fed on a high carbohydrate and low protein diet displayed higher activity rates than colonies fed on a low carbohydrate and high protein diet. In contrast, control colonies of P. advenus fed on a high carbohydrate and low protein diet displayed lower activity rates than colonies fed on a low carbohydrate and high protein diet. These results indicate that arrival sequence can modulate the agonistic reaction displayed by interacting species in situations of conflict. This work also demonstrates that species adjust activity rates in response to diet, but different species do so differently. Therefore, arrival sequence and diet could explain species mutually exclusive distribution patterns observed in nature. 


\subsection{Introduction}

Species typically arrive into a community at different times. The arrival sequence of species in the colonization process often favours the species that arrives first (the "primary species") and reduces establishment success of subsequent species ("secondary species"), thus influencing the fitness of organisms and community assembly (Cole, 1983a, b; Weslien et al., 2011). When the primary species is able to negatively impact the secondary species, this process is called priority effect (Victorsson, 2012). The mechanisms conferring competitive advantage to the primary species and, consequently, determining the outcome of future interspecific interactions can include: numerical advantage (Louette and De Meester, 2007), exploitative resource competition (Miller-Pierce and Preisser, 2012; Victorsson, 2012), larger body size (Alford and Wilbur, 1985), defensive strategies (Wilson, 1974), aggressive behaviour (Cole, 1983b), or even familiarity with the local environment (Ridley et al., 2010). Additionaly, nutrient availability might also affect the outcome of interspecific interactions and shape communites (Blüthgen et al., 2004).

The availability of suitable food sources is also crucial to ensure animal nutrient balance and fitness (Davidson, 1997; Jervis et al., 2008; Dussutour and Simpson, 2012). Changes in the dietary intake have been shown to elicit distinct activity rates and behavioural responses in a number of organisms (Kay et al., 2010; Kohler et al., 2012). A poor diet can influence multi-species communities throughout the biological hierarchy, affecting individuals, populations, and finally the entire community (Wagner et al., 2013). Species feeding on higher concentrations of energetic substrates could accelerate their metabolic rates and display behaviours that further enhance their abilities to secure resources (Kay et al., 2010; Kay et al., 2012). Alternatively, the abundance or scarcity of essential food sources could modulate the tempo of species and tune their foraging activity rates (Oster and Wilson, 1978). 
Here, I studied the interspecific interaction between two ant species, Monomorium antarcticum and Prolasius advenus. Both are native species frequently found throughout New Zealand. They are able to tolerate a wide range of abiotic conditions (Don, 2007). Both P. advenus and M. antarcticum use venom during aggressive interactions (Don and Jones, 1993; Grangier and Lester, 2011); are generalist foragers and nest in the soil, under logs or rocks (Brown, 1958; Don, 2007). Monomorium antarcticum is a ubiquitous species in open habitats (Brown, 1958) and P. advenus is widely dispersed in beech forest (Nothofagus spp.) (Burne, 2012). In open habitats, colonies of M. antarcticum were observed to have high number of workers $(\sim 1,800$ workers; median number) (Wang and Lester, 2005). In forest areas, colonies of $P$. advenus were observed to have nest size of up to 6,000 worker (Burne, 2012). However, these species seldom co-occur out of their natural range, but likely co-exist on transitional zones between forest and open habitats. When occasionally occurring out of their usual range, both species had lower colony size $(\sim 300$ workers) than those observed in their usual range.

In this study, I subjected $P$. advenus and M. antarcticum to interspecific interactions in controlled conditions to test the hypothesis that arrival sequence and diet can modulate the outcome of behavioural interactions. I investigated whether the primary species deploys strategic behaviours that enhance their ability to secure resources and persist in the presence of a competitor arriving in the territory after. Also, I assessed the effects of diet variation on modulating species aggressive and foraging behaviour. Thus, arrival sequence and nutrient availability are two factors that could potentially shape New Zealand ant communities and explain the negative co-occurrence patterns between $P$. advenus and $M$. antarcticum frequently observed in nature. 


\subsection{Methods}

\section{Ant colony collection and preparation}

Colonies of $P$. advenus were collected in New Zealand from forest areas in Nelson Lakes National Park $\left(41^{\circ} 48^{\prime} \mathrm{S} ; 172^{\circ} 38^{\prime} \mathrm{E}\right)$ and Kaitoke Regional Park $\left(41^{\circ} 4^{\prime} \mathrm{S} ; 175^{\circ} 11^{\prime} \mathrm{E}\right)$ between 2010 and 2011. Monomorium antarcticum colonies were excavated from open areas in Nelson Lakes National Park during the same time period. The ant $M$. antarcticum likely represents a species complex that may be composed of 3-5 species (Brown, 1958; Don and Jones, 1993; Wang and Lester, 2004). Therefore, I collected colonies of M. antarcticum with similar morphologies from a single location. From large, near-complete colonies collected from the field, I prepared sub-colonies containing 200 (small colony) or 1,000 (large colony) workers and two queens, according to the desired population size (see below). Colonies were placed in plastic containers $(13 \times 9 \times 6 \mathrm{~cm})$ with the sidewalls painted with Fluon ${ }^{\mathrm{TM}}$ (polytetrafluoroethylene PTFE-30; BioQuip Products, Inc.), and a segment of plastic tubing $(0.5 \mathrm{~cm}$ internal diameter; $10 \mathrm{~cm}$ length) connected as a nest exit. The tubing exit was initially plugged with aluminium foil to stop ants leaving the artificial nest while not connected with the foraging area. In each container I placed three $10-\mathrm{mL}$ nesting tubes one-third filled with water, plugged with cotton wool and covered with aluminium foil. For acclimation sub-colonies were kept at $20 \pm 1{ }^{\circ} \mathrm{C}$ for one week and fed three times (two-day interval) via soaked cotton wool with $20 / 80 \%$ honey/water (volume/volume) and a mealworm (Tenebrio molitor; larva) cut into three parts.

Colonies were connected by the plastic tubing to opposite sides of a foraging area, which was composed of a plastic tray $(51 \times 37 \times 4.5 \mathrm{~cm})$ with the sidewalls coated with Fluon ${ }^{\mathrm{TM}}$. The plastic tray simulated foraging conditions where ants sought food sources and where the primary species established its territory prior to the arrival of the secondary species. During the experiment 
different diets were offered three times a week. The energetic diet consisted of a cotton dish $(\sim 2 \times 2 \mathrm{~cm} ; 0.2 \mathrm{~cm}$ thick) soaked in $20 / 80 \%$ (high carbohydrate) or 2/98 \% (low carbohydrate) honey/water solution $(\mathbf{v} / \mathbf{v})$. The source of protein was a single mealworm cut in three parts $(\sim 0.09 \mathrm{~g}$ : high protein $)$ or $1 / 3$ mealworm ( $\sim 0.03 g$ : low protein). Low and high carbohydrate concentrations were chosen based on previous observations indicating that $P$. advenus, in similar treatments, increased foraging activity in response to reduced carbohydrate resources (Duthie and Lester, 2013; Grangier, umpubl. data). Both food substrates were offered on separate pieces of aluminium foil $(4 \times 4$ $\mathrm{cm}$ ) randomly placed in the foraging area.

\section{Experimental design}

I used a $2 \times 2$ factorial design with four replicates and controls (16 experimental units) to evaluate the effects of arrival sequence and diet on the aggression rates, foraging activity and colony survival of $M$. antarcticum and $P$. advenus. The independent variables were: (1) arrival sequence - small colonies of $M$. antarcticum used the foraging area for a week first than large colonies of $P$. advenus, and large colonies of $P$. advenus used the foraging area for a week

first than small colonies of $M$. antarcticum; $(2)$ diet - high carbohydrate-low protein (HCLP); low carbohydrate-high protein (LCHP). As a control, small colonies of $M$. antarcticum and large colonies of $P$. advenus were subjected to the same diets (HCLP and LCHP; $n=4$ ), but not subjected to interspecific interactions. Therefore, I had a total of 32 experimental units.

Preliminary observations showed that small colonies of $P$. advenus subjected to interspecific interactions with large colonies of $M$. antarcticum ( $n$ =4) had their nests invaded right after the confrontation initiated and were exterminated by $M$. antarcticum. When species were subjected to interspecific interactions in groups containing equal number of workers $(10 \times 10, n=10$; 
$200 \times 200, n=4), P$. advenus was also exterminated. These preliminary results provide evidence of the superiority of $M$. antarcticum in open areas, where they are numerically dominant. The overall colony size of $P$. advenus in beech forests is higher than colony size of $M$. antarcticum found in open areas (Wang and Lester, 2004; Burne, 2012). Therefore, I chose to use colonies of $M$. antarcticum with lower size than $P$. advenus to evaluate their responses in realistic scenarios that could occur in beech forest, where nest of $M$. antarcticum are smaller than in open areas.

\section{Interspecific aggression level}

Patterns of interspecific aggression were scored using the following behavioural categories adapted from Suarez et al. (1999): touch (score 1) = contact followed by antennation, when one ant tapped the other ant with its antennae; avoid (score 2) = after contact ants retreat in opposite directions; aggression (score 3) = head biting, leg biting, raising up the gaster or spraying acid; and fighting (score 4$)=$ prolonged aggression $(>5 \mathrm{~s})$ between individuals with one or both ants locking mandibles onto a body part, carrying the other with the mandibles, or gripping and flexing the gaster in an attempt to use chemical defences. Interactions between species in the foraging area were scored for $5 \mathrm{~min}$ every $15 \mathrm{~min}$ for $3 \mathrm{~h}$ after the first interspecific encounter. Scores were computed for the species that initiated the behavioural interaction. If at the encounter between two individuals species simultaneously reacted to each other (e.g. both species simultaneously retreat in opposite direction), both were scored. The mean aggression index was calculated based on all interactions observed for each 5-min period. Additionally, I counted the number of individuals of each species in the foraging area at the end of each 5 -min period of observations, while species were being scored. Therefore, at the end of $3 \mathrm{~h}$ I had the level of aggression 
displayed by each species and the number of individuals involved with these interactions.

\section{Colony activity and survival}

Following the observations of interspecific interactions, I recorded colony activity of both species by counting the total number of ants in the foraging area for 65 days. Counting was performed twice a day, on three occasions per week. The first reading reflects the "food-searching activity" and was performed before offering food into the foraging area. The second reading aims to evaluate the number of workers in the foraging area $2 \mathrm{~h}$ after the placement of the food source and is herein referred to as the "foodcollecting activity". Each counting session was performed at the same time of the day for all treatments.

After 65 days of trials, all nests were opened and live workers of both $P$. advenus and $M$. antarcticum quantified. Colony survival rate was used to assess the impacts of different diets and the effects of interspecific interaction between ants in different arrival sequences on a colony level.

\section{Statistical analyses}

Interspecific aggression level was analysed using a linear mixed models (LMM) with the R package "nlme” (Pinheiro et al., 2013). The arrival sequence and diet were fixed effects. The number of workers from the opponent ant species in the foraging area at each time interval of observation was accounted as a covariate, with colony included as the random factor. I used Spearman's coefficient of rank correlation to measure the linear dependence of the aggression level displayed by one species towards the opponent species and the number of workers from the opponent species.

Colony activity rate was analysed using generalized estimating equations (GEE) with the R package "geepack" (Højsgaard et al., 2006). First, 
the effects of diet on the food searching and collecting activity of control colonies was evaluated and then compared with different arrival sequences. For the grouped GEEs analysis, fixed factors were "group" (which include the controls and colonies in different arrival sequence - Pf; Mf) and "diet" (HCLP; LCHP). The number of workers from the opponent ant species searching or collecting activity food over 65 days of interactions was accounted as a covariate on the grouped analysis (e.g. the number of $M$. antarcticum workers seeking or collecting food in the foraging area simultaneously to $P$. advenus at the moment counting was performed). I used a Poisson response function and chose an autoregressive correlation structure, where the correlation between observations is modelled as a function of the distance (time) between observations. Prior to analysis, foraging activity data were $\log$ transformed.

Colony survival rate was analysed using generalized linear models (GLM) with Gamma error distribution. Fixed factors were diet (HCLP; LCHP) and group - which included species in different arrival sequence (Mf; Pf) and controls. As colonies of M. antarcticum blocked their nest entrances, I also included nest blocking as a binary factor affecting colony survival. Data were square root transformed prior to analysis as gamma distributions need values $>0$. Akaike's Information Criteria (AIC) was adopted to evaluate the relative goodness of fit of our models.

All statistical analyses described were performed per species and the reference category was the experimental set in which $M$. antarcticum arrived first, fed on an HCLP diet. A full factorial model design was initially utilized for all analysis. However, after accounting for different sources of variability, I choose the most appropriate model structure. All data analyses presented were performed in $R$ version 2.15.1 ( $R$ Development Core Team, 2012) and significance for all tests was set at $P<0.05$. 


\subsection{Results}

\section{Interspecific aggression level}

The effects of arrival sequence and diet on the ability of species to persist when in the presence of a competitor were tested by subjecting $P$. advenus and M. antarcticum to interspecific interactions. When $P$. advenus was the first to arrive in the territory, both species displayed higher levels of aggression (Figure 4.1; Table 4.1; $P<0.011$ ), indicating a significant effect of arrival sequence on the intensity of agonistic reactions between species. However, each species did not react in the same fashion to the abundance of an opponent. Greater numbers of $M$. antarcticum workers increased the aggression of $P$. advenus $\left(r_{\mathrm{s}}{ }^{(142)}=0.39, P<0.0001\right)$. Conversely, $M$. antarcticum decreased their aggression level in response to the number of $P$. advenus workers $\left(r_{\mathrm{s}}{ }^{(142)}=-0.17, P=0.047\right)$. There was no significant effect of diet on the aggression level displayed by both $P$. advenus and M. antarcticum (Figure 4.1; Table $4.1 ; P>0.269)$.

\section{Colony activity}

After interspecific confrontations, workers of P. advenus invaded 8 out of $16 \mathrm{M}$. antarcticum nests on the first day of interaction. The invaded colonies were probably killed as no activity was observed after the initial invasion. Conversely, all colonies of P. advenus that faced interspecific interactions did not appear to be hindered in their searching or collecting of food sources (Figures 4.2, 4.3). The eight nests of $M$. antarcticum that resisted raids of $P$. advenus did so by blocking and displaying sentinel behaviour at their nest entrance. Workers of $M$. antarcticum from colonies that blocked their nest entrance displayed low activity over the 65 days and appeared to be hindered in their use of the foraging area (Figure 4.2e, f; Figure 4.3e, f). 
Figure 4.1. Boxplots comparing the levels of aggression displayed by $P$. advenus (top panel) and $M$. antarcticum (bottom panel) in different arrival sequences and food treatments. White boxes are the aggression levels of workers when $M$. antarcticum was the first to arrive. Grey boxes are the aggression level of workers when $P$. advenus was the first to arrive. The two diets are high carbohydrate-low protein diet and low carbohydratehigh protein diet. Aggression index on $y$-axis represents the average level of aggression between species ranging from 0 (not aggressive) to 4 (highly aggressive). Boxes represent the lower and upper quartile, the bold line is the median and whiskers represent extreme values observed during interspecific confrontations. Aggression levels of $P$. advenus and $M$. antarcticum were significantly affected by arrival sequence, but not diet. For detailed LMM information see Table 1. "ns" stands for $P>0.05$; "**" for $P<0.05$; and "*****" for $P<0.0001$. In each treatment, $\mathrm{n}=4$ colonies.

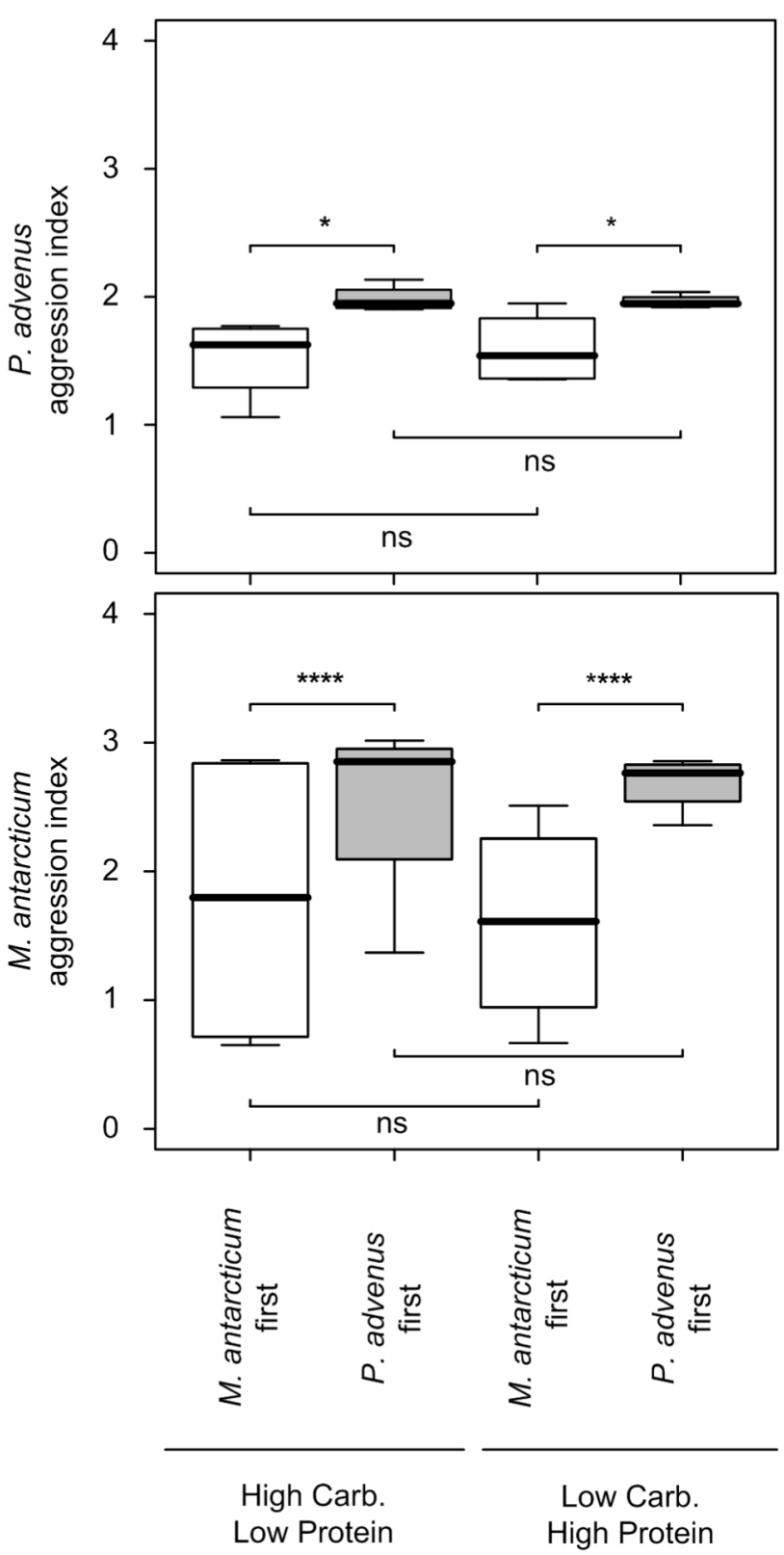

Control colonies of $P$. advenus fed on LCHP diet displayed significantly higher activity rates than colonies fed on HCLP diet in both food searching (Figure 4.2a; GEE; $b=0.70 \pm 0.09 ; \mathrm{W}=64.6 ; P<0.0001)$ and collecting activity (Figure 4.3a; GEE; $b=0.42 \pm 0.07 ; \mathrm{W}=36.6 ; P<0.0001)$. The food searching activity of control colonies of $M$. antarcticum was also affected by changes in diet. When alone, M. antarcticum displayed a significant increase in food searching activity when fed on an HCLP diet (Figure 4.2d; GEE; $b=-1.07 \pm$ $0.17 ; \mathrm{W}=38.5 ; P<0.0001)$, but there was no significant difference in their 
food collecting activity, regardless of $\operatorname{diet}(\mathrm{GEE} ; b=-0.15 \pm 0.09 ; \mathrm{W}=2.45 ; P=$ 0.12 ) (Figure 4.3d).

Table 4.1. Results of the LMMs to evaluate the effects of the arrival sequence (Pf; Mf $^{\dagger}$ ), *diet (HCLP or LCHP) and the number of interactive opponent species workers on the level of aggression displayed by colonies of $P$. advenus and $M$. antarcticum subjected to interspecific interaction.

\begin{tabular}{llccccc}
\hline & predictors & df & \multicolumn{2}{c}{$\beta(\mathrm{sem})$} & $t$ & $P$ \\
\hline P. advenus & intercept & 1,105 & 1.479 & $(0.071)$ & 20.700 & $<0.0001$ \\
& arrival sequence & 1,105 & 0.256 & $(0.099)$ & 2.585 & $\mathbf{0 . 0 1 1}$ \\
& diet & 1,105 & 0.065 & $(0.078)$ & 0.827 & 0.410 \\
& M. antarcticum & 1,105 & 0.006 & $(0.002)$ & 2.529 & $\mathbf{0 . 0 1 3}$ \\
\hline abundance & & & & & \\
\hline M. antarcticum & intercept & 1,105 & 1.806 & $(0.290)$ & 6.218 & $<0.0001$ \\
& arrival sequence & 1,105 & 0.893 & $(0.201)$ & 4.416 & $<\mathbf{0 . 0 0 0 1}$ \\
& diet & 1,105 & 0.003 & $(0.201)$ & 0.013 & 0.989 \\
& P. advenus & 1,105 & -0.001 & $(0.004)$ & -0.189 & 0.850 \\
& abundance & & & & & \\
\hline
\end{tabular}

In each treatment, $\mathrm{n}=4$ colonies. Significant results are highlighted in bold $(P<$ 0.05). Pf: P. advenus first; Mf: $M$. antarcticum first. *HCLP: high carbohydrate-low protein; LCHP: low carbohydrate-high protein.

The activity of control colonies of $M$. antarcticum was clearly higher than the activity of colonies subjected to interspecific interactions with $P$. advenus (Figures 4.2, 4.3; Table 4.2; $P<0.0001$ ). The grouped analyses, which includes different arrival sequences and controls, indicates that the food searching activity of $M$. antarcticum did not significantly change in different arrival sequences (Table $4.2 ; P=0.220$ ). However, their food collecting activity was higher when $P$. advenus arrived first (Table $4.2 ; P=0.004)$. Diet alone did not cause significant effects on the food searching and collecting activity of $M$. antarcticum (Table 4.2; $P>0.290$ ). However, the number of $P$. advenus workers in the foraging area significantly affected food searching and collecting activity of $M$. antarcticum (Table $4.2 ; P<0.0001)$. 
There was no significant effect of arrival sequence on the colony activity of $P$. advenus (Table $4.2 ; P>0.416$ ), but colonies in different arrival sequences differed from controls (Table $4.2 ; P<0.0001$ ). This indicates that the presence of small colonies of $M$. antarcticum affected food searching and
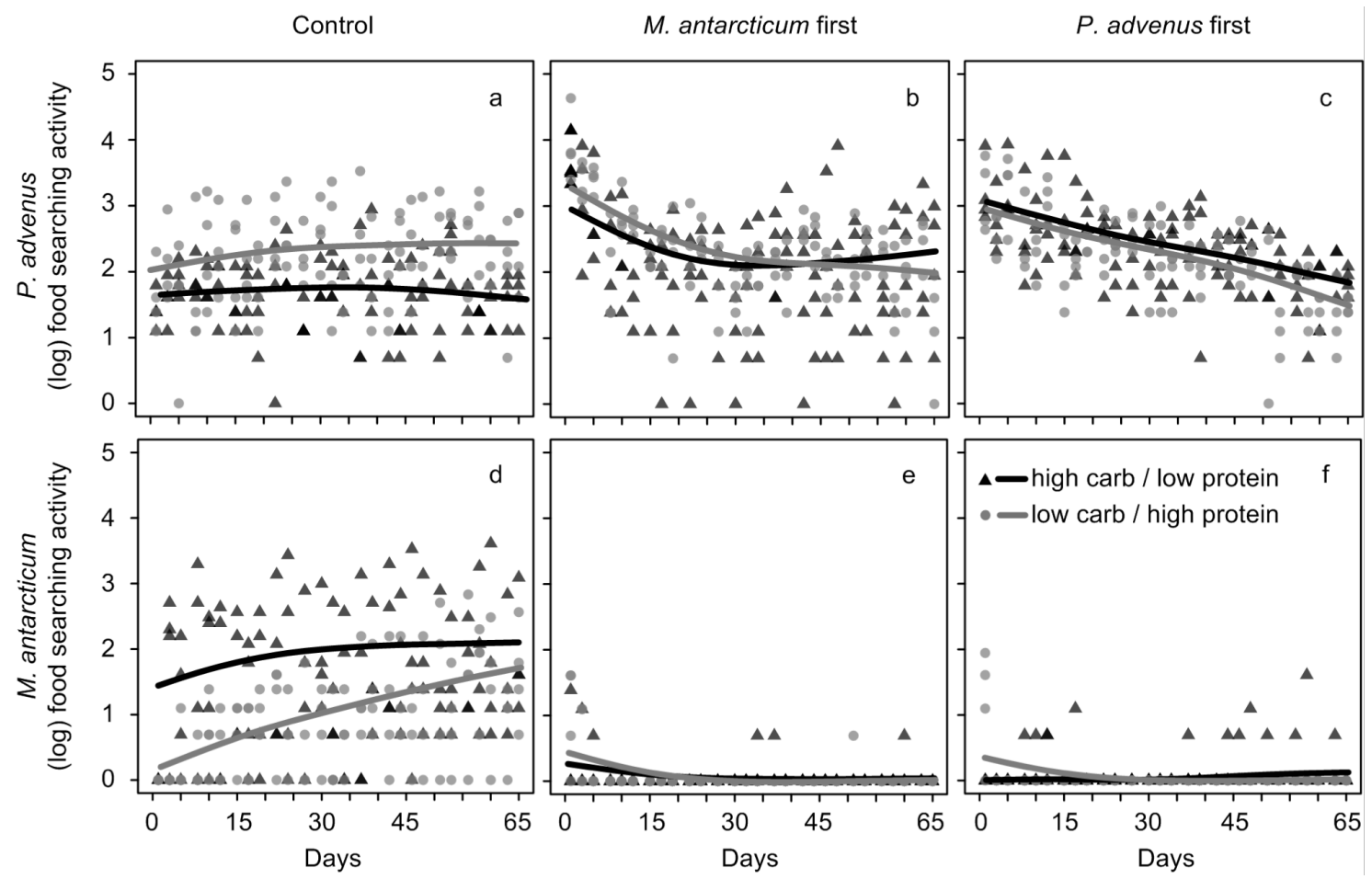

Figure 4.2. Food searching activity displayed by $P$. advenus (top panels) and $M$. antarcticum (bottom panels) in different arrival sequences, food treatments and the activity of controls colonies. Food searching activities of $P$. advenus on panels are: (a) control (b) $M$. antarcticum first (c) $P$. advenus first. Food searching activities of $M$. antarcticum on panels are: (d) control (e) M. antarcticum first (f) P. adsenus first. Colonies in control treatments were fed with different diet and utilized the foraging area, but did not face interspecific interactions. The black triangles and grey circles are different food treatments. The black elements are the activity of colonies fed on a high carbohydrate-low protein diet. The grey elements are the activity of colonies fed on a low carbohydrate-high protein diet. Food searching activity was log transformed. Solid lines indicate the smoothed spline $(d f=3)$ for different food treatments. In each treatment, $\mathrm{n}=4$ colonies. 


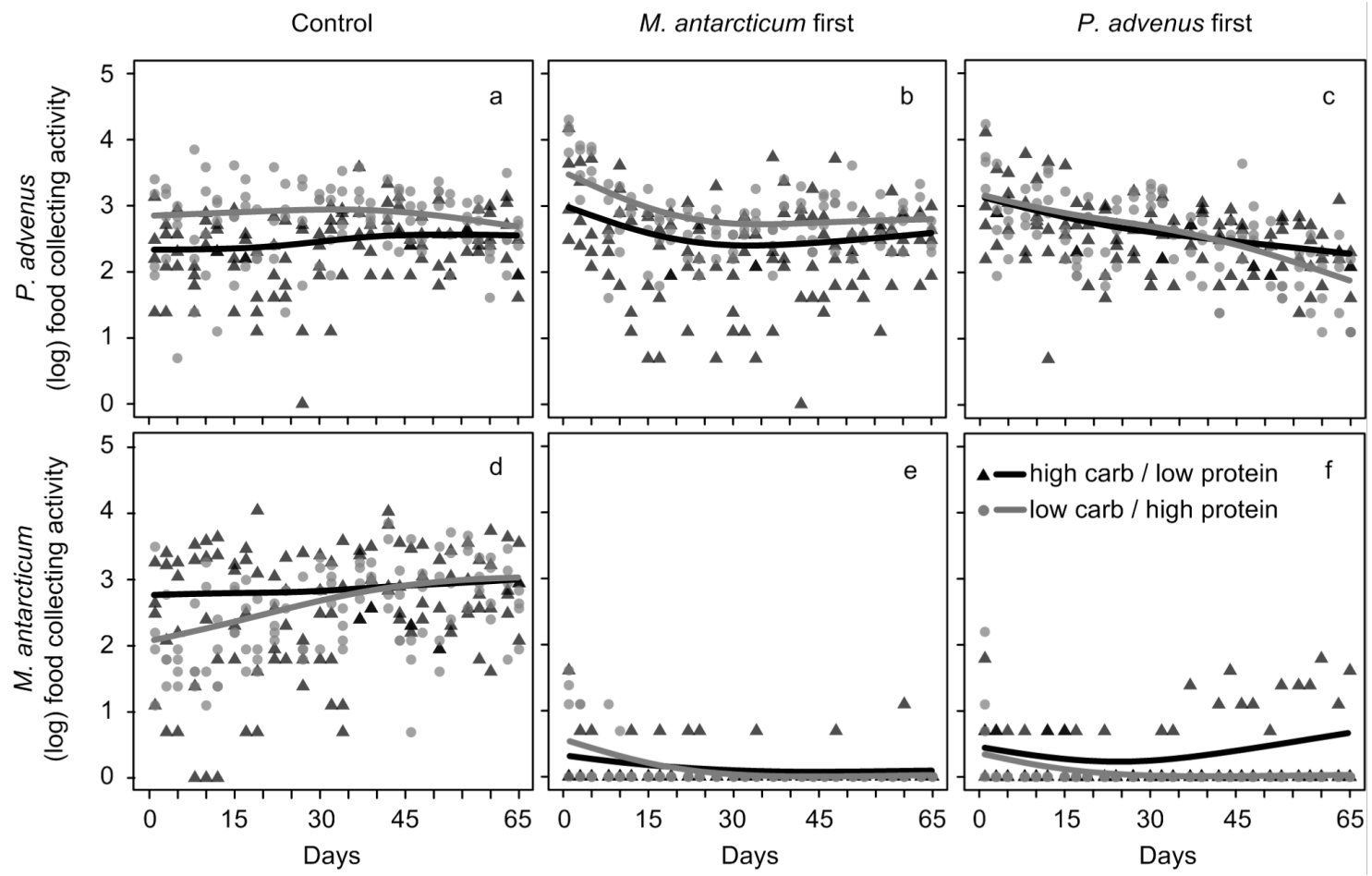

Figure 4.3. Food collecting activity displayed by P. advenus (top panels) and $M$. antarcticum (bottom panels) in different arrival sequences, food treatments and the activity of controls. Food collecting activities of $P$. advenus on panels are: (a) control (b) M. antarcticum first (c) P. advenus first. Food collecting activities of $M$. antarcticum on panels are: (d) control (e) M. antarcticum first (f) $P$. advenus first. Colonies in controls treatments were fed with different diet and utilized the foraging area, but did not face interspecific interactions. The black triangles and grey circles are different food treatments. The black elements are the activity of colonies fed on a high carbohydrate-low protein diet. The grey elements are the activity of colonies fed on a low carbohydrate-high protein diet. Food collecting activity was $\log$ transformed. Solid lines indicate the smoothed spline $(d f=3)$ for different food treatments. In each treatment, $\mathrm{n}=4$ colonies.

collecting activity of $P$. advenus, regardless of arrival sequence. Furthermore, the activity of small colonies of $M$. antarcticum that persisted exerted significant influence on the activity of large nests of $P$. advenus (Table $4.2 ; P<$ 0.0001). Independent of arrival sequence and diet, $P$. advenus displayed a peak activity on the first days of interspecific interaction (Figures 4.2b,c; 4.3b,c). However, after approximately 35 days $P$. advenus reduced their food-searching activity to similar levels exhibited by control colonies that were not subjected to interspecific interactions (Figures 4.2a, 4.3a). Surprisingly, there was no 
significant effect of diet on the food searching activity of $P$. advenus when comparing groups in different arrival sequences and controls (Table $4.2 ; P=$ 0.368). This result suggests that colonies of $P$. advenus fed on different diets searched for food in a similar fashion. Conversely, the grouped analysis indicates significant main effects of diet (Table $4.2 ; P<0.0001$ ) and a significant diet $\times$ arrival sequence interaction effect on the food collecting activity of $P$. advenus, indicating they displayed distinct food collecting activity rates when fed on different diets and in distinct arrival sequences (Table $4.2 ; P$ $=0.015)$.

\section{Colony survival}

Although numerically disadvantaged, three colonies of $M$. antarcticum fed on an HCLP diet and one colony fed on an LCHP diet persisted for the duration of the experiment. Colonies of $M$. antarcticum that persisted did so by blocking their own nest entrances and displaying constant sentinel behaviour. Workers of $M$. antarcticum appear to stand guard and displayed offensive postures with the gaster while defending their nest entrances. The colonies of M. antarcticum that did not prominently protect their nest entrances were invaded, exterminated, and had their nests posteriorly occupied by P. advenus.

The survival probability of $M$. antarcticum was analysed with (GLM; $b=$ 1.384, $P<0.0001, \mathrm{AIC}=-23.975)$ and without $(\mathrm{GLM} ; b=0.156, P=0.047, \mathrm{AIC}$ $=129.04)$ nest blocking as a predictor of colony survival. Given this change in AIC values when the nest blocking ability was added to the GLMs, the improvement of the model's predictability it is noticeable. However, the models evaluating the survival probability of $P$. advenus did not show any significant improvement after the insertion of $M$. antarcticum nest blocking ability (with blocking: GLM; $b=0.037 ; P<0.0001, \mathrm{AIC}=111.86$; without blocking: GLM; $b=0.037 ; P<0.0001, \mathrm{AIC}=113.85)$. Thus, I selected the 
Table 4.2. Results of generalized estimating equations (GEE) evaluating the effects of arrival sequence (Pf; Mf'), diet (HCLP; LCHP*), and the activity of the opponent species on the food searching and collecting activity of $M$. antarcticum and $P$. advenus.

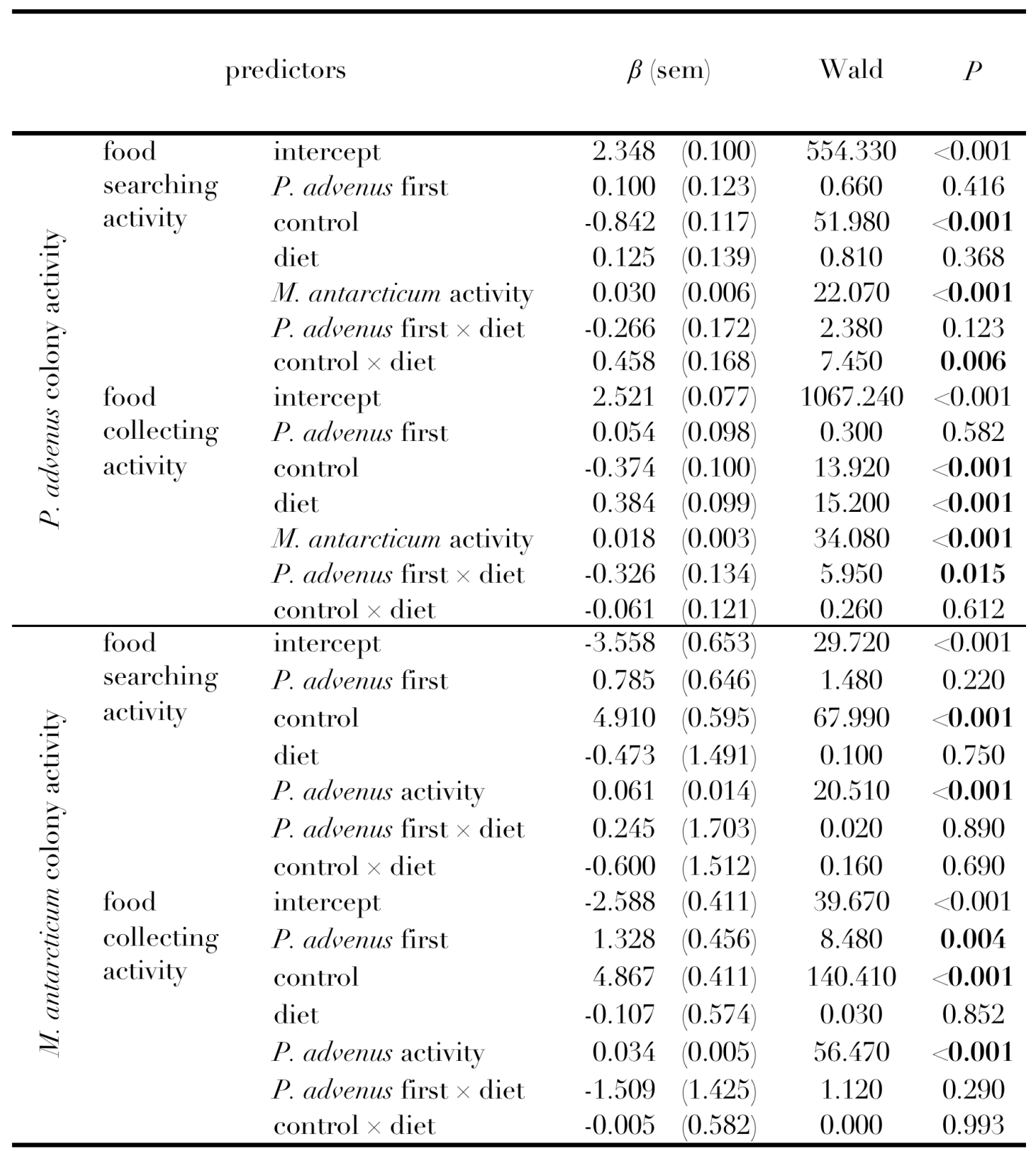

I also compare the activity of colonies in different arrival sequences to control colonies. Control colonies were fed with different diets and utilized the foraging area, but were not subjected to interspecific interaction. The reference category for the analysis was the group in which $M$. antarcticum arrived first, fed in a HCLP diet. In each treatment, $\mathrm{n}=4$ colonies. Significant results are highlighted in bold $(P<0.05)$. Pf: $P$. advenus first; Mf: $M$. antarcticum first. *HCLP: high carbohydrate-low protein; LCHP: low carbohydrate-high protein 
Table 4.3. Results of the generalized linear models (GLM) to evaluate the effects of arrival sequence (Pf; Mf $)$, diet (HCLP or LCHP*) and nest blockage behaviour of $M$. antarcticum on the colony survival of $P$. advenus on $M$. antarcticum.

\begin{tabular}{|c|c|c|c|c|c|c|}
\hline & predictors & $\mathrm{df}$ & $\beta$ & em) & $t$-value & $P$ \\
\hline & intercept & 23 & 0.037 & $(0.002)$ & 21.329 & $<0.0001$ \\
\hline & P. advenus first & 1,21 & 0.004 & $(0.002)$ & 1.953 & 0.068 \\
\hline $8 \overline{0}$ & control & 1,21 & 0.003 & $(0.002)$ & -1.190 & 0.250 \\
\hline 亲 & diet & 1,20 & -0.002 & $(0.002)$ & -0.956 & 0.353 \\
\hline & M. antarcticum block & 1,19 & 0.000 & $(0.001)$ & 0.058 & 0.955 \\
\hline 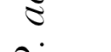 & P. advenus first $\times$ diet & 1,17 & -0.001 & $(0.003)$ & -0.406 & 0.690 \\
\hline & control $\times$ diet & 1,17 & 0.002 & $(0.003)$ & 0.659 & 0.519 \\
\hline & intercept & 23 & 1.384 & $(0.021)$ & 64.716 & $<0.0001$ \\
\hline$\cong \overline{5}$ & P. advenus first & 1,21 & 0.063 & $(0.007)$ & 9.620 & $<0.0001$ \\
\hline$\cdot \stackrel{S}{S}$ & control & 1,21 & -1.311 & $(0.021)$ & -61.147 & $<0.0001$ \\
\hline$\stackrel{3}{3}$ & diet & 1,20 & 0.019 & $(0.005)$ & 3.774 & 0.002 \\
\hline छ & M. antarcticum block & 1,19 & -1.302 & $(0.021)$ & -61.052 & $<0.0001$ \\
\hline$\geq \overline{8}$ & P. advenus first $\times$ diet & 1,17 & -0.051 & $(0.037)$ & -1.391 & 0.182 \\
\hline & control $\times$ diet & 1,17 & -0.019 & $(0.005)$ & -3.440 & 0.003 \\
\hline
\end{tabular}

I also compare the survival rates of colonies in different arrival sequences to control colonies. Control colonies were fed with different diets and utilized the foraging area, but were not subjected to interspecific interaction. The reference category for the analysis was the group in which $M$. antarcticum arrived first, fed in a HCLP diet. In each treatment, $\mathrm{n}=4$ colonies. Significant results are highlighted in bold $(P<$ 0.05). Pf: P. advenus first; Mf: $M$. antarcticum first. *HCLP: high carbohydrate-low protein; LCHP: low carbohydrate-high protein

models including $M$. antarcticum nest blocking ability as a factor influencing colony survival for both $P$. advenus and $M$. antarcticum.

All nests of $P$. advenus persisted for the duration of the experiment and neither diet nor the nest blocking behaviour of $M$. antarcticum affected their survival (Table 4.3; $P>0.353$ ). The survival rates of $P$. advenus colonies that faced interspecific interaction did not differ from controls (Table $4.3 ; P=$ $0.250)$. However, there was a tendency towards a significant effect of arrival sequence and colonies of $P$. advenus utilizing the territory first experienced higher mortality rates (Figure 4.4; Table 4.3; $P=0.068$ ). 
Figure 4.4. Boxplots comparing the number of living workers of $P$. advenus (top panel) and $M$. antarcticum (bottom panel) at the end of 65 days in different treatments. Dashed lines indicate the colony size of each species at the beginning of the experiment. Boxes on different colours are different treatments: control (white boxes), $M$. antarcticum first (light grey boxes), $P$. advenus first (dark grey boxes). Colonies in control treatments were fed with different diets and utilized the foraging area, but did not face interspecific interactions. Boxes represent the lower and upper quartile, the bold line is the median and whiskers represent extreme values of colony survival rates. For significant values see Table 2 . In each treatment, $\mathrm{n}=4$ colonies.

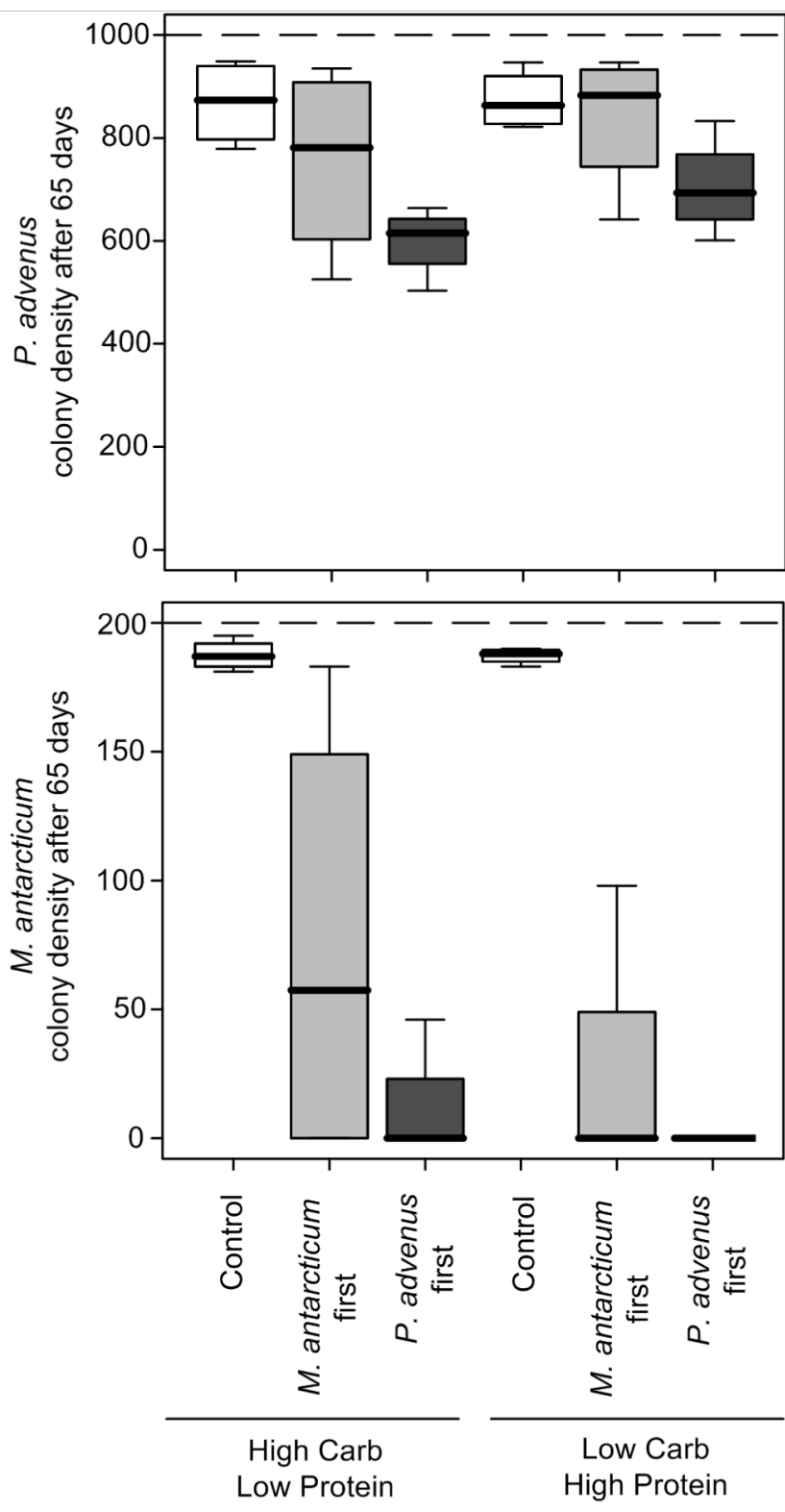

Nest blocking ability increased the survival probability of $M$. antarcticum (Table 4.3; $P<0.0001)$. Also, colonies of $M$. antarcticum utilizing the territory first had higher survival probability than colonies that accessed the foraging area after $P$. advenus (Figure 4.4; Table 4.3; $P<0.001$ ). I also found significant main effects of diet on the survival rates of $M$. antarcticum $(P=0.002)$ and colonies of $M$. antarcticum that faced interspecific interactions had higher survival rates when fed on a HCLP diet (Figure 4.4). 


\subsection{Discussion}

Previous works have indicated that multiple factors give competitive advantages to the primary species (Cole, 1983b; Louette and De Meester, 2007; Victorsson, 2012; Kardol et al., 2013). It is also known that diet can modulate interspecific interactions between competitors (Kay et al., 2010; Wagner et al., 2013). I demonstrated that the arrival sequence influences aggression level and affects colony survival of $P$. advenus and M. antarcticum. Diet modulated their colony activity. Interestingly, reactions displayed by both species in different arrival sequence and diets were asymmetrical in nature. Large colonies of $P$. advenus displayed increased aggression when arriving first, and small colonies of $M$. antarcticum prominently displayed a defensive reaction when arriving first. Colonies of $M$. antarcticum that were not subjected to interspecific interactions and fed on an HCLP diet displayed higher activity rates than colonies fed on an LCHP diet. On the other hand, control colonies of $P$. advenus fed on an HCLP diet displayed lower activity rates than colonies fed on an LCHP diet. Thus, these results indicate that arrival sequence and diet should have an effect on the probability of these two ant species co-occurring.

The abundance of a competitor influenced both aggression level and colony activity of both ant species, suggesting that workers are evaluating risks (Robinson et al., 2009). The sentinel behaviour displayed by colonies of $M$. antarcticum increased their survival probability. It is known that sentinel behaviour effectively prevents fitness loss of animals in the presence of risks; however, this behaviour can also restrict their access to food sources and should affect colony fitness (Wilson, 1974). The triggering of sentinel activity protected small nests of $M$. antarcticum from raids of $P$. advenus and prevented M. antarcticum from losing workers.

As soon as the nest entrance was blocked, few $M$. antarcticum workers left the nest and fought against $P$. advenus. A similar reaction was observed when small groups of $M$. antarcticum fought against large colonies of 
Linepithema humile (Sagata and Lester, 2009). Workers of M. antarcticum tried, with no success, to protect the colony against recurrent attacks of $L$. humile by standing guard at the nest entrance. Previous observations showed that colonies of $M$. antarcticum, when in numerical advantage, did not display sentinel activity when fighting against $P$. advenus. Neither was such behaviour observed by Sagata and Lester (2009). These results suggest that the reaction displayed by $M$. antarcticum is colony-size dependent and triggered in situations of risk to the colony.

The triggering of aggressive behaviour as a response to quantitative or qualitative variation in diet seems to be evident in ant communities (Hölldobler, 1979; Davidson, 1997). Although other ant species can modulate their levels of aggression towards opponents when fed with distinct diets (Grover et al., 2007; Kay et al., 2010), my results do not support the hypothesis that interspecific aggression between $P$. advenus and $M$. antarcticum is a response to or is modulated by the availability of adequate food resources. The constant level of aggression displayed by both species, regardless of diet, could be a result of a not physiologically significant reduction of carbohydrate/protein dosages offered to the colonies. However, this seems to be improbable as control colonies of both species displayed distinct activity levels according to diet. A possible explanation for the increased aggression displayed by $P$. advenus when they were the first to arrive could be related to their level of territoriality. Prolasius advenus are abundantly found in the honeydew-rich beech forest and may exert a "level III" territoriality (Vepsalainen and Pisarski, 1982) by defending not only nest sites (level I) and resources areas (level II), but full territories constantly patrolled by workers (level III). Monomorium antarcticum, on the other hand, may exert an intermediate level of territoriality (level II). According to Vepsalainen and Pisarski (1982), "level II" species can be displaced by "level III" species through numerical advantage and organized recruitment of nest mates. 
In the present study, the lack of carbohydrates did increase colony activity of $P$. advenus. A similar response was predicted by the "tempo hypothesis" (Oster and Wilson, 1978). The concept of "tempo" suggests ants should be classified as either low- or high-tempo species. High-tempo species are prone to a high-level performance while low-tempo species act carefully. The concept of tempo is not only related to how fast an individual moves, but to the probability of and how fast individuals find and exploit suitable food sources (Leonard and Herbers, 1986). In the beech forests of New Zealand, $P$. advenus seems to be adapted to a predictable honeydew-rich environment and may reduce tempo in response to the facility for utilizing an energy-rich food source. When deprived of an energetic food source, the foraging behaviour or tempo increases and $P$. advenus simultaneously increases the probability of finding resources and displacing competitors. The tempo hypothesis may also explain the low numbers of $P$. advenus observed in areas where the invasive wasp Vespula sulgaris are actively controlled by toxic baiting (Duthie and Lester, 2013). This invasive wasp is a well-established competitor of P. advenus in beech forests (Grangier and Lester, 2011, 2012) and also consumes high quantities of honeydew (Moller and Tilley, 1989). A reduction in the wasp population should increase the availability of honeydew in beech forest and, as a consequence, decrease food searching and collecting activity rate of $P$. advenus.

Multiple stochastic and deterministic processes are claimed to be drivers of community assembly (Abrams, 1996; Chase and Myers, 2011; Cerdá et al., 2013). Behavioural responses likely contribute to shaping the whole community structure by creating behavioural type-dependent patterns of occurrence and regulating population dynamics (Cole, 1983a, b; Sanders and Gordon, 2010; Gravel et al., 2011; Sih et al., 2012). I demonstrated that agonistic responses, either defensive or aggressive in nature, and diet are two mechanisms that could determine competitive ability and potentially drive 
community structure. Clearly, these results emphasize the role of priority effects modulating agonistic behaviour, and diet as a regulatory factor modulating the probability of species to interact with competitors and their environment. Priority effects and diet are two factors that could explain the negative patterns of co-occurrence observed between $P$. advenus and $M$. antarcticum. However, other factors such as thermal tolerance (Cerdá et al., 1997), habitat preference (Czechowski and Markó 2005) or even parasitism (Donald and Fenner, 2000; Zhao et al., 2013) may also contribute to the patterns observed in nature. Furthermore, the monopolization of rich food sources by territorial species may also be related to the evolution of defence mechanisms (Davidson, 1997). Future work integrating a wide range of behavioural strategies and multiple factors modulating their expression are necessary to understand how competitive interactions, at the individual and colony levels, can scale to higher levels of organization. 


\section{Chapter 5: Synergistic effects of temperature, diet and colony size on competition}

Publication: Barbieri RF, Grangier J and Lester PJ (In review) Synergistic effects of temperature, diet and colony size on the competitive ability of two ant species. Austral Ecology 


\subsection{Abstract}

Multiple biotic and abiotic factors influence species coexistence and cooccurrence patterns. In a competitive environment, for example, temperature and diet variation may both modify foraging behaviour and aggression, changing competitive interactions and species co-occurrence patterns. In New Zealand, two ant species (Prolasius advenus and Monomorium antarcticum) often form allopatric distributions; though also periodically do co-occur in the same habitat. Here, we performed a long-term laboratory experiment in an attempt to understand how diet, colony size, and environmental conditions may influence these co-occurrence patterns. The consequences of temperature and diet variation differed between $\mathrm{P}$. advenus and $\mathrm{M}$. antarcticum. Colonies of P. advenus displayed increased aggression and foraging activities at higher temperatures. In addition, P. advenus colonies augmented their foraging activities when deprived of a carbohydrate-rich food source. Conversely, small M. antarcticum colonies displayed higher aggression than when in large colonies, and increased their foraging activities in lower temperatures. The modulation of aggression and foraging behaviour may influence the likelihood of small P. advenus and M. antarcticum colonies to persist in the long term. Our results are compatible with the hypothesis that the environment is likely to be a strong filter for the negative co-occurrence patterns we observe between P. advenus and M. antarcticum in New Zealand. Furthermore, this study provides a mechanistic explanation for potential impacts of climate warming on community structure. The modification of aggression and foraging behaviour by the environment could potentially modify competitive interactions and influence community assembly. 


\subsection{Introduction}

Synergistic interactions between biotic and abiotic factors may up- and down-regulate the ability of species to compete and co-exist with each other (Leibold et al. 2004). Studies have suggested that behaviours relating to interspecific competition (e.g. aggression and foraging behaviour) can be major forces shaping communities (Diamond 1978; Cerdá et al. 2013; Delong and Vasseur 2013). Temperature and diet, for example, are two factors that might change the outcome of animal interactions. Temperature variation is reported to alter foraging activities and the probability of ants to find food sources (McGrannachan and Lester 2013), to modify the behavioural hierarchy of communities (Bestelmeyer 2000), and to adjust temporal co-existence patterns of competitors (Cerdá et al. 1997). The availability of adequate food sources may modulate populations and community dynamics (Davidson 1997; Wagner et al. 2013). Changes in dietary intake are reported to elicited distinct foraging activity rates (Oster and Wilson 1978), modulate aggressive behaviour (Kay et al. 2010), and determine the dominance hierarchy of ant communities (Bluthgen et al. 2004; Bluthgen and Fiedler 2004). For example, the patterns of niche occupancy of Australian tropical ant communities are influenced by homopteran honeydew. In these systems, two dominant ants (Oecophyla smaragdina Fabricius and Anonychomyrma gilberti Forel) control and exclude non-dominant ant species from honeydew rich areas (Bluthgen et al. 2004).

The ability of group-living and social organisms, such as ants, to compete for resources is frequently related to their colony size and behavioural plasticity (Sagata and Lester 2009; Rice and Silverman 2013). The invasive Argentine ant (Linepithema humile Mayr) and the ant Monomorium antarcticum Fr. Smith, for example, were observed to modify their interspecific behaviour according to the size of their colonies during interspecific interactions (Sagata and Lester 2009). In larger colonies, the Argentine ant displayed higher aggression towards $M$. antarcticum. Conversely, M. antarcticum 
adopted a defensive strategy when outnumbered by Argentine ants. Such behavioural changes altered the probability of these ants to persist (Sagata and Lester 2009).

In this study, we subjected two ant species (Prolasius advenus Fr. Smith and $M$. antarcticum) to interspecific interactions in controlled conditions. We examined for synergistic effects of temperature, diet, and colony size on the $i$ ) interspecific aggression, ii) foraging activities, and iii) the probability of persistence and the colony survival of these two ant species. Both P. advenus and $M$. antarcticum are generalist foragers, have similar nesting habits and are endemic to New Zealand (Brown 1958; Don 2007). Colonies of P. advenus are widely dispersed in beech (Nothofagus spp.) forest (Don 2007; Burne 2012). Colonies of $M$. antarcticum are ubiquitous in grasslands (Wang and Lester 2004; Don 2007). These species frequently appear to form allopatric distributions, though have been occasionally co-occurring together within New Zealand (Taylor 1959). The aggressive behaviour frequently observed between $P$. advenus and $M$. antarcticum during interspecific encounters suggests that biological interactions may influence the negative co-occurrence patterns we have observed in nature. It is also possible that these cooccurrence patterns result or change according to temperature or food availability or preferences. However, there is no current information on how the environment filters the expression of aggressive behaviours and modulates the foraging activities of species such as $P$. advenus and $M$. antarcticum. The modification of foraging behaviour and aggression by temperature and diet variation could potentially modify the ratio and intensity of interspecific interactions and competition strength. The modulation of foraging behaviour and aggression possibly has different effects for developing colonies (small in size) than in large established colonies. In a competitive environment, small colonies are expected to have a lower probability of utilizing and fighting for resources than large colonies due to their numerical disadvantage. 


\subsection{Methods}

\section{Nest collection and laboratory conditions}

We collected P. advenus colonies $(\mathbf{n}=17)$ from beech forests in Nelson

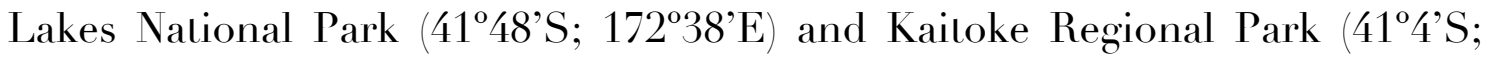
$175^{\circ} 11^{\prime} \mathrm{E}$ ) (New Zealand) during 2010 and 2011. We excavated M. antarcticum (n = 21) from grasslands in Nelson Lakes National Park during the same period. The ant $M$. antarcticum likely represents a species complex that may be composed of three to five species (Brown 1958; Wang and Lester 2004). The M. antarcticum colonies that we collected all belonged to the same morphotype, which was previously described as Monomorium nitidum (Brown 1958 .

Our experiment used a fully factorial design with two temperature treatments, two different carbohydrate diets, two protein treatments, and two colony sizes. We divided and standardized the collected colonies into groups of 200 ("small" colonies) or 1000 ("large" colonies) workers, each with two queens. Different colony sizes (small or large) aims to evaluate the responses of $P$. advenus and M. antarcticum in scenarios frequently observed in nature. In beech forests, large $P$. advenus colonies containing up to 6,000 workers are abundant (Burne 2012), and small M. antarcticum colonies ( 200 workers; personal observation) are occasionally found. Conversely, in grasslands large M. antarcticum colonies are numerous $(\sim$ 1,800 workers; median number) (Wang and Lester 2004) and small P. advenus colonies are occasionally found (Don 2007) ( 200 workers; personal observation).

Colonies were placed in plastic containers $(13 \times 9 \times 6 \mathrm{~cm})$ with the sidewalls painted with Fluon ${ }^{\mathrm{Tm}}$ (Polytetrafluoroethylene PTFE-30; BioQuip Products, Inc.). In each container, we allocated three vials $(2 \mathrm{~cm}$ internal diameter; $14 \mathrm{~cm}$ length) for ants nesting. Vials were one third filled with water, plugged with cotton wool and covered with aluminium foil. The 
interspecific pairs of colonies of different sizes (small or large) to opposite sides of a plastic tray $(51 \times 37 \times 4.5 \mathrm{~cm})$ with the sidewalls coated with Fluon ${ }^{\mathrm{TM}}$. This plastic tray simulated a common foraging arena where ants sought food sources and interacted with each other. A segment of plastic tubing $0.5 \mathrm{~cm}$ internal diameter; $10 \mathrm{~cm}$ length) was used to connect colonies to the plastic tray, which simulated a common foraging arena where ants sought food sources and interacted with each other. For acclimation, we kept each experimental setup, containing interspecific pairs of colonies connected to a foraging arena at experimental conditions of temperature and diet (see below) for a three-week period. During this time, we plugged the plastic tubing with aluminium foil during acclimation to stop the ants leaving the artificial nest. We offered the food treatments inside the artificial nest during this acclimation period.

We set the temperature controlled rooms at $14 \pm 1^{\circ} \mathrm{C}$ or $20 \pm 1^{\circ} \mathrm{C}$, and 12/12 hours light-dark cycle. The use of these temperatures was based on a previous study that demonstrates significant changes in mobility for both $P$. advenus and $M$. antarcticum in similar temperature range (McGrannachan and Lester 2013). Furthermore, the ground temperatures registered in the field (forest and grasslands) during the summer occasionally exceed $20^{\circ} \mathrm{C}$.

We fed ant colonies three times a week (two-day interval) with a source of carbohydrate and a source of protein. The carbohydrate food source consisted of a cotton pad $(\sim 2 \times 2 \mathrm{~cm} ; 0.2 \mathrm{~cm}$ thick) soaked with $2 \mathrm{~mL}$ of a 2/98\% (low carbohydrate) or 20/80\% (high carbohydrate) honey/water solution $(\mathrm{v} / \mathrm{v})$. The protein food source were freshly killed mealworm larvae (Tenebrio molitor $)$. The low protein treatment was given 1/3 mealworm $(\sim 0.03 \mathrm{~g})$. The high protein treatment was given the entire mealworm $(\sim 0.09 \mathrm{~g})$. We offered the food substrates on separated pieces of aluminium foil $(4 \times 4 \mathrm{~cm})$, which were placed in the centre of the foraging arena. We choose these different 
diets based on a previous study indicating that both ant species changed their foraging activity in response to reduced carbohydrate resources.

\section{Experimental design}

We used a full factorial design with four replicates and controls to evaluate the effects of different colony size, temperature and diet on the aggression level, foraging activity and colony persistence of interacting ant species. To summarize the above, the independent variables were: i) colony size: small colonies (200 workers) and large colonies (1000 workers); ii) temperature: $14 \pm 1^{\circ} \mathrm{C}$ and $20 \pm 1^{\circ} \mathrm{C}$; iii) diet: high carbohydrate - low protein (HCLP) and low carbohydrate - high protein (LCHP). As a control treatment, we also kept large and small colonies of both species $(\mathbf{n}=4)$ under $14 \pm 1^{\circ} \mathrm{C}$ or $20 \pm 1{ }^{\circ} \mathrm{C}$ and in HCLP or LCHP diet regimes but did not subject colonies to interspecific interactions. These control colonies were used to assess the effects of temperature and diet variation on foraging behaviour and on the likelihood of colonies to persist in the absence of interspecific interactions. This experimental design is an artificial environment where $P$. advenus and $M$. antarcticum are forced to interact in a small space with limited food sources. However, the assessment of multiple variables in controlled conditions is crucial for a deeper understanding of how biotic and abiotic factors affect the expression of aggression and foraging behaviour.

\section{Interspecific aggression index}

To start the experiment, we unplugged the nests thus allowing ants to access a common foraging arena. We then scored the interactions between $P$. advenus an $M$. antarcticum workers for a three-hour period, after the first interspecific encounter between ant species. We scored the patterns of interspecific interaction for five minutes, every 15 minutes, for a three-hour 
period using the following behavioural categories (adapted from Suarez et al. 1999): touch (score 1) = contact followed by antennation, when one ant tapped the other ant with its antennae; avoid (score 2 ) = after contact, ants retreat in opposite directions; aggression (score 3) = head biting, leg biting, raising up the gaster, or spraying acid; and fighting (score 4) = prolonged aggression $>5$ sec) between individuals with one or both ants locking mandibles onto a body part, carrying the other with the mandibles, or gripping and flexing the gaster to use chemical defences.

We computed the interaction score for the ant colony (small or large) that initiated the behavioural interaction. When the interacting workers of a small and a large colony simultaneously reacted to each other (e.g. P. advenus and $M$. antarcticum workers simultaneously retreat to opposite directions), we scored both the small and the large colony of each species. Additionally, we counted the number of $P$. advenus and $M$. antarcticum workers in the foraging arena at the end of each $5 \mathrm{~min}$ period of observations. Therefore, at the end of a three-hour period we scored the aggression levels displayed by each small and large interacting colonies and the number of individuals in the foraging arena at the time the interactions occurred. We calculated the interspecific aggression score for each colony/species as the average of all interactions observed during each five-minute period $(\mathbf{n}=12)$. Control colonies were not subjected to interspecific interactions.

\section{Foraging activity and survival}

We recorded the foraging activities of all colonies subjected to interspecific interactions and in the controls by counting the total number of ants in the foraging arena. We counted ants twice a day, on three occasions per week, for 65 days. The first count reflected the "food-searching activity" and was performed prior to offering food into the foraging arena. The second 
count was to evaluate the number of workers in the foraging arena two hours after the placement of the food items, and is herein referred to as the "foodcollecting activity". Ants were always counted at the same time of the day (between the hours of $11 \mathrm{am}$ and $12 \mathrm{pm}$ ).

At the end of the 65-day trial we examined all nests to quantify the total number of workers alive in each colony. We used the number of workers alive at the end of the trial as a proxy for the probability of ant colonies to persist when subjected to different treatment conditions.

\section{Statistical analyses}

We assessed the interspecific aggression levels of $P$. advenus and $M$. antarcticum using general linear mixed models (GLMM). Fixed effects were: colony size, temperature, and diet. We used "colony" as a random-effect. We initially used the numbers of $P$. advenus and $M$. antarcticum workers in the foraging arena, at each five-minute time interval, as covariates. This analysis allowed us to evaluate if the aggression levels displayed by $P$. advenus and $M$. antarcticum colonies during interspecific interactions varied according to the total number of individuals in the foraging area at the moment they interact with each other. However, we found no significant effects of the covariates on the interspecific aggression displayed by $P$. advenus and $M$. antarcticum $\left(\chi^{2} \geq\right.$ 3.619; d.f. $=1 ; P \geq 0.057$; see Table A1 in Appendix A). Thus, these covariates were removed from the analyses.

We evaluated the food-searching and -collecting activity of both $P$. advenus and $M$. antarcticum using generalized estimating equations (GEE). We performed two sets of analyses. Firstly, we assessed the effects of temperature and diet variation on ant foraging (either searching for food or food collection) of large colonies subjected to interspecific interaction and large control colonies of $P$. advenus and $M$. antarcticum, separately. Then, we assessed the 
effects of temperature and diet on small control colonies of $P$. advenus and $M$. antarcticum only. This approach was appropriate given that small colonies of both ant species displayed limited foraging activity, or were prevented of using the foraging arena in treatments where they interacted with large colonies of the opponent ant species. The comparison between large control colonies and large colonies subjected to interspecific interaction allowed us to assess the effects of a competitor on the foraging behaviour of both $P$. advenus and $M$. antarcticum. For all GEE models, we used a Poisson response function and chose an autoregressive correlation structure, which means that the correlation between observations is modelled as a function of the distance (time) between observations.

Finally, we compared the proportion of $P$. advenus and $M$. antarcticum workers alive in each colony after 65 days of trials using general linear models (GLM). Fixed factors were: "treatment" (a four-level factor that consists of small and large colonies subjected to interspecific interactions and small and large control colonies not subjected to interspecific interaction); temperature $\left(14 \pm 1^{\circ} \mathrm{C} ; 20 \pm 1^{\circ} \mathrm{C}\right)$; and $\operatorname{diet}($ HCLP; LCHP).

For all analyses herein presented, we initially adopted a full factorial model design among fixed effects. After an assessment of the significance of each term in the model structure, we performed a stepwise model selection to choose the adequate model structure by the removal of interaction terms. However, we maintained main effects in the models to assess their significance. The significance of each term of the full factorial design for all analyses herein presented is reported in the Appendix A (Tables A1-A4). We performed all data analyses in $\mathrm{R}$ version 2.15.3 ( $\mathrm{R}$ Development Core Team 2013). We used the package lme4 (Bates et al. 2012) for the GLMM. For the GEE models, we used the package geepack (Højsgaard et al. 2006). We set the significance for all tests at $P<0.05$. 


\subsection{Results}

\section{Interspecific aggression level}

Workers of $P$. advenus and $M$. antarcticum were highly aggressive towards each other, biting and pulling their opponents. The use of chemical defence was also common. Prolasius advenus was observed spraying formic acid on M. antarcticum workers. A strong odour of formic acid was detected, especially when large $P$. advenus colonies interacted with small $M$. antarcticum colonies. Monomorium antarcticum workers displayed offensive postures with their gasters to use their venom alkaloid when fighting against $P$. advenus (Figure 5.1).

Figure 5.1. A P. advenus worker (left) and the ant $M$. antarcticum (right and back) during an interspecific encounter. Prolasius advenus is tapping $M$. antarcticum with its antennae. Monomorium antarcticum workers are displaying their gaster ("gaster flagging") in the use their venom against $P$. advenus.

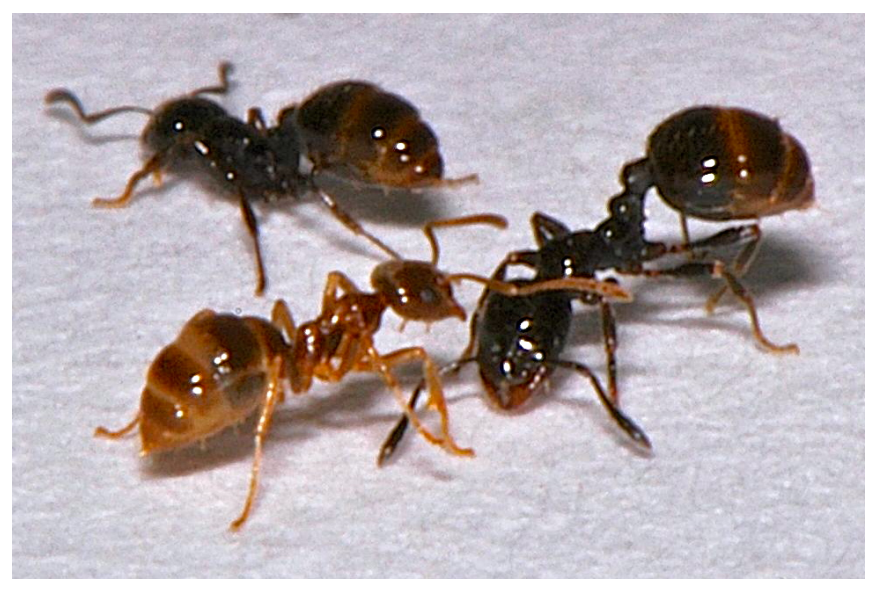

Interestingly, $P$. advenus and $M$. antarcticum colonies displayed different behaviours when under attack, regardless temperature and diet conditions. Large M. antarcticum colonies raided small $P$. advenus colonies. However, when numerically disadvantaged, $M$. antarcticum workers appeared to adopt a defensive strategy and fought against $P$. advenus workers primarily at the entrance of their nest. We did not observe a similar behavioural change of $P$. advenus colonies, which left their nests and fought against $M$. antarcticum workers away from their nest entrance, regardless of their colony size. 
Prolasius advenus - the interspecific aggression index of $P$. advenus colonies was not significantly affected by changes in diet and colony size (Table 5.1; $P \geq 0.746$ ). However, at $20^{\circ} \mathrm{C}, P$. advenus colonies displayed significantly greater levels of aggression towards $M$. antarcticum than at $14^{\circ} \mathrm{C}$ (Figure 5.2a) (Table 5.1; $P<0.001)$.

Monomorium antarcticum - the interspecific aggression index of $M$. antarcticum colonies was not significantly affected by changes in diet and temperature (Table 5.1, $P \geq 0.185$ ). However, small $M$. antarcticum colonies interacting against large $P$. advenus colonies displayed significant higher aggression than large $M$. antarcticum colonies interacting against small $P$. advenus colonies (Figure 5.2b) (Table 5.1; $P<0.001)$.

Table 5.1. Results of the general linear mixed models for the aggression index displayed by $P$. advenus and $M$. antarcticum during interspecific interactions. Fixed factors were colony size (small; large), temperature $\left(14 \pm 1^{\circ} \mathrm{C} ; 20 \pm 1^{\circ} \mathrm{C}\right.$ ) and diet (HCLP: high carbohydrate - low protein; LCHP: low carbohydrate high protein). For each treatment, $\mathrm{n}=4$ colonies.

\begin{tabular}{llcccc}
\hline \multicolumn{1}{c}{ species } & \multicolumn{1}{c}{ predictor } & \multicolumn{2}{c}{$\beta(\mathrm{sem})$} & $t$ & $P$ \\
\hline P. advenus & colony size & -0.008 & $(0.046)$ & -0.172 & 0.864 \\
& temperature & 0.178 & $(0.046)$ & 3.891 & $<\mathbf{0 . 0 0 1}$ \\
& diet & -0.015 & $(0.045)$ & -0.324 & 0.746 \\
M. antarcticum & colony size & 0.342 & $(0.065)$ & 5.217 & $<\mathbf{0 . 0 0 1}$ \\
& temperature & 0.087 & $(0.065)$ & 1.332 & 0.185 \\
& diet & 0.002 & $(0.066)$ & 0.026 & 0.979 \\
\hline
\end{tabular}

Significant P-values are highlighted in bold. 
Figure 5.2. Boxplots comparing the interspecific aggression score displayed by workers of $(a)$ $P$. advenus and (b) M. antarcticum in different colony sizes, diets and temperatures. Colony sizes were small (200 workers) and large (1000 workers). Diets were high carbohydrate-low protein (HCLP) and low carbohydratehigh protein (LCHP). The interspecific aggression index ranges from 0 (not aggressive) to 4 (highly aggressive). Boxes represent the lower and upper quartile, the bold line is the median and whiskers represent extreme values observed during interspecific encounters. In each treatment, $\mathrm{n}=4$ colonies.

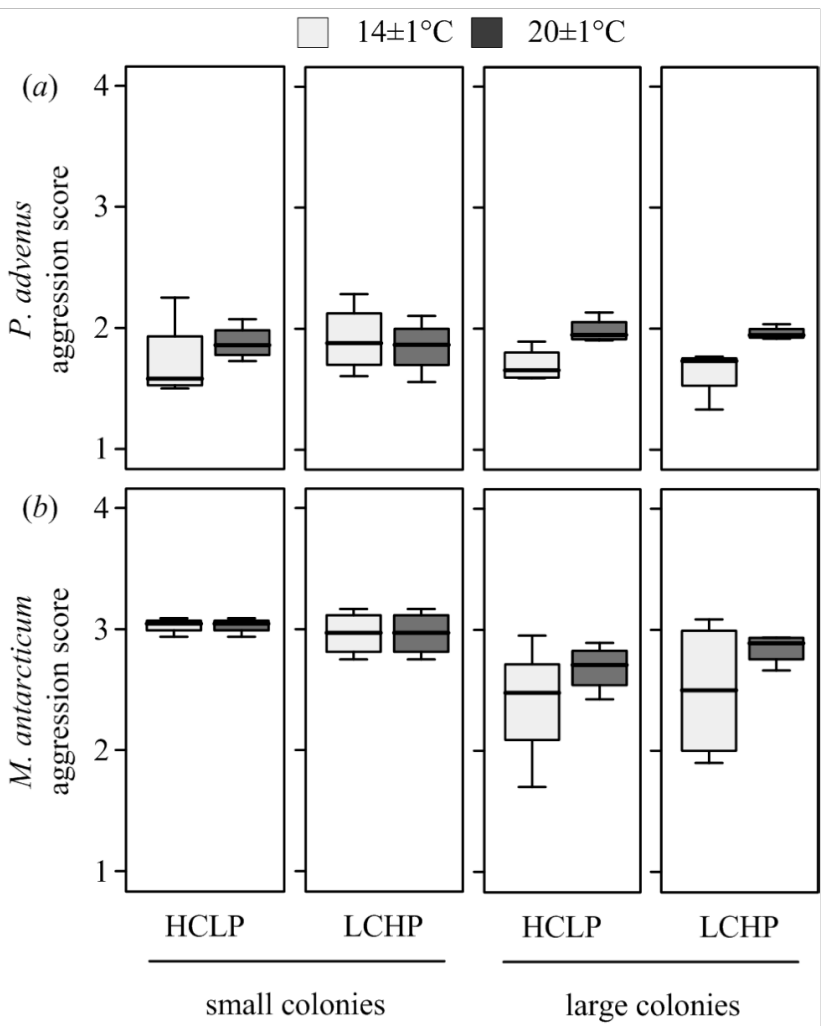

\section{Colony activity}

Small $P$. advenus and M. antarcticum colonies subjected to interspecific interactions against large colonies of the opponent species had either marked reductions in their "food-searching" and "food-collecting" activities, or were even completely excluded from using the foraging arena over the 65 days trial (Figures A1 and A2 on Appendix A). Conversely, large P. advenus and $M$. antarcticum colonies subjected to interspecific interactions and their control colonies (small and large colonies not subjected to interspecific interactions) used the foraging arena and prominently searched and collected food sources over the 65 days trial (Figures A3 and A4 on Appendix A).

Large $P$. advenus colonies - the "food-searching" activity of large $P$. advenus colonies subjected to interspecific interactions significantly differed from the activity in large control colonies (Table $2 ; P=0.031$ ). The "foodsearching" activity of large $P$. advenus control colonies was constant over the 
65 days of trials (Figure 3a). Large P. advenus colonies subjected to interspecific interactions, however, had the highest level of "food-searching" activity during the first days of trials (Figure $3 \mathrm{~b}$ ). At $20^{\circ} \mathrm{C}$, the "food-searching" activity of these large $P$. advenus colonies was significantly higher than at $14^{\circ} \mathrm{C}$ in either controls or confronted colonies (Table $2 ; P=0.027)$. Furthermore, large $P$. advenus colonies fed with a LCHP diet displayed higher "foodsearching" activity than colonies fed with a HCLP diet (Table $2 ; P=0.012$ ). The "food-collecting" activity of large $P$. advenus colonies subjected to interspecific interactions did not significantly differ from their large control colonies (Table $2 ; P=0.190$ ) and was solely affected by diet variation (Table 2; $P=0.001)$.

Large $M$. antarcticum colonies - the "food-searching" activity of large $M$. antarcticum subjected to interspecific interactions did not differ from their control colonies (Table $2 ; P=0.240$ ). We also found no main effects of temperature and diet variation on their "food-searching" activity (Table $2 ; P>$ 0.290). However, we found a significant "group $\times$ temperature" interaction (Table 2; $P<0.001$ ), which indicated that large $M$. antarcticum colonies subjected to interspecific interaction and their control colonies displayed different foraging activities at different temperatures. Such results likely reflected an atypically lower foraging activity observed in one particular treatment replicate "large $M$. antarcticum fed with a HCLP" (Figure S4b). The "food-collecting" activity of large M. antarcticum control colonies (Figure 3c) was significantly higher than the "food-collecting" activity of their large colonies subjected to interspecific interactions (Figure 3d) (Table 2; $P=0.005$ ). We found no main effect of temperature on the "food-collecting" activity of large $M$. antarcticum colonies (Table $2 ; P=0.170$ ). However, there was a significant effect of diet variation on the "food-collecting" activity of large $M$. antarcticum colonies (Table $2 ; P=0.047$ ), which may also be explained by the 
lower foraging activity observed in a particular replicate of the treatment "large M. antarcticum fed with a HCLP" (Figure Súb).

Small $P$. advenus control colonies - we found significant main effects of temperature on the "food-searching" and "food-collecting" activity of small $P$. advenus control colonies (Table 3; $P<0.001$ ). Small $P$. advenus colonies displayed higher activity at higher temperatures $\left(20^{\circ} \mathrm{C}\right)$ (Figure 3e). Interestingly, lower temperatures had a greater effect on the food-searching and -collecting activity of small $P$. advenus colonies fed with a LCHP diet, than on colonies fed with a HCLP diet (Figure S1).

Small M. antarcticum control colonies - we found significant main effects of temperature on the "food-searching" and "food-collecting" activity of small M. antarcticum control colonies (Table 3; $P<0.006$ ). However, differently from the foraging patterns observed in small $P$. advenus colonies, the food-searching and collecting activity of small M. antarcticum colonies was higher at $20^{\circ} \mathrm{C}$ than at $14^{\circ} \mathrm{C}$ (Figure $3 \mathrm{f}$ ). 

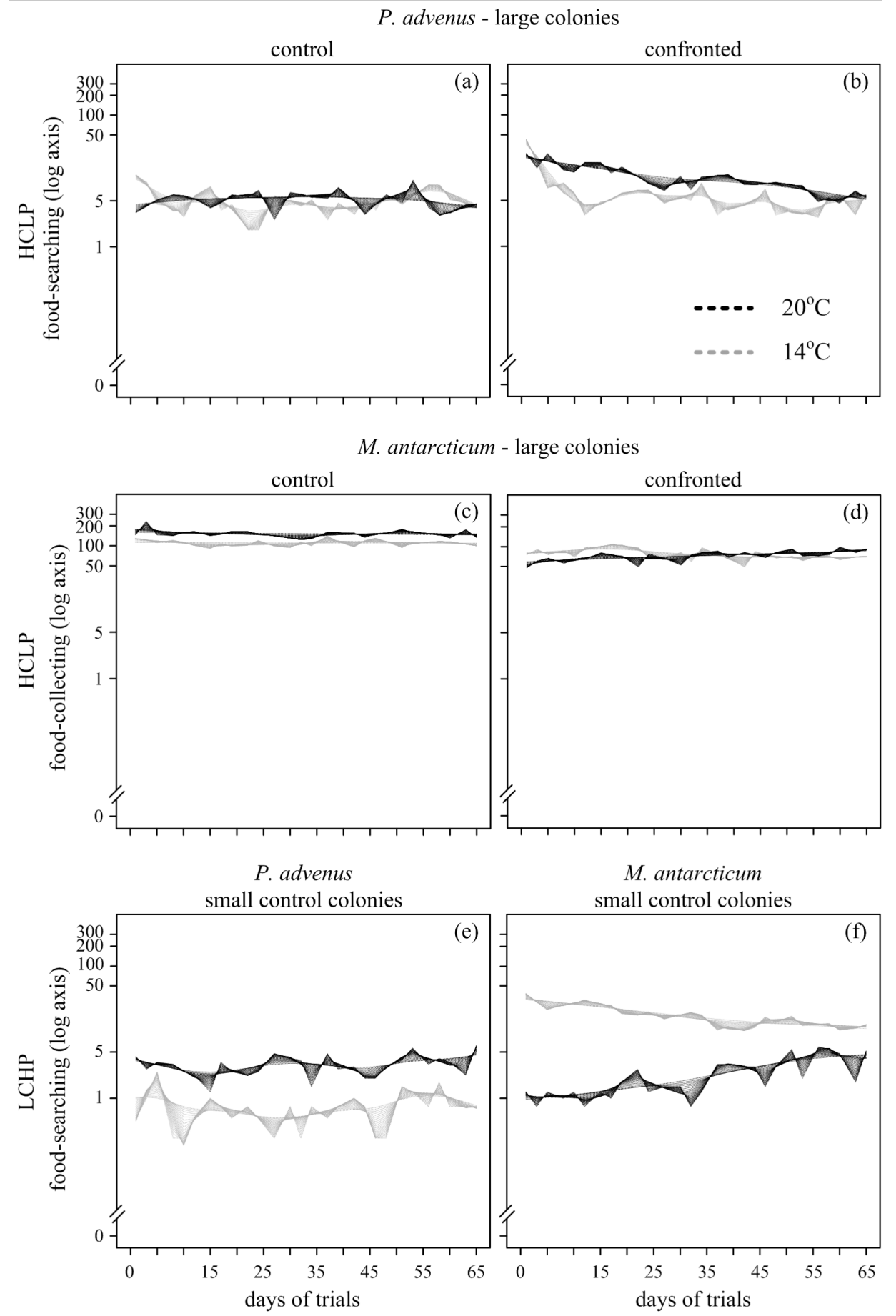

Figure 5.3. The foraging activity displayed by $P$. advenus and $M$. antarcticum colonies over 65 days in different treatments. Controls were not subjected to interspecific interactions. Diets were high carbohydrate-low protein (HCLP) and low carbohydratehigh protein (LCHP). Lines are the overlapped smoothed splines ranging from d.f. $=2<$ $x<28$, which provide an appropriate curve fitting for the variation observed in the foodsearching and -collecting activity of both species. In each treatment, $n=4$ colonies. See Appendix A for complete graphical representation. 


\section{Colony survival}

Prolasius advenus - small P. advenus colonies subjected to interactions against large $M$. antarcticum colonies experienced a significant decrease in worker numbers (GLM; $b=-86.03, t=-33.64, P<0.001)$ compared to their control colonies not subjected to interspecific interactions. Only one small $P$. advenus colony persisted throughout the 65 days of trials, but colony size was reduced to numbers lower than $20 \%$ of its original worker number. Small $P$. advenus colonies that were unable to persist had their nests invaded and occupied by $M$. antarcticum. Large $P$. advenus colonies subjected to interactions against small $M$. antarcticum colonies persisted, but also experienced a significant loss of workers (GLM; $b=-21.75, t=-8.51, P<0.001$ ) when compared to control colonies not subjected to interspecific interactions (Figure 4a). Large P. advenus colonies subjected to interspecific interactions had their colony size reduced to numbers lower than $70 \%$ of their original size. The proportion of $P$. advenus workers alive in either small or large control colonies did not differ significantly (GLM; $b=0.88, t=0.35, P=0.732$ ). We also found no main significant effects of temperature (GLM; $b=-1.48, t=$ $0.82, P=0.416)$ or diet variation (GLM; $b=3.57, t=1.97, P=0.053)$ on the survival rates of either large or small $P$. advenus colonies.

Monomorium antarcticum - small M. antarcticum colonies subjected to interactions against large $P$. advenus colonies experienced a significant loss of workers (GLM; $b=-87.93, t=-32.06, P<0.001)$ when compared to their control colonies not subjected to interspecific interactions. Only two small $M$. antarcticum colonies persisted throughout the 65 days of trials, but the size of these colonies was reduced to numbers lower than $20 \%$ of their original worker number. Small M. antarcticum colonies that were unable to persist had their nests invaded and occupied by $P$. advenus. In one experimental set (LCHP and $\left.14^{\circ} \mathrm{C}\right), 13$ workers from a small $M$. antarcticum colony were still alive at the end of the experiment, but these workers were all in the foraging 
arena and no $M$. antarcticum queens remained alive. However, P. adsenus workers occupied their nest. Large $M$. antarcticum colonies subjected to interactions against small P. advenus colonies persisted. These large colonies had no significant loss of worker numbers (GLM; $b=-5.02, t=-1.83, P=$ 0.072 ) when compared to control colonies not subjected to interspecific interactions (Figure 4b). The colony size of large $M$. antarcticum colonies subjected to interspecific interactions was reduced to numbers not lower than $80 \%$ of their original size. Furthermore, the proportion of $M$. antarcticum workers alive in either small or large control colonies did not significantly differ (GLM; $b=4.94, t=1.80, P=0.077$ ). We found no main significant effects of temperature (GLM; $b=3.53, t=1.82, P=0.074)$ or diet variation (GLM; $b=-1.57, t=-0.81, P=0.423)$ on colony survival rates of either large or small $M$. antarcticum colonies.

Table 5.2. Results of the generalized estimating equations evaluating the food-searching and food-collecting activity of large $P$. advenus and $M$. antarcticum colonies at different temperatures $\left(14 \pm 1^{\circ} \mathrm{C} ; 20 \pm 1^{\circ} \mathrm{C}\right)$ and diet conditions (HCLP: high carbohydrate - low protein; LCHP: low carbohydrate - high protein). The predictor "Group" were large control colonies and large colonies subjected to interspecific interactions. Control colonies were not subjected to interspecific interactions. For each treatment, $\mathrm{n}=4$ colonies.

\begin{tabular}{|c|c|c|c|c|c|c|}
\hline \multicolumn{2}{|c|}{ response } & \multirow{2}{*}{$\frac{\text { predictor }}{\text { Group }}$} & \multicolumn{2}{|c|}{$\boldsymbol{\beta}(\mathrm{sem})$} & \multirow{2}{*}{$\frac{w}{4.640}$} & \multirow{2}{*}{$\begin{array}{c}P \\
\mathbf{0 . 0 3 1}\end{array}$} \\
\hline large & food & & -0.534 & $(0.248)$ & & \\
\hline \multirow{5}{*}{$\begin{array}{l}\text { P. advenus } \\
\text { colonies }\end{array}$} & -searching & Temperature & -0.468 & $(0.212)$ & 4.880 & 0.027 \\
\hline & & Diet & 0.506 & $(0.203)$ & 6.250 & 0.012 \\
\hline & food & group & -0.223 & $(0.170)$ & 1.720 & 0.190 \\
\hline & -collecting & temperature & -0.059 & $(0.174)$ & 0.120 & 0.734 \\
\hline & & diet & 0.500 & $(0.152)$ & 10.750 & 0.001 \\
\hline \multirow{8}{*}{$\begin{array}{l}\text { large } \\
\text { M. antarcticum } \\
\text { colonies }\end{array}$} & food & group & 0.389 & $(0.328)$ & 1.410 & 0.240 \\
\hline & -searching & temperature & 0.248 & $(0.267)$ & 0.870 & 0.350 \\
\hline & & diet & 0.193 & $(0.181)$ & 1.140 & 0.290 \\
\hline & & group x temperature & -1.810 & $(0.361)$ & 25.090 & $<0.001$ \\
\hline & food & group & 0.706 & $(0.251)$ & 7.910 & 0.005 \\
\hline & -collecting & temperature & 0.239 & $(0.174)$ & 1.880 & 0.170 \\
\hline & & diet & 0.532 & $(0.268)$ & 3.940 & 0.047 \\
\hline & & group $\mathrm{x}$ diet & -0.641 & $(0.343)$ & 3.500 & 0.062 \\
\hline
\end{tabular}

Significant $P$-values are highlighted in bold. 
Table 5.3. Results of the generalized estimating equations analysis evaluating the food-searching and food-collecting activity of small $P$. advenus and $M$. antarcticum control colonies at different temperatures $\left(14 \pm 1^{\circ} \mathrm{C} ; 20 \pm 1^{\circ} \mathrm{C}\right)$ and diet conditions (HCLP: high carbohydrate - low protein; LCHP: low carbohydrate - high protein). Control colonies were not subjected to interspecific interactions. For each treatment, $\mathrm{n}=4$ colonies.

\begin{tabular}{|c|c|c|c|c|c|c|}
\hline \multicolumn{2}{|c|}{ response } & \multirow{2}{*}{$\frac{\text { predictor }}{\text { temperature }}$} & \multicolumn{2}{|c|}{$\beta($ sem $)$} & \multirow{2}{*}{$\frac{w}{17.050}$} & \multirow{2}{*}{$\frac{P}{<0.001}$} \\
\hline small & food & & 0.662 & $(0.160)$ & & \\
\hline \multirow{5}{*}{$\begin{array}{l}\text { P. advenus } \\
\text { control colonies }\end{array}$} & -searching & diet & 0.192 & $(0.186)$ & 1.060 & 0.303 \\
\hline & & temperature $\mathrm{x}$ diet & 0.794 & $(0.286)$ & 7.720 & 0.006 \\
\hline & food & temperature & 0.966 & $(0.218)$ & 19.610 & $<0.001$ \\
\hline & -colles & diet & 0.024 & $(0.186)$ & 0.020 & 0.896 \\
\hline & & temperature $\mathrm{x}$ diet & 0.519 & $(0.273)$ & 3.600 & 0.058 \\
\hline \multirow{4}{*}{$\begin{array}{l}\text { small } \\
\text { M. antarcticum } \\
\text { control colonies }\end{array}$} & food & temperature & -1.604 & $(0.402)$ & 15.890 & $<0.001$ \\
\hline & -searching & diet & 0.207 & $(0.237)$ & 0.760 & 0.380 \\
\hline & food & treatment & -0.532 & $(0.195)$ & 7.450 & 0.006 \\
\hline & -collecting & temperature & 0.047 & $(0.183)$ & 0.070 & 0.798 \\
\hline
\end{tabular}

Significant $P$-values are highlighted in bold. 
Figure 5.4. The proportion (mean $\pm \mathrm{se}$ ) of (a) P. advenus and (b) M. antarcticum workers alive after 65 days in different colony sizes, diets and temperatures. Dark grey bars are small control colonies. Black bars are small colonies subjected to interspecific interactions with large colonies of the opponent species. White bars are large control colonies, which were not subject to interspecific interactions. Light grey bars are large colonies subjected to interspecific interactions with small colonies of the opponent species Diets were high carbohydrate-low protein (HCLP) and low carbohydrate-high protein (LCHP). In each treatment, $\mathrm{n}=$ 4 colonies.

$\square$ small colonies (control) $\quad \square$ large colonies (control)
small colonies (vs. large) $\quad \square$ large colonies (vs. small)
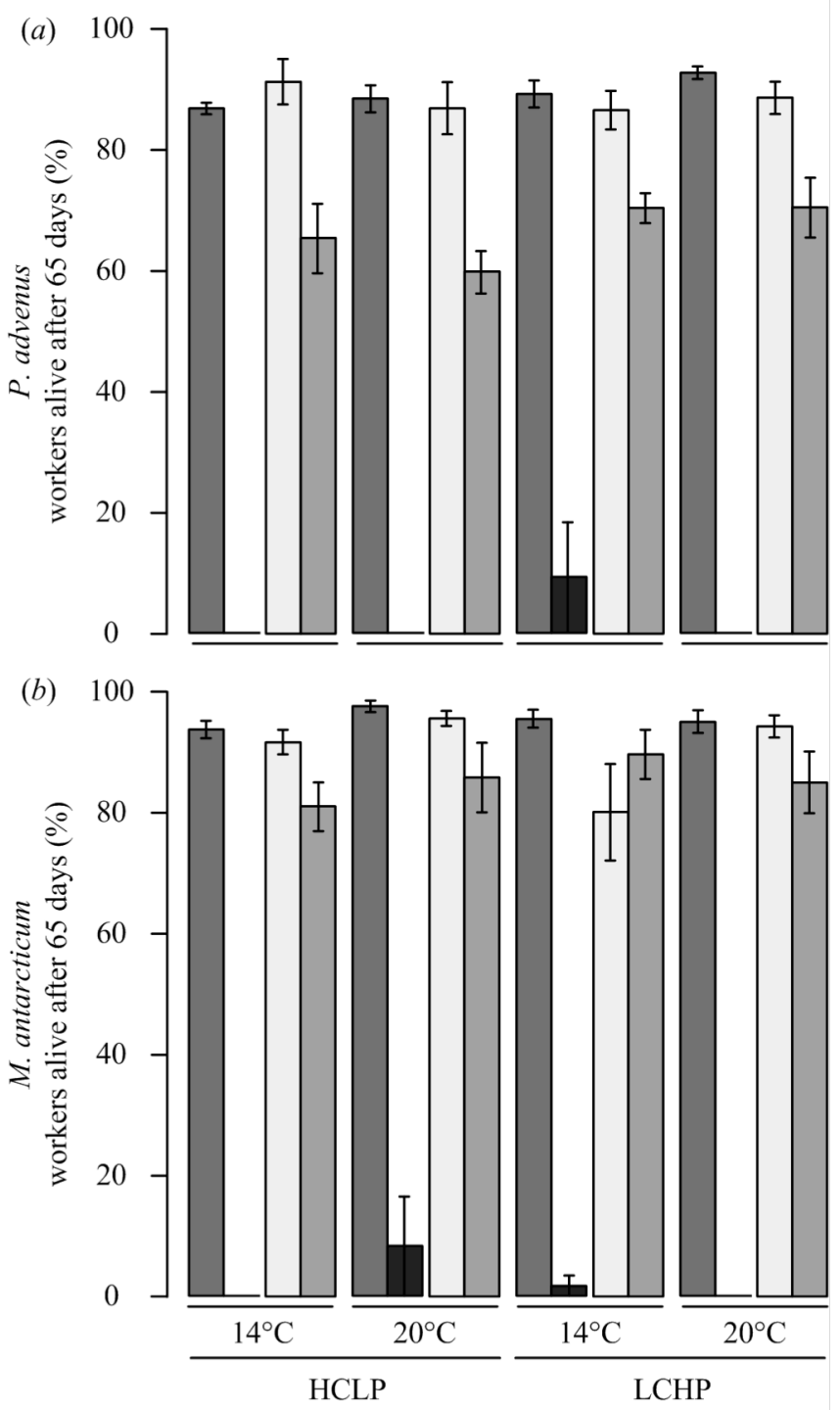


\subsection{Discussion}

Biotic and abiotic factors may up- and down-regulate the ability of species to compete and co-exist with each other. Here, we examined for the synergistic effects of temperature, diet, and colony size on interspecific aggression, foraging activities, and the probability of colony survival of two ant species. The increased aggression and higher foraging activity of $P$. advenus colonies at higher temperatures, and the modulation of their foraging activity by diet variation, are compatible with the hypothesis that the environment is an important filter for the occurrence patterns of $P$. advenus colonies. Conversely, group size was the key factor determining the aggression levels and the foraging rates of $M$. antarcticum colonies. Small $M$. antarcticum colonies displayed higher levels of aggression and, different from P. advenus, higher foraging rates at lower temperatures. Such changes in aggression and foraging behaviour observed in small $M$. antarcticum colonies suggest that the environment has little influence on the occurrence patterns of $M$. antarcticum, but perhaps perform better at low temperatures. Interestingly, we found no evidence of temperature and diet variation having a lethal effect on the probability of $P$. advenus and $M$. antarcticum colonies to persist, regardless their size. Thus, the consequences of temperature and diet variation appear to rely on the modulation of aggressive and foraging behaviour.

The ability of organisms to use and compete for resources is frequently related to their behavioural plasticity and to how external factors modulate the outcomes of their behaviour (Sih et al. 2012). When different species occurring within a community have different thermal preferences (e.g. $P$. advenus are more active at higher temperatures than $M$. antarcticum), temperature variation may create temporal niches (Cerdá et al. 1997) or filter for optimum physiological ranges (Amarasekare and Sifuentes 2012). The modification of foraging behaviour by changes in temperature and nutrient 
availability could influence the probability of individuals finding and monopolizing resources (Leonard and Herbers 1986; McGrannachan and Lester 2013). Such changes may also alter the probability of encounter between competitors (Oster and Wilson 1978).

The interaction among colonization events, competition and environmental factors likely modulate the dynamics of many communities wherein species interact with each other (Diamond 1978; Leibold et al. 2004; Moritz et al. 2013). In ant communities, for example, Rice and Silverman (2013) found that temperature mediates coexistence between the Argentine ant and the Asian needle ant (Pachycondyla chinensis Emery). A broad thermal tolerance favoured both establishment and expansion of Asian needle ant colonies, even though Argentine ants were dominant at food sources. In this study, differences in temperature and diet had distinct effects on ant colonies of different sizes. In periods of food shortage - or during the initial development of recently established colonies - the modification of foraging activities and aggression rates may have a strong influence on coexistence patterns between $P$. advenus and $M$. antarcticum. The numeric dominance of $P$. advenus in beech forests and $M$. antarcticum in grasslands may be filtered by differences in temperature between habitats (e.g. warmer temperatures in the forest than in grasslands).

In ant communities, coexistence can be strongly influenced by competition (Cerdá et al. 2013) and likely to be frequently determined during the colonization process (Andersen 2008). In unfavourable habitats, the persistence of ant species in numerical disadvantage may be brief and mostly be related to their ability to modulating their aggression and maximize their foraging behaviour in response to the abundance of their opponents and the environment. In natural conditions, small P. advenus colonies in grasslands and small $M$. antarcticum colonies in the forest may be more vulnerable to variation in temperature and diet, as we observed in this laboratory study. For 
example, the modulation of aggression and foraging behaviour may overexpose individuals of small $P$. advenus colonies in grasslands while seeking for food sources. However, the likelihood of small $M$. antarcticum colonies to persist in forest habitats may be enhanced by their ability to defend their nests.

The hierarchical lottery competition model predicts that similar competitive abilities facilitate coexistence (Abrams 1996). The asymmetric responses observed between $P$. advenus and $M$. antarcticum might thus explain their negative co-occurrence patterns. Other stochastic and deterministic factors, such as the interactions among multiple species in hierarchical communities (Grime 1977; Southwood 1977; Cerdá et al. 2013), parasitism (Feener 2000; Zhao et al. 2013), and the arrival sequence of individuals, may also influence community assembly. There is increasing concern regarding the impact of climate change on population and community dynamics (Kearney et al. 2009; Estay et al. 2014). Here, we provided a mechanistic explanation for the potential impacts of climate change on the outcome of interspecific interactions and community structure. Temperature change could potentially readjust the probability of $P$. advenus to achieve numerical dominance in forest areas, and for $M$. antarcticum in grasslands, thus influencing community assembly. The modification of aggressive and foraging behaviour by abiotic factors, such as temperature and diet availability, may thus direct the processes determining the patterns of co-occurrence we frequently observe in natural communities. 


\section{Chapter 6: Human mediated stressor: a neurotoxic pesticide changes the outcome of aggressive interactions}

Publication: Barbieri RF, Lester PJ, Miller AS and Ryan KG (2013) A neurotoxic pesticide changes the outcome of aggressive interactions between native and invasive ants. Proceedings of the Royal Society B. doi:10.1098/rspb.2013.2157. 


\subsection{Abstract}

Neurotoxic pesticides, such as neonicotinoids, negatively affect the cognitive capacity and fitness of non-target species, and could also modify interspecific interactions. I tested whether sublethal contamination with neonicotinoid could affect foraging, colony fitness, and the outcome of behavioural interactions between a native (Monomorium antarcticum) and an invasive ant species (Linepithema humile). The foraging behaviour of both ants was not affected by neonicotinoid exposure. Colonies of the invasive species exposed to the neonicotinoid produced significantly fewer brood. In interspecific confrontations, individuals of the native species exposed to the neonicotinoid lowered their aggression towards the invasive species, although their survival probability was not affected. Exposed individuals of the invasive species interacting with non-exposed native ants displayed increased aggression and their survival probability reduced. Non-exposed individuals of the invasive species were less aggressive, but more likely to survive when interacting with exposed native ants. These results suggest that non-target exposure of invaders to neonicotinoids could either increase or decrease the probability of survival according to the exposure status of the native species. Given that in any community, different species have different food preferences and thus different exposure to pesticides, non-target exposure could potentially change the dynamics of communities and even influence invasion success. 


\subsection{Introduction}

Non-target effects of pesticide use are an important global issue. There is increasing evidence that pesticide use at lethal and sublethal concentrations is contributing towards pollinator declines and affecting behavioural responses of non-target organisms (Blacquiere et al. 2012; Desneux et al. 2007; Johnson et al. 2010; Williamson and Wright 2013). Pesticides such as the neonicotinoids are widely used and are effective in the control of many insect pests (Tomizawa and Casida 2005; Watson et al. 2011). These chemicals interact with acetylcholine receptors and directly affect the central and peripheral nervous system of insects (Brown et al. 2006; Palmer et al. 2013). Due to their neurotoxic action, neonicotinoids can impair the cognitive function of insects to an extent that their ability to interpret external signals and learn is reduced, or even lost (Williamson and Wright 2013). Exposure of pollinators such as bees to pesticides has demonstrated a range of physiological and behavioural changes (Gill et al. 2012; Palmer et al. 2013; Whitehorn et al. 2012). Bumblebees exposed to sublethal concentrations of a neonicotinoid had longer foraging trips, decreased food collection, produced fewer workers, and hives had higher worker mortality and loss while foraging (Gill et al. 2012; Whitehorn et al. 2012). Another study showed that small doses of two neonicotinoids: imidacloprid and clothianidin; inhibited the neuronal responses in the brain of honeybees (Palmer et al. 2013) and therefore demonstrated that neonicotinoids act in zones of insect brain responsible for cognition, learning and behaviour.

Sublethal exposure to neonicotinoids may also change behaviour of other insects. For example, the tunnelling behaviour of the subterranean termite Reticulitermes sirginicus reduced when exposed to sublethal doses of the neonicotinoid imidacloprid (Thorne and Breisch 2001). Sublethal contamination with imidacloprid also affected brain development and the motility of callow stingless bee workers (Melipona quadrifasciata anthidioides) 
(Tome et al. 2012). The grooming behaviour of the leaf-cutting ant Acromyrmex subterraneus subterraneus, which is a defensive action that prevents colony contamination by pathogens such as the entomopathogenic fungus Beauveria bassiana, was also reduced after exposure to sublethal doses of imidacloprid (Galvanho et al. 2013). Behaviour also has an important role in determining community shape and dynamics (Sih et al. 2012). Changes in behaviour are expected to modulate competitive ability of sympatric and allopatric species and affect the establishment and spread of newcomers (Wolf and Weissing 2012). The success of invasive species, for example, is linked both to their highly aggressive behaviour and to their ability to displace native communities and manipulate food sources (Holway et al. 2002; Holway and Suarez 1999).

In all communities, individual species will have different food preferences. This is certainly the case for ant communities, wherein species are specialized on a particular plant material (e.g. seeds), on indirect consumption of plant material through mutualists (e.g. aphids), or may even be solely predatory in nature (Cerdá et al. 2013; Lester et al. 2003). Such variation in food preferences likely results in different degrees of exposure to various chemicals such as pesticides that may have been released into the environment. Competition for resources substantially influences the success and fitness of many organisms, including social insects such as ants Cerdá et al. 2013). The ability of ants to compete for resources is frequently related to their colony size and behavioural plasticity (Sagata and Lester 2009). Thus, the modification of behaviour and learning may have broad effects on communities (Wolf and Weissing 2012). It is possible that changes in behaviours caused by pesticide exposure could moderate the outcome of interspecific interactions. Such changes are probably most relevant when they involve interactions between native and invasive species. Any amplification of the effects of invasive species would be problematic, given their existing role in biodiversity loss and global change (Brook et al. 2008). 
In this study I exposed colonies of two ant species, the invasive Argentine ant Linepithema humile and the native Southern ant Monomorium antarcticum, to sublethal doses of a neonicotinoid and accounted for the impacts of differential exposure on their interactions. The Argentine ant is a globally distributed invasive species associated with biodiversity loss and modification (Holway et al. 2002; Roura-Pascual et al. 2011). In New Zealand, the invasive Argentine ant was first observed in 1990, but is now distributed throughout the North Island and some regions in the South Island Ward et al. 2010). The Southern ant is abundant and widespread within New Zealand (Don 2007). Both species have similar habitat and food preferences and are aggressive towards each other (Don 2007; Sagata and Lester 2009), making them an ideal model to evaluate the effects of neonicotinoid pesticides on interacting species. I firstly assessed the effects of sublethal doses of a neonicotinoid on workers and colonies of each species. Then, I asked if competitive ability and the outcomes of interspecific interactions between the invasive Argentine ant and the native Southern ant could be influenced by sublethal exposure to the neonicotinoid pesticide. 


\subsection{Methods}

\section{Colonies and food treatments}

I collected four colonies of the Argentine ant Linepithema humile from invaded areas of North Wellington, New Zealand (41 ${ }^{\circ}$ ' S; $\left.174^{\circ} 9^{\prime} \mathrm{E}\right)$. Five colonies of the native Southern ant Monomorium antarcticum were excavated from open grasslands in Nelson Lakes National Park (41 ${ }^{\circ} 48^{\prime} \mathrm{S}$; $\left.172^{\circ} 4^{\prime} \mathrm{E}\right)$. Nests of both species were dug out in March 2012. Each soilless colony was placed in a plastic container $(21 \times 15 \times 10 \mathrm{~cm})$ containing several $30 \mathrm{~mL}$ nesting tubes one third filled with water, plugged with cotton wool and covered with aluminium foil. The number of nesting tubes varied from five to eighteen, according to colony size. Full colonies were kept in laboratory conditions at 20 $\pm 1^{\circ} \mathrm{C}$ with a $12: 12 \mathrm{~h}$ artificial light cycle. Colonies were fed ad libitum with a $20 / 80 \%$ honey/water (volume/volume) solution via soaked cotton wool and cut mealworms (Tenebrio molitor, larva). Colonies of both species were utilized in the experiment within seven months of collection.

From full colonies I removed 10 sub-colonies of each species containing 300 workers and two queens. The use of sub-colonies, or groups of workers, instead of full colonies is widely applied in ant behavioural studies (Retana and Cerda 1995; Roulston et al. 2003; Sagata and Lester 2009) and aims to avoid group effects on the behavioural responses of workers. Each sub-colony was placed in a plastic containers $(13 \times 9 \times 6 \mathrm{~cm})$ with the sidewalls painted with fluon ${ }^{\text {TM }}$ (Polytetrafluoroethylene PTFE-30; BioQuip Products, Inc.), and a segment of plastic tubing $(0.5 \mathrm{~cm} ø ; 7 \mathrm{~cm}$ length $)$ connected as a nest exit. The tubing exit was plugged with aluminium foil to stop ants leaving the artificial nest. In each artificial nest I placed three 10mL-nesting tubes, one third filled with water, plugged with cotton wool and covered with aluminium foil. The top lids of the artificial nests had five holes $(0.5 \mathrm{~cm} ø)$ and 
were covered with a mesh to permit air flux, but keep ants inside the artificial nest.

For acclimation, sub-colonies were kept under experimental conditions of temperature and food for two weeks prior to the initiation of the trials. Temperature was set at $20 \pm 1^{\circ} \mathrm{C}$ with a $12: 12 \mathrm{~h}$ artificial light cycle. Subcolonies were fed three times a week with $1 \mathrm{~mL}$ of a $20 / 80 \%$ honey/water $(\mathrm{v} / \mathrm{v})$ solution (containing or not containing the neonicotinoid insecticide according feeding treatments; see bellow $)$ and a mealworm $(\sim 0.09 \mathrm{~g})$ cut into three parts. The solution was offered via soaked cotton pad $(2 \times 2 \mathrm{~cm})$ placed on aluminium foiled. The cut mealworms were also placed on aluminium foil.

\section{Insecticide preparation}

I dissolved $5 \mathrm{~g}$ of the commercial neonicotinoid insecticide Confidor ${ }^{\circledR}$ (active ingredient: imidacloprid $50 \mathrm{~g} / \mathrm{Kg}$; water dispersible granule; brand: Yates) in $100 \mathrm{~mL}$ of water to produce a stock solution containing $0.0025 \mathrm{~g}$ imidacloprid $/ \mathrm{mL}$. An aliquot of $0.1 \mathrm{~mL}$ of the stock solution was diluted a second time in $200 \mathrm{~mL}$ of water to produce a $1.25 \mu \mathrm{g} / \mathrm{mL}$ solution. Both the stock and diluted solution were kept in glass bottles covered with aluminium foil and stored in a dark cabinet to prevent UV degradation of the active ingredient. Imidacloprid is a common pesticide used in urban and agricultural settings to control aphids and other sucking piercing insect pests. The use of a low dosage of this insecticide simulates realistic sublethal effects on nontarget species reported in the literature (Blacquiere et al. 2012).

\section{Feeding treatments}

Five colonies of each ant species - the native Southern ant and the invasive Argentine ant - were randomly assigned to one of the following treatment groups: colonies exposed to sublethal doses of the neonicotinoid 
$(\mathrm{NIC}+)$; and colonies not exposed to the neonicotinoid (NIC-). For the NIC+ treatment, $5 \mathrm{~mL}$ of honey was mixed with $20 \mathrm{~mL}$ of an aqueous solution containing $1.25 \mu \mathrm{g} / \mathrm{mL}$ of the neonicotinoid imidacloprid. For the NICtreatment I offered a 20/80\% honey/water $(\mathrm{v} / \mathrm{v})$ solution not containing the insecticide imidacloprid.

Colonies of both native and invasive species subjected to the $\mathrm{NIC}+$ and NIC- treatments were randomly assigned into two feeding cycles, which were fed on: Mondays, Wednesdays and Fridays (cycle A); and Tuesdays, Thursdays and Saturdays (cycle B) for the duration of the trials. Food was removed from the artificial nests 24 hours after it was initially offered and colonies were left to fast for a further 24 hours before being subjected to trials. All colonies were fed at the same time of the day (after trails) to guarantee similar exposure to the active ingredient imidacloprid for all groups.

\section{Experimental design}

This experiment consisted of two distinct experimental designs. The first aims to evaluate the effects of sublethal doses of the pesticide on individual workers and colony fitness. The second assess the effects of these sublethal doses of the neonicotinoid on the outcomes of interactions between native and invasive species.

Respecting the feeding cycles (cycle A or B), four colonies were randomly selected for each set of observations and placed with the entry tubing aligned to the start point on each maze. Colonies were selected at random for each trial with no replacement. Thus, colonies previously subjected to a trial were not selected again until all colonies from the same feeding cycle were also subjected to a trial. A cotton pad soaked with the NIC+ or NIC- honey/water solution (according food treatment) was randomly assigned to position "a" or "b" (Figure 6.1). The plug blocking the nest exit 
was then removed from the entry tubing, allowing ants to access the maze. Colonies were observed for a period of three hours. Once the three-hour observation period elapsed the tubing was plugged and ants were returned into their artificial nests. Maze trials were conducted over a period of 61 days, making a total of eight trials per colony.

Figure 6.1. The maze used in the trials. The dark grey area is the raised wooden maze. The light grey area was immersed in water. Each nest was placed on the plinth and accessed the maze using the tubing connected to the nest. Food was offered at points marked "a" and "b". Each numbered segment on the maze is $5 \mathrm{~m}$ long.

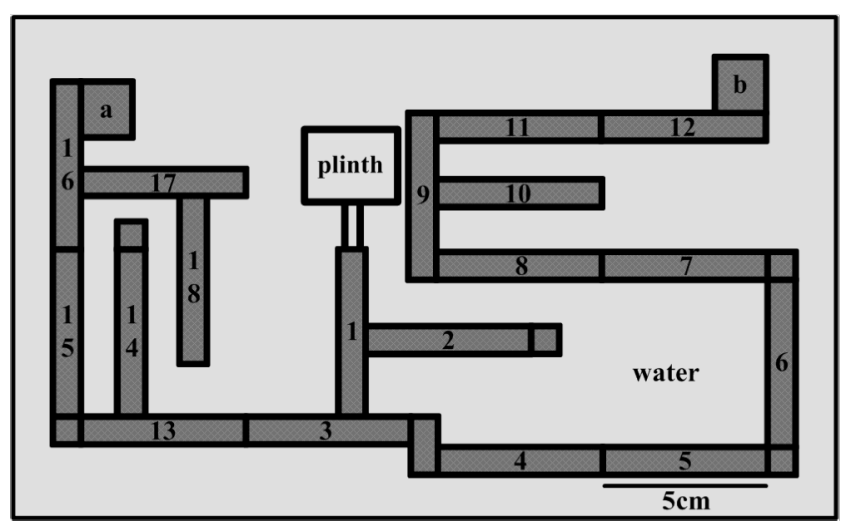

While ants searched for food on the maze, I counted the total number of ants on the maze at set intervals $(5,10,20,40,60,80,100,120,140,160,180$ minutes) and measured the following responses:

i) Walking speed: how fast an ant crossed a 5cm-long segment. Lines were placed at $5 \mathrm{~cm}$ intervals on the maze and assigned a number between 1 and 17 (Figure 6.1). I used a randomization procedure with replacement to generate a corresponding number every five minutes. During the five-minute periods, the time taken for an ant to walk from one end of the segment to the other was recorded. All ants that entered and continuously crossed the selected segment during this period were timed;

ii) Food discovery: the time taken for one ant worker to locate the food source after the first worker accessed the maze; 
iii) Drowning rates: the number of ants that fell off the edge of the raised maze into the surrounding water during each trial. These ants were immediately removed from the water and placed in a container lined with absorbent paper towel for the remainder of the trial period. The paper towel dried ants out to prevent death. Drowning rates were corrected using a per capita rate, which was calculated from the number of ants drowning and the number of individuals entering the maze during the three-hour period. The use of a proportional value allowed us to compare drowning rates among colonies despite differences in recruitment. Once the three-hour period of each trial had elapsed ants were returned to their respective nesting boxes. The use of drowning rates aims to evaluate the performance of individual ants exposed or not exposed to the neonicotinoid. The water surrounding the maze simulates habitat complexity and, consequently, a factor that could reduce fitness if the cognitive system of individuals were somehow affected by sublethal exposure to the neonicotinoid.

To evaluate the effects of sublethal doses of the neonicotinoid on colony fitness, I quantified the total number of ants alive and the brood production of each nest. Once all trials were fully completed, including the interspecific interactions described below, the number of live ants remaining in each nest was counted. The number of ants removed from each colony for the trials involving interspecific interactions (see below) was noted and added to the final counting to ensure that only the effects of sublethal exposure to the neonicotinoid on the colony size was taken into account in the analysis. This procedure was necessary as I removed different number of ants from each colony to produce a total of 20 repetitions for each one of the interactive groups described below. Also, the total brood produced by each colony was quantified under a microscope (Nikon SMZ 1500) at the end of the trials. During the initial experimental setup I took care to remove all eggs from the 
colony, including those being carried by workers. This allowed us to accurately assess brood production.

\section{Agonistic interaction and worker survival probability}

Groups of both native and invasive species, exposed or not to the neonicotinoid, were subjected to interspecific interactions. I observed the behavioural responses and the survival probability of interacting groups. After 61 days of trials I randomly selected colonies in different treatments and removed groups of ten ants. I used a $2 \times 2$ factorial design with 20 repetitions. The independent variables were: i) species: native; invasive; and ii) pesticide exposure status: colonies exposed to the neonicotinoid ( $\mathrm{NIC}+$ ); colonies not exposed to the neonicotinoid (NIC-). Therefore, four different interactive groups were set, as follow:

Set 1: Native (NIC+) vs. Invasive (NIC+);

Set 2: Native (NIC+) vs. Invasive (NIC-);

Set 3: Native (NIC-) vs. Invasive (NIC-);

Set 4: Native (NIC-) vs. Invasive (NIC+).

I observed three replicates at a time. I adopted a random procedure to select the sequence of the three replicates under observation (e.g. NIC+ vs. NIC+; NIC- vs. NIC+; NIC- vs. NIC-). I also set four external control treatments for each one of the four factor levels. Controls consisted of groups (10 workers) that faced the same colony manipulation procedures and were maintained under the same experimental conditions. However, control groups were not subjected to interspecific interactions. The use of controls aims to evaluate the survival probability of ant workers exposed or not exposed to the pesticide in the absence of interspecific interaction, but under the same experimental conditions. 
Heterospecific groups of ants interacted with each other in a plastic container $(14 \times 10 \times 8 \mathrm{~cm})$. Inside the plastic container I allocated a ring $(5 \mathrm{~cm}$ $ø$; $5 \mathrm{~cm}$ high) with the inner and outer sides coated with fluon to initially isolate ants from each other. Interactive groups containing ten ants of each species were randomly placed either inside or outside the ring. I kept the interspecific groups of ants apart from each other for 10 minutes to reduce stress caused by the separation of them from their colonies. After 10 minutes, I removed the ring to allow interspecific interactions. While native and invasive species interacted with each other I scored their interaction.

Patterns of interspecific interaction were noted as non-aggressive (do not harm the opponent species) or aggressive behaviours (could potentially harm the opponent species) and were characterized using the following behavioural categories (adapted from Suarez et al. 1999):

i) non-aggressive: "ignore" = body contact with no interest; "touch" = contact followed by antennation, when one ant tapped the other ant with its antennae; "avoid" = after contact ants retreat in opposite directions;

ii) aggressive: "aggression" = head biting, leg biting, raising the gaster or spraying acid; "fighting" = prolonged aggression $(>5$ sec) between individuals with one or both ants locking mandibles onto a body part, carrying the other with the mandibles, or gripping and flexing the gaster in an attempt to use chemical defences.

Interspecific interactions were scored for 20 seconds every 2 min for 20 minutes. The behavioural action was computed for the species that initiated the behavioural interaction. If at the encounter between two individuals both species simultaneously reacted to each other (e.g. both species simultaneously retreat in opposite direction), both were scored.

The number of individuals alive of both species was constantly monitored every 2 minutes during the behavioural observations and at the 
following set intervals from the initiation of the interactions: $25 \mathrm{~min}$, 30min, $40 \mathrm{~min}, 50 \mathrm{~min}, 1 \mathrm{~h}, 2 \mathrm{~h}, 4 \mathrm{~h}, 8 \mathrm{~h}, 16 \mathrm{~h}$, and $32 \mathrm{~h}$. At the second hour of interaction I add a cotton pad $(2 \mathrm{~cm} \times 2 \mathrm{~cm} ; 2 \mathrm{~mm}$ thick $)$ into the container, which was constantly humidified, to avoid ants to die due to desiccation.

\section{Statistical analyses}

All data analyses and randomizations were performed in $\mathrm{R}$ version 2.15.3 (R Development Core Team 2013). For randomizations I used the function "sample()". Significance for all tests was set at $P<0.05$.

Ant walking speed and drowning rates were analysed using linear mixed effect models (LMER) with the package lme4 (Bates et al. 2012). Ant species and treatment were fixed effects and "colony" was set as the nested random-effect. This approach is appropriate given that the sub-colonies are meaningful within a particular full colony.

Food discovery was analysed using a survival analysis with the package survival (Therneau 2012). This analysis is appropriate given that data were right-skewed and right-censored. I used Cox proportional hazard regression models (Coxph) to assess the effects neonicotinoid exposure on the probability of ants to find food. I found no effects of food position on the probability of species finding food sources $\left(\chi^{2}=2.477 ; d f=1 ; P=0.115\right)$. Thus, this factor was removed from the model.

The number of workers alive and the quantity of brood after 61 days of trials were compared using generalized linear models (GLM) with a Gaussian family distribution. The final number of queens per colony was initially included as a covariate in the analysis. There was no effect of queen number on the brood rate $\left(\chi^{2}=0.602 ; d f=1 ; P=0.438\right)$, and therefore this factor was removed from the model. 
Interspecific interaction level between groups of workers in different treatments were analysed using generalized mixed effect models (GLMM) with the package lme4 (Bates et al. 2012). Non-aggressive and aggressive behavioural reactions were modelled as a binary response. Heterospecific groups of ants in different treatments were set as fixed effects and "colony/sub-colony group" was included as the multiple nested random-effect term. Thus, the random effect has two levels. The first level is the full colony from where the subcolonies were extracted and the second level is the sub-colony from where groups of 10 workers were removed for behavioural observation.

The survival probability of ants in different treatments, including controls, was analysed using a survival analysis with the package survival (Therneau 2012). I used Cox proportional hazard regression models (Coxph) to compare the survival probability of interacting groups in different treatments, including controls. 


\subsection{Results}

Effects of sublethal doses of the neonicotinoid on workers and colony fitness

The walking speed and drowning rate of the native Southern ant and the invasive Argentine ant were not affected by exposure to the neonicotinoid (Table 6.1; $P \geq 0.051$. Although the invasive Argentine ant was more likely to find food sources (Figure 6.2) (d.f. $=3, b=-0.83, z=-3.18, P=0.002$, Coxph), the food discovery probability of both the native Southern ant (d.f. $=3, b=$ $0.021, z=-0.075, P=0.940$, Coxph) and invasive Argentine ant (d.f. $=3, b=$ $0.168, z=0.727, P=0.467$, Coxph) were not affected by exposure to the neonicotinoid.

There were no differences in the number of workers alive after 61 days of trials in colonies either of the native Southern ant or the invasive Argentine ant (Figure 6.3a) (d.f. $=1$, d.f. .rror $_{1}=17, b=-18.5, t=-0.67, P=0.512$, GLM), regardless of treatment $($ d.f. $=1$, d.f. error $=17, b=-49.7, t=-1.8, P=0.089$, GLM). However, the effects that neonicotinoid exposure had on brood production (Figure 6.3b) differed between the native Southern ant and the invasive Argentine ant (d.f. $=1$, d.f. error $=16, b=-173.4, t=-3.19, P=0.006$, GLM). Although brood production of the native Southern ant was not affected by sublethal doses of the neonicotinoid (d.f. $=1$, d.f. -error $=16, b=-1.5, t=-0.06$, $P=0.957, \mathrm{GLM})$, the brood production of the invasive Argentine ant was reduced in $\mathrm{NIC}+$ treatments $($ d.f. $=1$, d.f. error $=16, b=-151.4, t=-2.79, P=$ 0.013, GLM). 
Figure 6.2. The food discovery probability over time for the native Southern ant (black lines) and invasive Argentine ant (grey lines). Dashed lines: colonies not exposed to the neonicotinoid (NIC-), solid lines: colonies exposed to sublethal doses of the neonicotinoid (NIC+). The food discovery probability is a one minus transformation of the estimated Kaplan Meier probability curves. For each treatment, $n=40$.

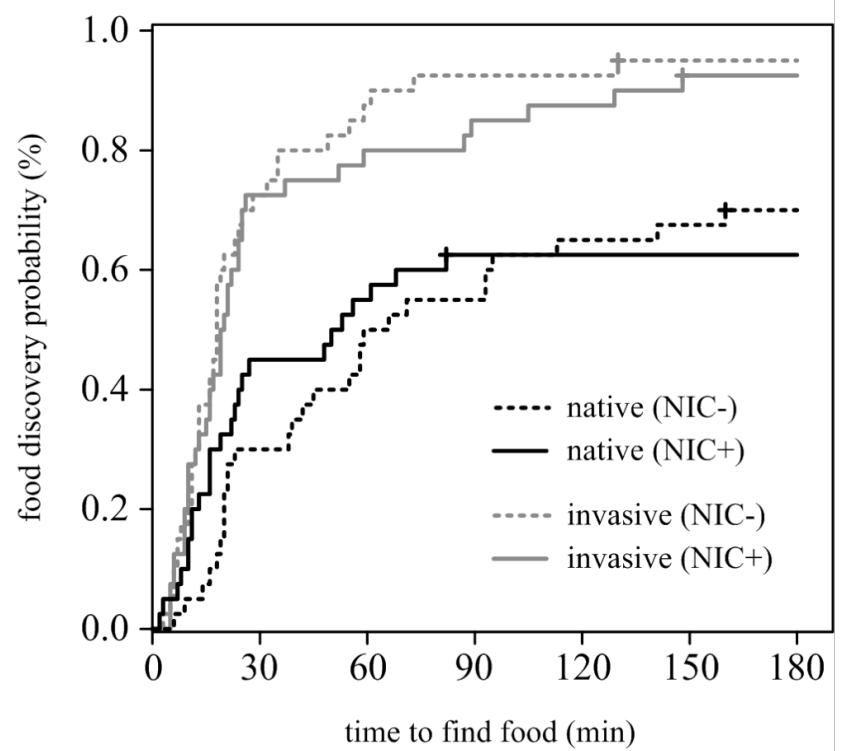

Table 6.1. Mean $( \pm$ se $)$ and the linear mixed effect models results comparing the walking speed and drowning rate of ants from colonies exposed not exposed (NIC-) and exposed to sublethal doses of the neonicotinoid (NIC+). For each treatment, $\mathrm{n}=40$.

\begin{tabular}{|c|c|c|c|c|c|c|}
\hline \multirow{2}{*}{ species } & \multirow{2}{*}{ response } & \multicolumn{2}{|c|}{$\overline{\text { mean }( \pm \mathrm{sem})}$} & \multirow{2}{*}{$\beta(\mathrm{sem})$} & \multirow{2}{*}{$t$} & \multirow{2}{*}{$p$} \\
\hline & & NIC- & $\mathrm{NIC}+$ & & & \\
\hline $\begin{array}{l}\text { native } \\
\text { Southern }\end{array}$ & $\begin{array}{c}\text { walking speed } \\
(\mathrm{cm} / \mathrm{s})\end{array}$ & $0.455(-0.020)$ & $0.476(-0.015)$ & $0.021(0.06)$ & 0.371 & 0.712 \\
\hline ant & Drowning rate & $2.854(0.448)$ & $2.038(0.315)$ & $-0.816(0.55)$ & -1.490 & 0.140 \\
\hline $\begin{array}{l}\text { invasive } \\
\text { Argentine }\end{array}$ & $\begin{array}{l}\text { walking speed } \\
\qquad(\mathrm{cm} / \mathrm{s})\end{array}$ & $0.833(0.028)$ & $0.765(0.021)$ & $-0.068(0.03)$ & -1.980 & 0.051 \\
\hline ant & Drowning rate & $1.137(0.176)$ & $2.246(0.446)$ & $1.109(0.75)$ & 1.473 & 0.145 \\
\hline
\end{tabular}

Effects of sublethal doses of the neonicotinoid on interspecific interaction and survival probability

Groups of 10 workers from both exposed and non-exposed colonies were subjected to interspecific interactions. Both the native Southern ant and the invasive Argentine ant were observed moving their gaster towards their opponent in an attempt to use their venom (noted as aggressive responses). During interspecific interactions, the native Southern ant and the invasive 
Argentine ant displayed higher rates of aggressive behaviours than nonaggressive behaviours, regardless their treatment status (Figure 6.4) (native: d.f. $=1, b=-1.53, z=-9.69, P<0.001$; invasive: d.f. $=1, b=-0.78, z=-6.43, P<$ 0.001, GLMM). The aggressive behaviour of the native Southern ant (Figure 6.4a) was significantly lower when exposed to the neonicotinoid (d.f. $=1, b=$ $0.41, z=-4.49, P<0.001$, GLMM), regardless the treatment status of the invasive Argentine ant (d.f. $=1, b=0.11, z=1.18, P=0.239$, GLMM).

Figure 6.3. The number of $(a)$ workers alive and (b) brood produced on colonies of the native Southern ant and the invasive Argentine ant after 61 days of trials (mean \pm se). In light grey are colonies of both species not exposed to the neonicotinoid (NIC). In dark grey are colonies of both species exposed to sublethal doses of the neonicotinoid $(\mathrm{NIC}+)$. The dashed line on top panel $(a)$ is the initial number of workers in each colony for all treatments. For each treatment, $\mathrm{n}=5$.
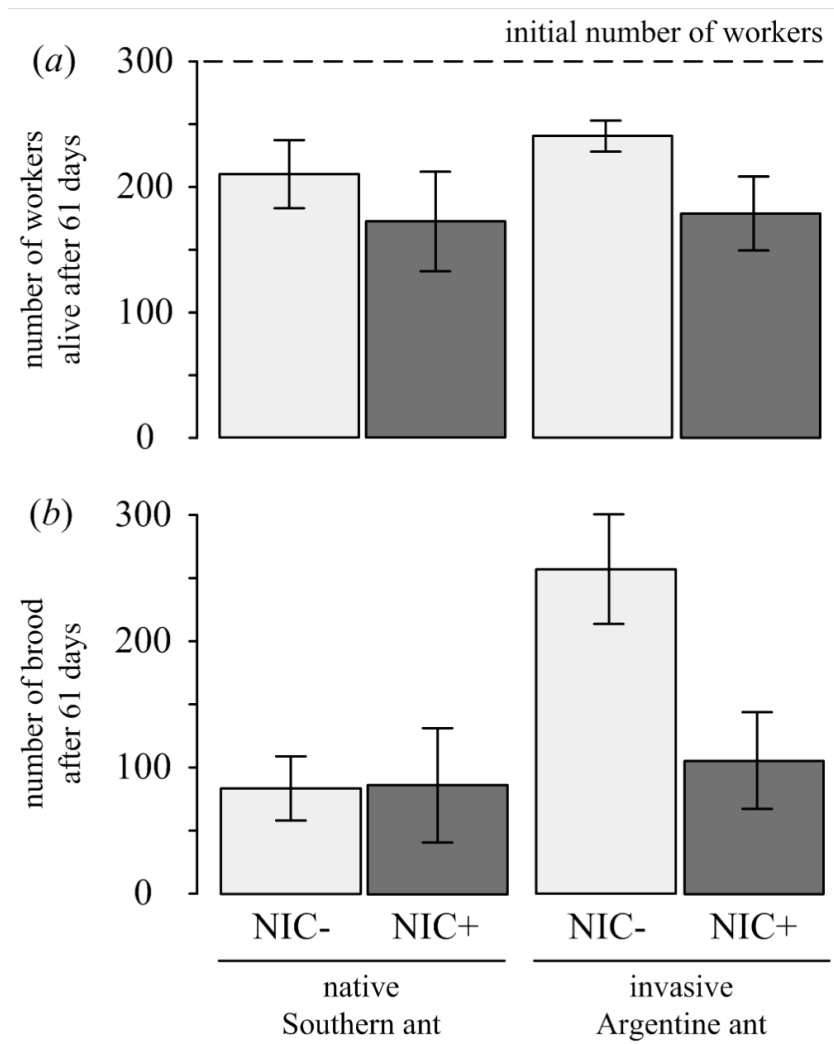

The aggressive behaviour of the invasive Argentine ant (Figure 6.4b) was affected by both their treatment status $($ d.f. $=1, b=0.31, z=3.91, P<$ 0.001, GLMM) and the treatment status of the native Southern ant (d.f. $=1, b=$ $-0.42, z=-5.39, P<0.001$, GLMM). Interestingly, the invasive Argentine ant did not modify their aggressive response towards the native Southern ant when both were exposed to the neonicotinoid $(\mathrm{NIC}+$ vs. NIC+) and under 
normal conditions (NIC- vs. NIC-) (d.f. $=1, b=-0.12, z=-1.02 ; P=0.308$, GLMM). Even though the invasive Argentine ant was not exposed to the neonicotinoid in the "Invasive (NIC-) vs. Native (NIC+)" treatment, they became less aggressive towards groups of exposed native Southern ant (d.f. = $1, b=-0.35, z=3.15 ; P=0.002$, GLMM). Conversely, in the "Invasive (NIC+) vs. Native (NIC-)" treatment the invasive Argentine ant displayed the highest levels of aggression (d.f. $=1, b=-0.47, z=-3.57 ; P<0.001$, GLMM).

After 32 hours of interspecific interaction, the survival probability of the native Southern ant (Figure 6.5a) was not affected in any treatment regardless of their treatment status $($ d.f. $=3, b=0.02, z=0.93 ; P=0.351$, Coxph) or the treatment status of the invasive Argentine ant (d.f. $=3, b=-0.04$, $z=-1.46 ; P=0.144$, Coxph). Furthermore, the external control groups of the native Southern ant, not subjected to interspecific interactions, did not differ from the other groups subjected to interspecific interaction with the invasive Argentine ant (d.f. $=3, b=-0.02, z=-0.01 ; P=0.994$, Coxph).

The survival probability of the invasive Argentine ant (Figure 6.5b) was influenced by both their treatment status (d.f. $=3, b=0.53, z=5.06, P<0.001$, Coxph) and the treatment status of the native Southern ant (d.f. $=3, b=-0.46$, $z=-4.13, P<0.001$, Coxph). The survival probability of the invasive Argentine ant in natural conditions (NIC- vs. NIC-) was relatively low (Figure 6.5b), and did not change when both the native Southern ant and Argentine ant were exposed to the pesticide $(\mathrm{NIC}+$ vs. $\mathrm{NIC}+)($ d.f. $=3, b=0.8, z=-1.48 ; P=0.14$, Coxph). Surprisingly, in the "Invasive $(\mathrm{NIC}+)$ vs. Native (NIC-)" treatment, which the invasive Argentine ant displayed the highest levels of aggression (Figure 5.4b), the invasive Argentine ant was completely exterminated during the first 16 hour of interaction (d.f. $=3, b=0.68, z=6.54 ; P<0.001$, Coxph). Importantly, in the "Invasive (NIC-) vs. Native (NIC+)" treatment, which the invasive Argentine ant displayed the lowest aggression levels (Fig 6.4b), I found significant increased survival probability of the invasive Argentine ant 
(d.f. $=3, b=-0.31, z=-2.83 ; P=0.005$, Coxph). Groups of the invasive Argentine ant subjected to interspecific interaction had lower survival probability than their external control groups not subjected to interactions (d.f. $=3, b=-3.09, z=-9.92 ; P<0.001, \mathrm{Coxph}$ ).

Figure 6.4. The proportion (mean \pm sem) of behavioural reactions displayed between groups containing 10 workers of each species in different treatment status. Groups of interacting ants were not exposed (NIC-) or exposed to sublethal doses of the neonicotinoid (NIC+). Dark grey columns are aggressive responses. Light grey columns are not aggressive responses. Top panel $(a)$ is the proportion of responses displayed by the native Southern ant during interspecific interactions with the invasive Argentine ant. Bottom panel $(b)$ is the proportion of responses displayed by the invasive Argentine ant during interspecific interactions with the native Southern ant. For each treatment, $\mathrm{n}=20$.
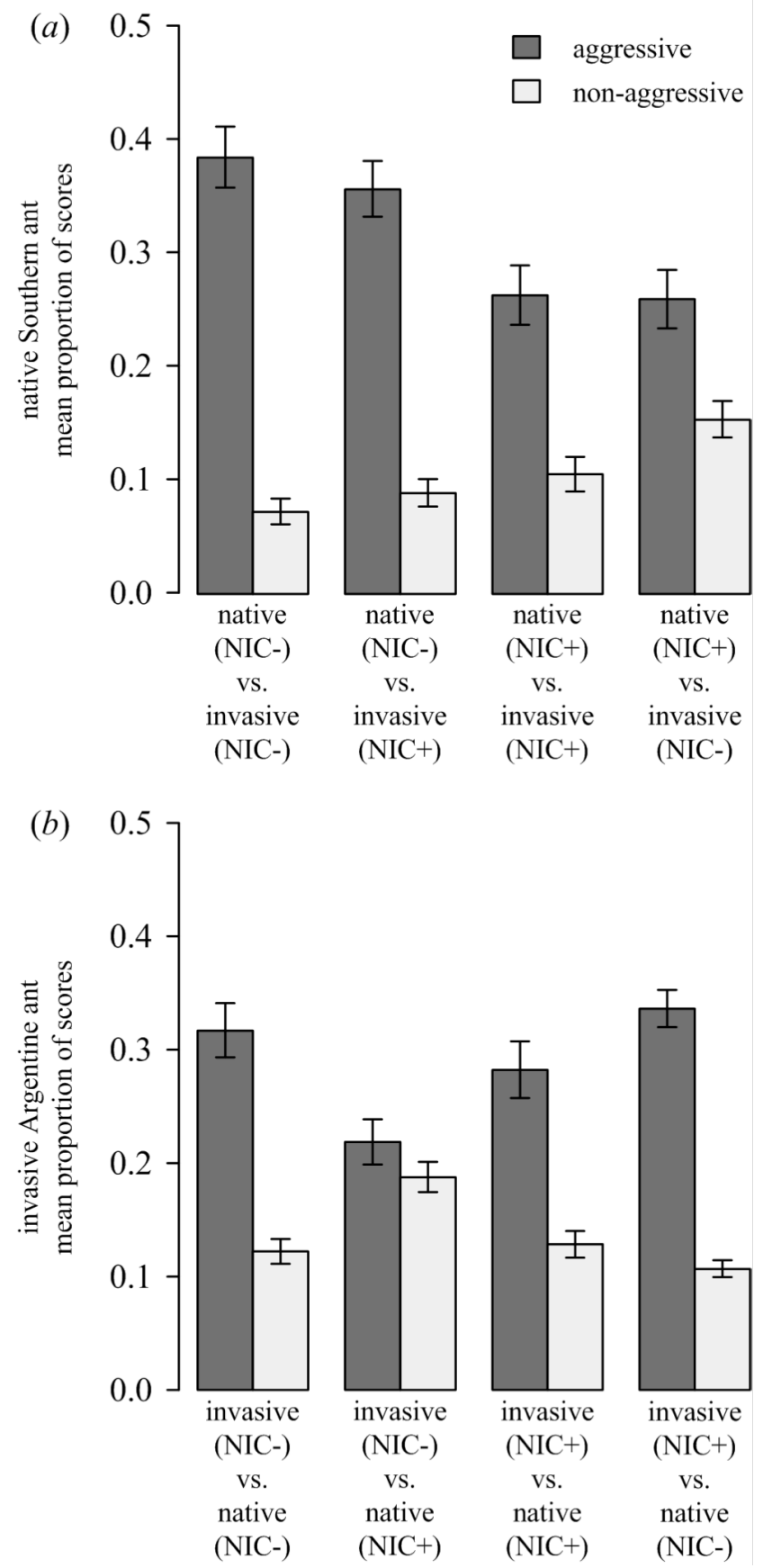
Figure 6.5. The survival probability of ants subjected to interspecific interactions in groups. Groups of interacting ants contained 10 ants of each species and were not exposed (NIC-) or exposed to sublethal doses of the neonicotinoid $(\mathrm{NIC}+)$. Top panels (a) are the survival probability over time of the native Southern ant during interspecific interactions with the invasive Argentine ant. Bottom panels $(b)$ are the survival probability over time of the invasive Argentine ant during interspecific interactions with the native Southern ant. Labels on the
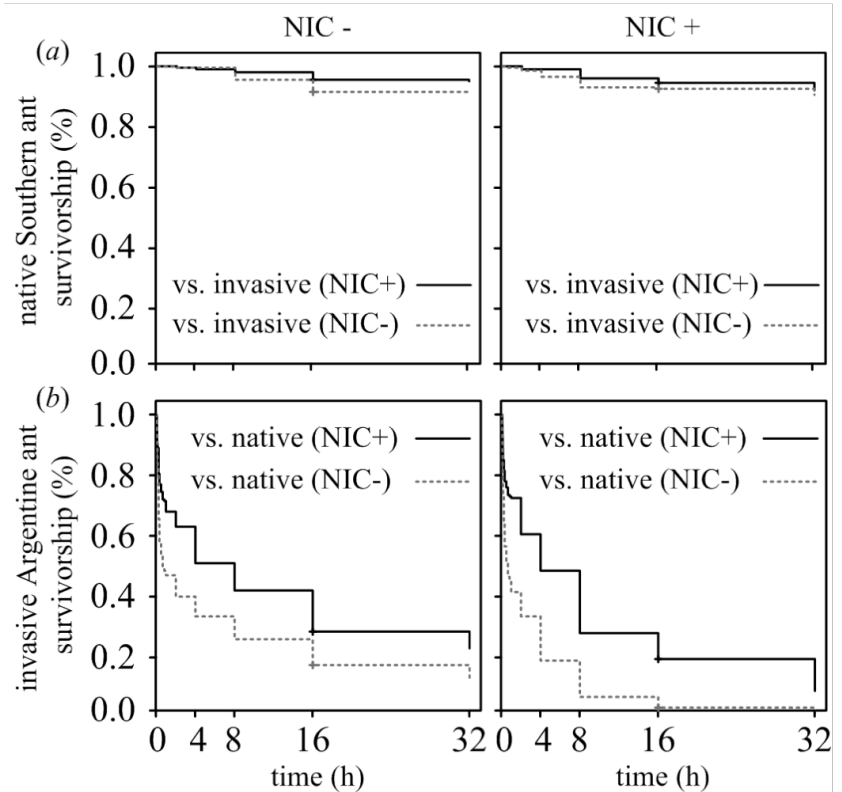

top of each panel are the treatment status of $(a)$ the native Southern ant, or $(b)$ the invasive Argentine ant when interacting with the opponent species (see legends). For each treatment, $\mathrm{n}=20$. 


\subsection{Discussion}

I found that non-target pesticide exposure to neonicotinoids alter the behaviour, fitness and community dynamics of ants. Our experiment demonstrates that the exposure to neonicotinoids had different impacts on the interspecific aggressive behaviour and colony fitness of the native Southern ant and the invasive Argentine ant. The invasive Argentine ant, whether exposed or not exposed to the neonicotinoid, showed a higher ability to locate and explore food sources than the native Southern ant. Brood production of the native Southern ant was not affected by the neonicotinoid. However, an important effect of sublethal exposure to the neonicotinoid in the invasive Argentine ant was to reduce brood numbers to approximately $50 \%$ of those in non-exposed colonies.

The success of the invasive Argentine ant is partially linked to their rapid recruitment and dominance of food sources (Holway et al. 2002). While neonicotinoids modified the foraging ability of bees (Gill et al. 2012), I found no effects of sublethal exposure on the foraging ability of either the native Southern ant and invasive Argentine ant. Bees and ants use different cues to locate and inform food position. Most ants use species- or colony-specific pheromones to guide themselves and to recruit nestmates to food sources. Chemosensory receptors located on their antennae identify the odours produced by colony members (Ozaki et al. 2005). On the other hand, foraging activity and orientation in bees is coordinated by ritualized modes of communication, including the waggle dance (Riley et al. 2005). Different species within any community are likely use different methods to perceive food resources or potential hazards (Wolf and Weissing 2012). I observed no such effects in our system. Because neonicotinoids affect specific neuronal pathways and specific behaviours, I expected variation in neonicotinoid effects between species. 
I found no significant effects of the pesticide on the aggression level and survival probability of the invasive species in a first scenario where both the native Southern ant and invasive Argentine ant were exposed or not exposed to the neonicotinoid. A second scenario where only the invasive Argentine ant was exposed to neonicotinoid prior to interaction with the native Southern ant showed that the invasive Argentine ant displayed higher levels of aggression, but were completely exterminated by the native Southern ant. Importantly, in a third scenario where only the native Southern ant was exposed to the pesticide prior to interaction with the invasive Argentine ant, I found that the invasive Argentine ant reduced their aggression but had increased survival probability.

The distribution of the invasive Argentine ant throughout the world is strongly linked with anthropogenic activities and also, in a smaller degree, with their biotic interaction with local species (Roura-Pascual et al. 2011). In New Zealand, for instance, the invasive Argentine ant is only found in urban and agricultural settings co-occurring and possibly competing for food sources with the native Southern ant (Sagata and Lester 2009; Ward et al. 2010). In these areas, pesticides such as neonicotinoids are commonly used to control insect pests and may affect ants via distinct pathways such as direct contact with the active ingredient applied in the environment, consumption of plant material containing the pesticide, or even ingestion of honeydew produced by mutualists. Other ant species in these communities are, for example, solely predatory in nature, just as in any other community. Thus, differential exposure to pesticides would almost certainly occur between species within any community.

It is important to highlight possible non-target effects of neonicotinoids on the biotic resistance imposed by native communities. In any given habitat where the local species had been previously exposed to neonicotinoids, the invasive Argentine ant could have significantly higher chances to monopolize 
food sources and survive. The reduced brood production of Argentine ant colonies exposed to the neonicotinoid gave them a similar outcome to the native Southern ant. Hence, in areas where both the native Southern ant and invasive Argentine ant co-occur, it is likely that the reduction in brood production as a result of sublethal exposure to the neonicotinoid in the invasive Argentine ant is more important to colony survival than the behavioural responses.

I note that there may be important effects of neonicotinoids on the invasive Argentine ant, depending on the community composition and context. In areas extensively dominated by the invasive Argentine ant, the combined effects of target and non-target pest control programs may exert synergistic effects and improve their control (Brightwell et al. 2010). Herein, for example, groups of Argentine ants previously exposed to the neonicotinoid had reduced brood production and were completely annihilated by groups of the native Southern ant that were not exposed to the pesticide. The reduced brood production of the invasive Argentine ants may significantly affect recently established colonies, in which the number of queens and workers are relatively small (Silverman and Brightwell 2008). These non-target effects combined with an appropriate control program targeting Argentine ants (Rust et al. 2004) could efficiently suppress their population in invaded areas.

The role of behaviour in determining the success of species and shaping communities is well established (Cerdá et al. 2013; Sih et al. 2012). The dose-dependent impacts of neonicotinoids in the neuronal activity of insect brains could impair cognition and learning of new behavioural tasks (Palmer et al. 2013). Our results showed that neurotoxic pesticides affect behaviour and fitness of different species in different ways. Thus, non-target effects of neonicotinoids could potentially have detrimental effects on natural communities and potentially act as a human-mediated driver of invasion. Uncontrolled use of neonicotinoids in urban and agricultural areas could 
therefore potentially modify aggressive responses and the outcome of interspecific interactions. Our results provide evidence of the potential effects of pesticides on the structure and dynamics of ant communities. I believe that within any community, different food preferences and behaviours between species will result in differential exposure to pesticides such as neonicotinoids. This exposure can clearly alter both intraspecific behaviours and the outcome of interactions within the community. ecology and evolution. 


\section{Chapter 7: General discussion}


In this thesis, I first described the co-occurrence patterns of two native ant communities in New Zealand. In the subsequent four chapters, I evaluated the role of interspecific aggression and the effects of several biotic and abiotic stressors on the modulation of interspecific aggression and foraging behaviour.

I found (chapter 2) that three ant species (Prolasius advenus, Huberia striata and Huberia brounii) are associated with forest habitats. Conversely, Monomorium antarcticum and Pachycondyla sp. mainly occur in grasslands. Among these species, $P$. advenus and $M$. antarcticum exhibited negative cooccurrence patterns. I found evidence (chapter 3) that interspecific aggression scales with co-occurrence patterns and survival probability in natural communities. I demonstrated (chapters 4-6) that the modulation of interspecific aggression and foraging behaviour could modify the outcomes of interspecific competition. Such changes potentially affect community assembly and may have contributed to the co-occurrence patterns observed in chapter 2.

In this section of my thesis, I provide an integrative overview of the factors that may influence the co-occurrence patterns I observed in two ant communities. I split this discussion in four main parts. Firstly, I discuss the role of aggression, arrival sequence and colony size, temperature, food sources, and habitat preference in the co-occurrence patterns of native ant communities. I mainly focus this discussion on the two ant species $(P$. advenus and $M$. antarcticum) that showed evidence of negative co-occurrence patterns. Secondly, I discuss the factors promoting differences in community assembly between my field sites. Then, I discuss the role of interspecific aggression and how the modification of aggression potentially affects biological invasions. Finally, I conclude by arguing that aggression, and its modulation by several external factors, is the main factor to be involved in assembling these two ant communities. 


\subsection{Native ant community assembly}

\section{The role of aggression}

The co-occurrence pattern of New Zealand's native ant communities appears to be strongly influenced by interspecific aggression. I demonstrated (chapter 3) that variation in interspecific aggression likely contributes to the occurrence patterns observed in the two ant communities I studied. Few studies have attempted to investigate the role of aggression in community assembly. Adler et al. (2007) and Wittman and Gotelli (2011), for example, used dominance indices to predict co-occurrence patterns in ant communities. Neither study was able to predict the likelihood of species to co-exist, probably because the behavioural responses of ants composing these communities may be strongly influenced by other factors such as colony size.

The main difference between the ant communities I studied and the ones studied by Adler et al. (2007) and Wittman and Gotelli (2011) is their different functional diversity. In both studies, for example, the communities had at least one top dominant species as defined in the context of global ant ecology (Dominant Dolichoderine; see Andersen (1997); Brown Jr. (2000) for further information on ant functional groups). Neither ant species in New Zealand's native ant community is a Dominant Dolichoderine. The absence of such functional group may change the expression of aggression and competition. Such effects are clear when evaluating the effects of top-predator and invasive species in community dynamics (McPeek 1998; Zavaleta et al. 2001) - which may either promote coexistence or enhance the interspecific interactions between resident species.

Coevolved species are expected to display innate responses during interspecific interactions (Vermeij 1982). The ontogenesis of behavioural responses may be a result of learning, imprint at individual or group level and 
subsequent genetic assimilation (Gordon 2013). The evolutionary foundations of differential aggression may be an extension of or related to the chemical communication signals used by social insects in discerning between kin and non-kin. A number of studies have addressed recognition systems among social insects (e.g. Errard et al. 2008; Hölldobler and Carlin 1987; Suarez and Garcia 1999). These recognition systems are chemically mediated and targeted on cuticular hydrocarbons (Vander Meer and Morel 1998). Kin recognition, though into genetically fixed chemical windows, is potentially co-determined by local external factors such as diet Buczkowski et al. 2005, Martin et al. 2013).

Species develop compensatory adaptations for defence (Vermeij 1982; LeBrun et al. 2014). Enemy specification, for example, is described by Wilson (1975) as an evolved defensive action directed to identify and react efficiently against the most powerful opponents (Wilson 1975). A number of studies explicitly or implicitly describe examples of enemy specification in ants (Carlin and Johnston 1984; Feener 1987; Hölldobler 1983; Jones et al. 2004; Knaden and Wehner 2003; Rajakumar et al. 2012; LeBrun et al. 2014). The different levels of aggression observed among the ant species that compose the ant communities I studied, and their frequent use of chemical weapons during interspecific interactions, seem unlikely to be examples of enemy specification. For example, M. antarcticum has ant-repellent venom alkaloids (Andersen et al. 1991; Don and Jones 1993) and P. advenus frequently spray formic acid (Grangier and Lester 2011) during aggressive interactions at food sources. Monomorium antarcticum and $P$. advenus did not use these chemical substances against all opponents during interspecific interactions (chapter 3). Thus, it is possible that coevolutionary processes have been driven the expression of interspecific aggression and influenced their co-occurrence patterns. 
The role of arrival sequence and colony size

The ability of ant colonies to persist is largely determined during the establishment process (Andersen 2008). New queens typically arrive into ant communities at different times. In a mangrove ant community, for example, ant species that arrived first have competitive advantages and a higher probability to persist over newcomers during the colonization process (Cole 1983a; b). In general, the establishment of new colonies is claustral - which means that queens do not leave the nest chamber - and interactions with their external environment often starts when the first workers emerge (Hölldobler and Wilson 1990). Therefore, priority effects are mostly related with how workers interact with competitors in the context of territoriality.

In chapter 4, I observed that the sequence of arrival modulated agonistic behaviour between $P$. advenus and $M$. antarcticum. Such changes may influence the probability of both ant species to establish new colonies and persist. Colonies of $P$. advenus adopt an aggressive strategy and $M$. antarcticum a defensive tactic. The success of $M$. antarcticum colonies in grasslands may derive from their ability to defend their nest sites and appears to be enhanced by their use of venom alkaloids (Andersen et al. 1991; Don and Jones 1993). In forest habitats, however, $P$. advenus is abundant and their nests frequently achieve large sizes (Burne 2012; Duthie and Lester 2013). The success of $P$. advenus in these environments may be related to their ability to: defend larger territories, achieve numerical dominance and use of formic acid during interspecific conflicts (Grangier and Lester 2011).

The expression of territorial behaviours may have stronger consequences in colonies with different sizes. For example, the highly aggressive reaction displayed by $P$. advenus may overexpose recently established colonies in open areas mostly dominated by $M$. antarcticum. As I demonstrated in chapter 4, small colonies of $P$. advenus were exterminated by large $M$. antarcticum colonies. On the other hand, the likelihood of initial $M$. 
antarcticum colonies to persist in forest habitats may be enhanced from their ability to defend their nest sites. Large colonies of $P$. advenus had significant loss of workers when fighting against small $M$. antarcticum colonies. Therefore, differences in territorial behaviour and the modulation of such reaction by priority effects may influence the co-occurrence patterns of these two native ant species.

\section{The role of temperature}

Habitat characteristics directly influence physiochemical conditions in adjacent ecosystem such as grassland-forest transitions (Murcia 1995). I observed that forest habitats offer more stable temperature conditions than grasslands (chapter 2). Differences in temperature between habitats may filter the occurrence of $P$. advenus in the forest and $M$. antarcticum in grasslands. Elsewhere, segregation in ant assemblages has been attributed to temperature variation (Albrecht and Gotelli 2001; Cerdá et al. 1997). Rice and Silverman (2013), for example, found that temperature mediates coexistence between the Argentine ant (Linepithema humile) and the Asian needle ant (Pachycondyla chinensis). A broad thermal tolerance favoured both establishment and expansion of Asian needle ant colonies, even though Argentine ants were dominant at food sources.

Ants, including New Zealand's native ant species, typically produce reproductive forms that disperse during the warmer periods of the year (spring/summer) (Don 2007; Hölldobler and Wilson 1990). Therefore, temperature per se may not filter the arrival and initial reproductive output of new queens either in grasslands or forest habitats. After summer, when the first workers emerge, temperatures under $5^{\circ} \mathrm{C}$ may reduce queen reproduction. In this thesis, I did not quantify the effects of temperature on queen oviposition rates. However, it is well established that temperature is an 
important constraint on insect reproduction and survival (Amarasekare and Sifuentes 2012).

In chapter 4, I showed that changes in temperature have stronger effects on the foraging activities of small colonies of $P$. advenus than on small colonies of $M$. antarcticum. McGrannachan and Lester (2013) also found that at $13^{\circ} \mathrm{C} P$. advenus is unlikely to find and recruit to food sources. On the other hand, $M$. antarcticum prominently found and recruited to food sources at temperatures that ranged from 13 to $23^{\circ} \mathrm{C}$. The cold temperatures that I observed in grasslands may reduce the foraging activities of small (and recently established) $P$. advenus colonies. I observed higher foraging activities and aggression of $P$. advenus on warm temperatures than on cold temperatures. Warm temperatures observed during the summer periods in my field sites may enhance foraging activity and aggression of $P$. advenus. Such behavioural changes may increase the territorial behaviour of $P$. advenus and thus reduce the probability of $M$. antarcticum to successfully establish new colonies in forest habitats.

My results (chapter 5) and those of McGrannachan and Lester (2013) suggest that temperature may have stronger effects on $P$. advenus than on $M$. antarcticum. The potential effects of low temperatures on queen reproduction (not explored in this thesis), aggression and on the foraging activities of small $P$. advenus colonies could have additive effects and filter the occurrence of $P$. advenus in grasslands. On the other hand, the effects of warmer temperatures may intensify the aggressive interaction between large colonies of $P$. advenus and small colonies of $M$. antarcticum in forest habitats. Although not explored in this thesis, temperature may similarly affect fitness and modulate the foraging activities and aggression of the other ant species in these communities. 
The role of food sources

Changes in food resources modulated foraging activities of $P$. advenus and $M$. antarcticum (chapter 3 and 4). For example, colonies of the two ant species fed on a high carbohydrate and low protein diet tended to decrease foraging activities. The increased foraging activity observed when $M$. antarcticum were fed with a high-protein/low-carbohydrate food source my result from food preferences (apparently recruiting higher number of workers for protein-based resource; personal observation). However, the modulation of foraging activities by food source availability appears to be an important factor determining the ecological success of $P$. advenus in these communities. The concept of "tempo" (Oster and Wilson 1978) defines the probability of and how fast individuals find and exploit suitable food sources. In beech forests of New Zealand, P. advenus seems to be adapted to a honeydew-rich environment and may reduce tempo in response to the facility for utilizing an energy-rich food source. When deprived of an energetic food source, the foraging behaviour (or "tempo") increases, and P. advenus simultaneously increases the probability of finding resources and displacing competitors. It is also possible that seasonal fluctuations in honeydew availability regulate foraging behaviour of $P$. advenus and directly reduce the probability of $M$. antarcticum to establish new colonies in forest habitats.

\section{Habitat preference}

Connell (1980) proposes that habitat shifts may occur via two major pathways: i) species may have evolved separately and are thus adapted to different environments; ii) species coevolved under pressure of competition. The co-occurrence patterns I observed in Kaitoke and St. Arnaud may derive from habitat affinities. Prior to human arrival, New Zealand was mostly covered with forest $(\sim 90 \%)$ (Leathwick 2001$)$. Ant species such as P. advenus would probably occupy the majority of the niches available and the 
distribution of $M$. antarcticum may have likely been restricted to forest glades. The expansion of $M$. antarcticum throughout New Zealand could thus be primarily associated with deforestation processes.

I demonstrated in this thesis that both $P$. advenus and $M$. antarcticum do occur out of their usual habitat. Apart from my study sites, I occasionally observed $P$. advenus in grasslands and $M$. antarcticum in the forest while collecting colonies for laboratory experiments. It is important to highlight that the size of such colonies was always small ( $\sim 200-300$ workers $)$. Don (2007) also observed $P$. advenus nesting in open areas and Taylor (1959) found $M$. antarcticum occurring in sympatry with $P$. advenus in grasslands. Furthermore, M. antarcticum was previously seen in forest habitats and appears to tolerate a variety of ecological situations (Brown 1958; Don 2007).

It is possible that what appears to be habitat preference is, in fact, a case of interspecific competition. The co-occurrence patterns of these two ant communities may be an example of community-wide character displacement. Diamond (1975) hypothesized that interspecific competition is one of the major forces influencing species co-existence. Diamond's assembly rules suggest that species living in sympatry should be less similar than species that seldom co-occur. According to Connell (1980), such limits to similarity would be only possible in communities with low species diversity. This is the case of New Zealand's ant communities, which is composed by only 11 native ant species (Don 2007).

Among the species I observed in my field sites, only $P$. advenus and $M$. antarcticum share similarities in their food habits - both are generalist foragers (H. brounii feeds in small arthropods in the soil cover; H. striata apparently feeds on root aphids; Pachycondyla is a predator) (Don 2007). The cooccurrence patterns I observed in my field sites may derive from similarities and dissimilarities in niche breathe. The sympatric patterns observed between M. antarcticum and Pachycondyla sp. may be facilitated by their differences in 
food preferences, as well as the co-occurrence among P. advenus, H. striata and H. brounii. Conversely, the negative co-occurrence patterns between $P$. adsenus and $M$. antarcticum may result from similar niche requirements. Therefore, habitat affinities I observed in Kaitoke and St. Arnaud may reflect coevolutionary processes in the community assembly and may thus reflect "the ghost of competition past” (Connell 1980).

\subsection{Differences in co-occurrence patterns between sites}

Differences in Nothofagus spp. Forest cover between sites may be an important factor determining ant community assembly. New Zealand's forest composition (which includes several broad-leaved tree species, conifers and Nothofagus spp.) has been influenced by local physicochemical characteristics, including solar radiation and moisture availability (Leathwick 2001; Leathwick and Whitehead 2001). However, there is strong evidence that temperature is the most important factor driving forest composition throughout New Zealand (Leathwick 2001; Wardle 1963). The different degrees of co-occurrence I observed in ant communities of Kaitoke and St. Arnaud may also result from differences in forest composition and temperature.

St. Arnaud appeared to have a higher availability of honeydew than Kaitoke. Differences in food source availability may enhance competition between $P$. advenus and other ants. For example, a "high tempo" activity in $P$. advenus workers resulting from limited honeydew availability may diminish the likelihood of $M$. antarcticum to establish new colonies in forest areas of Kaitoke. On the other hand, a "low tempo" could increase the probability of other species to occur in forest habitats in St. Arnaud. 


\subsection{Anthropogenic impacts and biological invasions}

Natural communities are frequently exposed to anthropogenic stresses (Desneux et al. 2007) and are at risk of invasions (Leibold et al. 2004). In chapter 3, I subjected the invasive Argentine ant L. humile to interspecific interaction with five native species (P. advenus, H. striata, H. brounï, $M$. antarcticum and Pachycondyla sp.). Only M. antarcticum and H. striata had severe effects on the survival probability of the Argentine ant.

The distribution of the invasive Argentine ant throughout the world is frequently associated with anthropogenic activities and, to a smaller extent, with their biotic interaction with resident species (Roura-Pascual et al. 2011). In New Zealand, for example, the invasive Argentine ant is generally found in urban and agricultural settings (Cooling et al. 2012; Sagata and Lester 2009; Ward et al. 2010) - there are no reports of Argentine ants occurring in forest habitats. Habitat modification and the microclimatic conditions may favour the establishment and persistence of this invader in New Zealand (Cooling et al. 2012; Roura-Pascual et al. 2011). The biotic resistance possibly imposed by M. antarcticum and H. striata could reduce the survival probability and limit the spread of Argentine ants throughout New Zealand.

There is evidence that the modification of the physicochemical environment affects animal behaviour (Desneux et al. 2007). I found that sublethal exposure to a neurotoxic pesticide (neonicotinoid) modulated the aggressive behaviour of both the native $M$. antarcticum and the invasive Argentine ant. Pesticide exposure reduced aggressive behaviour in the native M. antarcticum and increased aggression of the invasive Argentine ant. Furthermore, changes in behaviour modified the survival probability of the invasive Argentine ant after interspecific interactions. The modification of aggression by pesticide exposure could have detrimental effects on natural communities and potentially act as a human-mediated driver of invasion. Furthermore, changes in interspecific behaviours may modulate the ability of 
species to compete for resources and thus influence their overall cooccurrence patterns.

\subsection{Contributions of this study and future directions}

This thesis contributed to current understanding of the role of behaviour in community assembly. I demonstrated that interspecific aggression strongly influences the species co-occurrence in New Zealand's native ant communities. Several biotic and abiotic stressors appear to amplify or attenuate the expression of behavioural traits. The effects of stressors on behaviour may be context dependent and even vary within populations. Few studies have directly addressed the effects of environmental stressors on behaviour and its consequences on community assembly. A valuable extension of this work would target this context dependence, and how individuals from different populations behave and interact with each other in distinct communities and environment contexts. The outcomes of such study would contribute to a deeper understanding of the evolutionary basis and expression of behaviour, as well as establish a link between physiology and behaviour.

A recent study highlighted the importance of venoms on ant community assembly (LeBrun et al. 2014). Another important extension of my thesis could focus on the role of the physicochemical environment on the production of venom by $P$. advenus and $M$. antarcticum. For example, the formic acid produced by $P$. advenus is carbon-based, and the venom produced by $M$. antarcticum is nitrogen-based (Andersen et al. 1991). It is possible that differences in the availability of suitable food sources in different habitats compromise the effectiveness of these venoms and the likelihood of $M$. antarcticum and $P$. advenus to compete with each other. 
Aggression appears to have evolved because of threats to the fitness of recipient individuals (Lima and Dill 1990). The high degree of endemism and the low diversity of New Zealand's ant community provide an ideal environment for future studies exploring the evolution of interspecific aggression and its consequences on community assembly. The influence of competitive behaviours on community structure is relatively difficult to ascertain. The appropriate way to test the effects of aggression on diversity and co-occurrence patterns would be to remove the behaviours. Such an experiment removing evolved and innate behaviours would be difficult. The closest approximation of this experiment is with invasive species. The recent arrival of Argentine ants and other ant species into New Zealand provides an unique opportunity to undertake such studies and investigate the role of learning and how interspecific behaviours evolve. 
Appendices 


\section{Appendix A - The foraging patterns of Prolasius advenus and Monomorium antarcticum and additional information regarding statistical models}


Table A1. Significance of each term of the full factorial general linear mixed models evaluating the interspecific aggression index displayed by $P$. advenus and $M$. antarcticum during interspecific interactions. Fixed factors are colony size (small; large), temperature $\left(14 \pm 1^{\circ} \mathrm{C} ; 20 \pm 1^{\circ} \mathrm{C}\right.$ ) and diet (HCLP: high carbohydrate - low protein; LCHP: low carbohydrate - high protein). The abundance of $P$. advenus and $M$. antarcticum workers in the foraging area during interspecific interactions were set as covariates. For each treatment, $\mathrm{n}=4$ colonies.

\begin{tabular}{llccc}
\hline \multicolumn{1}{c}{ species } & \multicolumn{1}{c}{ predictor } & $\chi^{2}$ & d.f. & \multicolumn{1}{c}{$P$} \\
\hline P. advenus & colony size & 1.868 & 1 & 0.172 \\
& temperature & 12.615 & 1 & $<\mathbf{0 . 0 0 1}$ \\
& diet & 0.003 & 1 & 0.954 \\
& P. advenus abundance & 0.105 & 1 & 0.746 \\
& M. antarcticum abundance & 3.619 & 1 & 0.057 \\
& colony size $\times$ temperature & 3.295 & 1 & 0.069 \\
& colony size $\times$ diet & 0.005 & 1 & 0.946 \\
& temperature $\times$ diet & 0.018 & 1 & 0.894 \\
& colony size $\times$ temperature $\times$ diet & 0.009 & 1 & 0.925 \\
\hline M. antarcticum & colony size & 4.058 & 1 & $\mathbf{0 . 0 4 4}$ \\
& temperature & 0.040 & 1 & 0.843 \\
& diet & 0.460 & 1 & 0.498 \\
& M. antarcticum abundance & 0.451 & 1 & 0.502 \\
& P. advenus abundance & 2.376 & 1 & 0.123 \\
& colony size $\times$ temperature & 0.040 & 1 & 0.841 \\
& colony size $\times$ diet & 0.338 & 1 & 0.561 \\
& temperature $\times$ diet & 2.921 & 1 & 0.087 \\
colony size $\times$ temperature $\times$ diet & 2.073 & 1 & 0.150 \\
\hline
\end{tabular}

Significant $P$-values are highlighted in bold 
Table A2. Significance of each term of the full factorial generalized estimating equation models evaluating the "food-searching" and the "food-collecting" activity displayed by large $P$. advenus and $M$. antarcticum colonies. Fixed factors are group (confronted colonies; control colonies), temperature $\left(14 \pm 1{ }^{\circ} \mathrm{C} ; 20 \pm 1{ }^{\circ} \mathrm{C}\right.$ ) and diet (HCLP: high carbohydrate - low protein; LCHP: low carbohydrate - high protein). For each treatment, $\mathrm{n}=4$ colonies.

\begin{tabular}{|c|c|c|c|c|c|}
\hline \multicolumn{2}{|c|}{ species } & \multirow[t]{2}{*}{ predictor } & \multirow{2}{*}{$\frac{\chi^{2}}{4.370}$} & \multirow{2}{*}{$\frac{\text { d.f. }}{1}$} & \multirow{2}{*}{$\frac{P}{0.037}$} \\
\hline large & food & & & & \\
\hline \multirow{13}{*}{$\begin{array}{l}\text { P. advenus } \\
\text { colonies }\end{array}$} & \multirow[t]{6}{*}{-searching } & temperature & 6.160 & 1 & 0.013 \\
\hline & & diet & 7.190 & 1 & 0.007 \\
\hline & & group $\times$ temperature & 0.080 & 1 & 0.774 \\
\hline & & group $\times$ diet & 2.930 & 1 & 0.087 \\
\hline & & temperature $\times$ diet & 3.010 & 1 & 0.053 \\
\hline & & group $\times$ temperature $\times$ diet & 0.440 & 1 & 0.508 \\
\hline & \multirow{7}{*}{$\begin{array}{l}\text { food } \\
\text {-collecting }\end{array}$} & group & 2.100 & 1 & 0.148 \\
\hline & & temperature & 0.290 & 1 & 0.592 \\
\hline & & diet & 11.950 & 1 & $<0.001$ \\
\hline & & group $\times$ temperature & 0.150 & 1 & 0.700 \\
\hline & & group $\times$ diet & 0.680 & 1 & 0.410 \\
\hline & & temperature $\times$ diet & 2.990 & 1 & 0.084 \\
\hline & & group $\times$ temperature $\times$ diet & 0.020 & 1 & 0.889 \\
\hline \multirow{14}{*}{$\begin{array}{l}\text { large } \\
\text { M. antarcticum } \\
\text { colonies }\end{array}$} & \multirow{7}{*}{$\begin{array}{l}\text { food } \\
\text {-searching }\end{array}$} & group & 2.480 & 1 & 0.116 \\
\hline & & temperature & 6.430 & 1 & 0.011 \\
\hline & & diet & 0.610 & 1 & 0.433 \\
\hline & & group $\times$ temperature & 30.760 & 1 & $<0.001$ \\
\hline & & group $\times$ diet & 3.240 & 1 & 0.072 \\
\hline & & temperature $\times$ diet & 0.030 & 1 & 0.872 \\
\hline & & group $\times$ temperature $\times$ diet & 0.010 & 1 & 0.906 \\
\hline & \multirow{7}{*}{$\begin{array}{l}\text { food } \\
\text {-collecting }\end{array}$} & group & 3.810 & 1 & 0.051 \\
\hline & & temperature & 1.870 & 1 & 0.172 \\
\hline & & diet & 0.810 & 1 & 0.369 \\
\hline & & group $\times$ temperature & 0.370 & 1 & 0.545 \\
\hline & & group $\times$ diet & 3.980 & 1 & 0.046 \\
\hline & & temperature $\times$ diet & 0.020 & 1 & 0.875 \\
\hline & & group $\times$ temperature $\times$ diet & 0.660 & 1 & 0.417 \\
\hline
\end{tabular}

Significant $P$-values are highlighted in bold 
Table A3. Significance of each term of the full factorial generalized estimating equation models evaluating the "food-searching" and the "food-collecting" activity displayed by small $P$. adsenus and $M$. antarcticum control colonies. Fixed factors are temperature $\left(14 \pm 1^{\circ} \mathrm{C} ; 20 \pm 1^{\circ} \mathrm{C}\right)$ and diet (HCLP: high carbohydrate - low protein; LCHP: low carbohydrate - high protein). For each treatment, $n=4$ colonies.

\begin{tabular}{lllccc}
\hline \multicolumn{2}{c}{ species } & \multicolumn{1}{c}{ predictor } & \multicolumn{1}{c}{$\chi^{2}$} & d.f. & $P$ \\
\hline small & food & temperature & 27.490 & 1 & $<\mathbf{0 . 0 0 1}$ \\
$\begin{array}{l}\text { P. advenus } \\
\text { control colonies }\end{array}$ & -searching & diet & 18.530 & 1 & $<\mathbf{0 . 0 0 1}$ \\
& & temperature $\times$ diet & 8.970 & 1 & $\mathbf{0 . 0 0 3}$ \\
\cline { 2 - 6 } & food & temperature & 67.100 & 1 & $<\mathbf{0 . 0 0 1}$ \\
& -collecting & diet & 7.600 & 1 & $\mathbf{0 . 0 0 6}$ \\
& & temperature $\times$ diet & 4.100 & 1 & $\mathbf{0 . 0 4 3}$ \\
\hline small & food & temperature & 16.430 & 1 & $<\mathbf{0 . 0 0 1}$ \\
control colonies & -searching & diet & 0.750 & 1 & 0.386 \\
& & temperature $\times$ diet & 3.320 & 1 & 0.068 \\
\cline { 2 - 6 } & food & temperature & 6.760 & 1 & $\mathbf{0 . 0 0 9}$ \\
& -collecting & diet & 0.070 & 1 & 0.792 \\
& & temperature $\times$ diet & 1.030 & 1 & 0.309 \\
\hline
\end{tabular}

Significant $P$-values are highlighted in bold 
Table A4. Significance of each term of the full factorial general linear model evaluating the proportion of $P$. advenus and $M$. antarcticum colonies alive after 65 days of trials. Fixed factors are treatment (small and large colonies subjected to interspecific interactions and their controls), temperature $\left(14 \pm 1^{\circ} \mathrm{C} ; 20 \pm 1^{\circ} \mathrm{C}\right)$ and diet (HCLP: high carbohydrate - low protein; LCHP: low carbohydrate - high protein). For each treatment, $\mathrm{n}=4$ colonies.

\begin{tabular}{clccc}
\hline \multicolumn{1}{c}{ species } & predictor & $\chi^{2}$ & d.f. & $P$ \\
\hline P. advenus & treatment & 1491.380 & 3 & $<\mathbf{0 . 0 0 1}$ \\
& temperature & 0.650 & 1 & 0.419 \\
& diet & 3.790 & 1 & 0.052 \\
& treatment $\times$ temperature & 2.070 & 3 & 0.558 \\
& treatment $\times$ diet & 3.280 & 3 & 0.350 \\
& temperature $\times$ diet & 0.100 & 1 & 0.749 \\
& treatment $\times$ temperature $\times$ diet & 2.910 & 3 & 0.405 \\
\hline M. antarcticum & treatment & 1621.770 & 3 & $<\mathbf{0 . 0 0 1}$ \\
& temperature & 3.450 & 1 & 0.063 \\
& diet & 3.680 & 1 & 0.410 \\
& treatment $\times$ temperature & 3.980 & 3 & 0.364 \\
& treatment $\times$ diet & 0.790 & 1 & 0.375 \\
& temperature $\times$ diet & 4.580 & 3 & 0.205 \\
\hline
\end{tabular}

Significant $P$-values are highlighted in bold. 


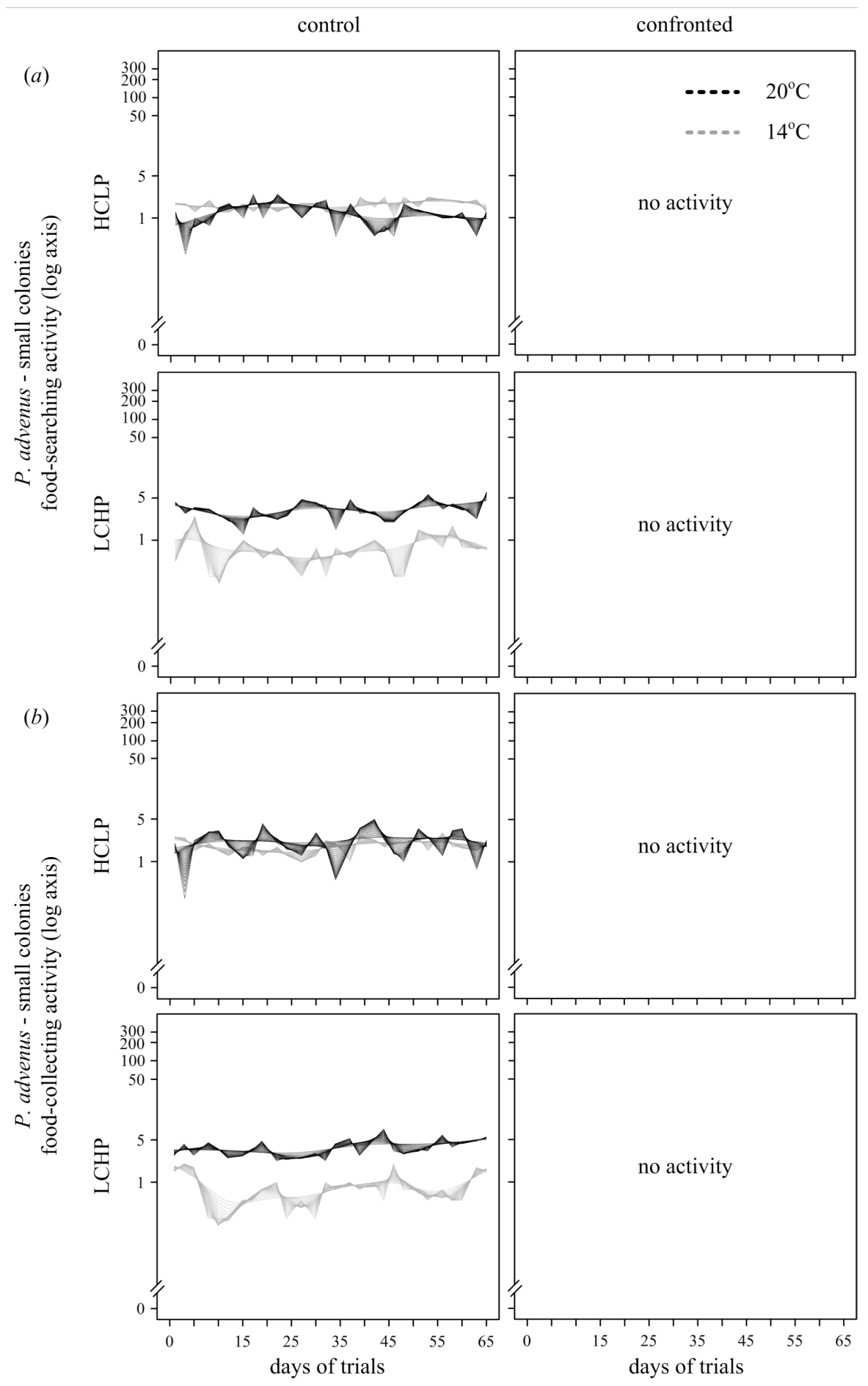

Figure A1. (a) Food-searching and (b) food-collecting activity displayed by small $P$. advenus colonies over 65 days, under different diet and temperature treatments. Left panels are control colonies. Right panels are colonies confronted with large $M$. antarcticum colonies. Control colonies were not subjected to interspecific interaction with large $M$. antarcticum colonies. Diets were high carbohydrate-low protein (HCLP) and low carbohydrate-high protein (LCHP). Lines are the overlapped smoothed splines ranging from d.f. $=2<x<28$, which provide an appropriate curve fitting for the variation observed in the food-searching and -collecting activity of both species. In each treatment, $\mathrm{n}=4$ colonies. 

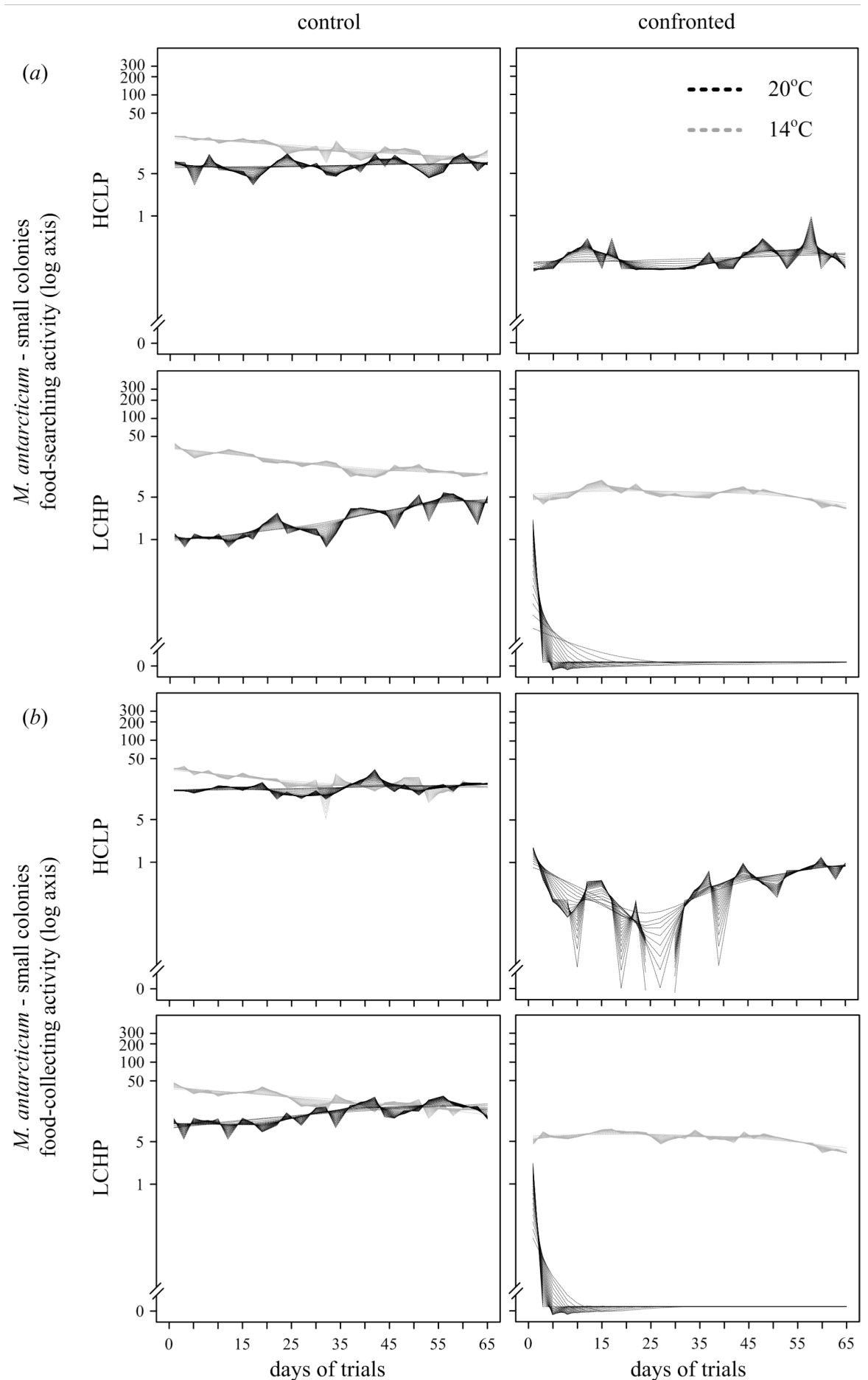

Figure A2. (a) Food-searching and (b) food-collecting activity displayed by small $M$. antarcticum colonies over 65 days, under different diet and temperature treatments. Left panels are control colonies. Right panels are colonies confronted with large $P$. advenus colonies. Control colonies were not subjected to interspecific interaction with large $P$. advenus colonies. Diets were high carbohydrate-low protein (HCLP) and low carbohydrate-high protein (LCHP). Lines are the overlapped smoothed splines ranging from d.f. $=2<x<28$, which provide an appropriate curve fitting for the variation observed in the food-searching and -collecting activity of both species. In each treatment, $\mathrm{n}=4$ colonies. 


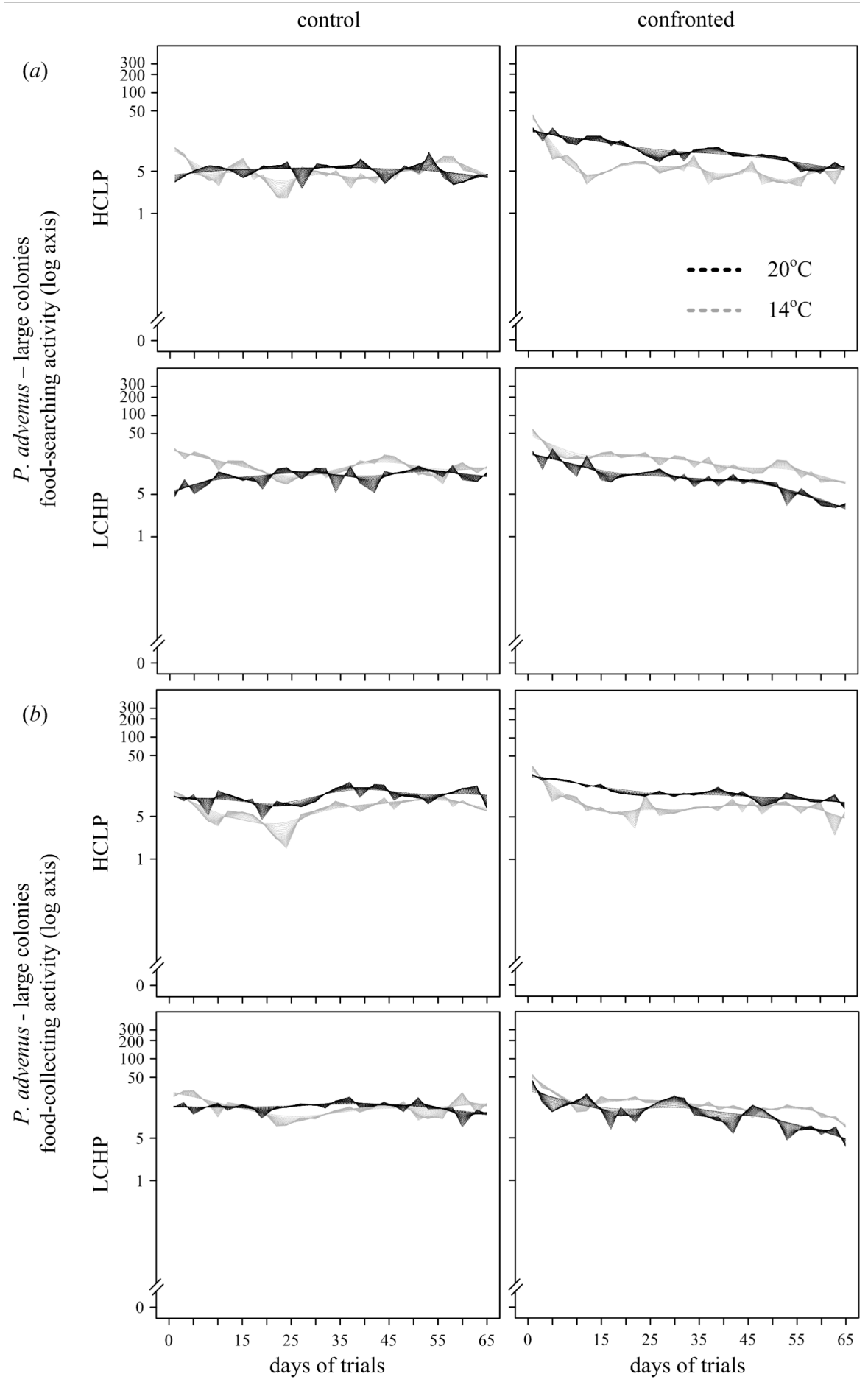

Figure A3. (a) Food-searching and (b) food-collecting activity displayed by large $P$. advenus colonies over 65 days, under different diet and temperature treatments. Left panels are control colonies. Right panels are colonies confronted with small $M$. antarcticum colonies. Control colonies were not subjected to interspecific interaction with small $M$. antarcticum colonies. Diets were high carbohydrate-low protein (HCLP) and low carbohydrate-high protein (LCHP). Lines are the overlapped smoothed splines ranging from d.f. $=2<x<28$, which provide an appropriate curve fitting for the variation observed in the food-searching and -collecting activity of both species. In each treatment, $\mathrm{n}=4$ colonies. 


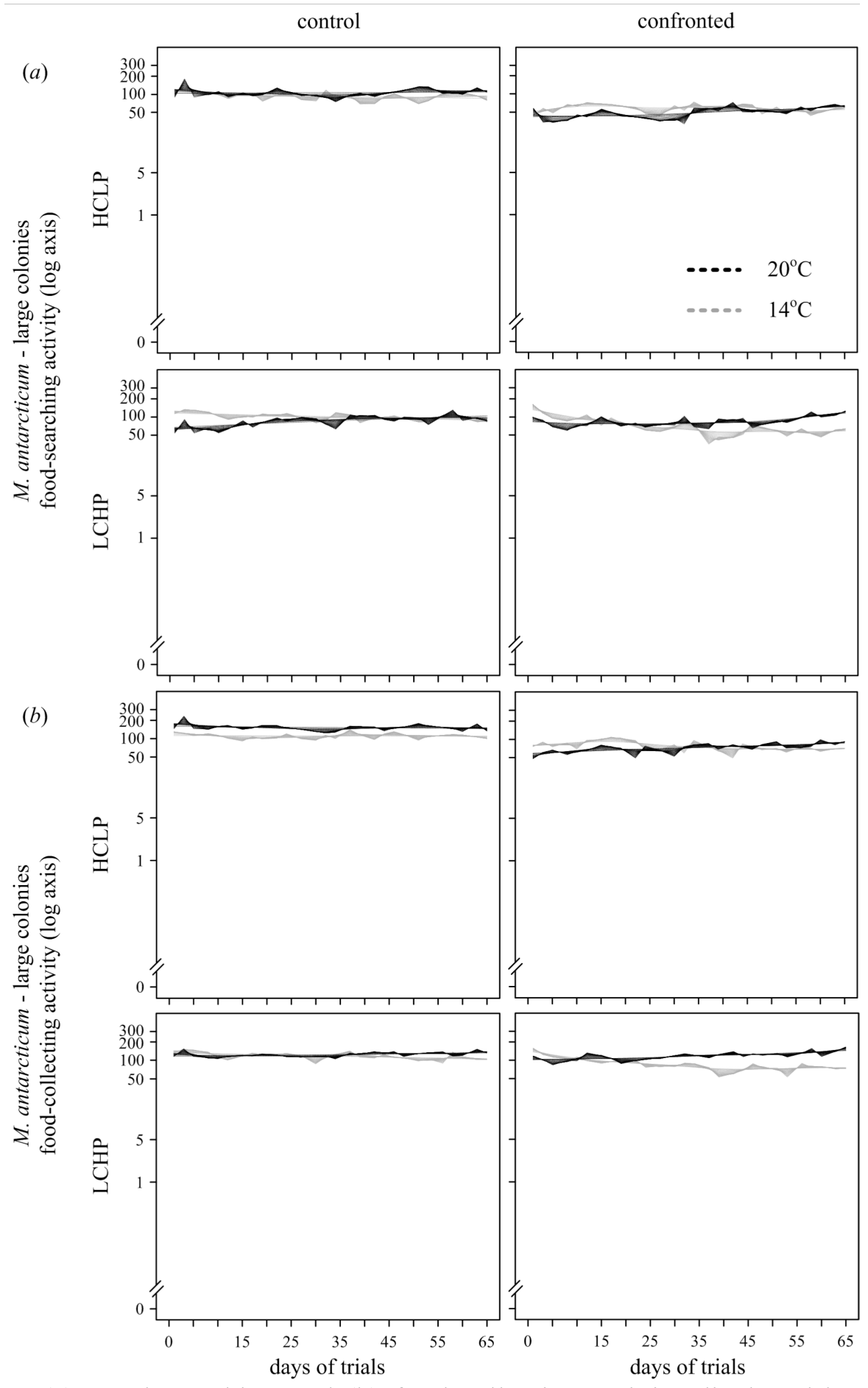

Figure A4. (a) Food-searching and (b) food-collecting activity displayed by large $M$. antarcticum colonies over 65 days, under different diet and temperature treatments. Left panels are control colonies. Right panels are colonies confronted with small $P$. advenus colonies. Control colonies were not subjected to interspecific interaction with small $P$. advenus colonies. Diets were high carbohydrate-low protein (HCLP) and low carbohydrate-high protein (LCHP). Lines are the overlapped smoothed splines ranging from d.f. $=2<x<28$, which provide an appropriate curve fitting for the variation observed in the food-searching and -collecting activity of both species. In each treatment, $\mathrm{n}=4$ colonies. 


\section{References}

Abrams P. (1983) The theory of limiting similarity. Annu. Rev. Ecol. Syst. 14: $359-376$.

Abrams P.A. (1996) Limits to the similarity of competitors under hierarchical lottery competition. Am. Nat. 148: 211-219.

Adamo S.A. \& Hoy R.R. (1995) Agonistic behavior in male and female field crickets, Gryllus-Bimaculatus, and how behavioral context influences its expression. Anim. Behav. 49: 1491-1501.

Adler F.R., LeBrun E.G. \& Feener D.H. (2007) Mantaining diversity in an ant community: modeling, extending, and testing the dominancediscovery trade-off. Am. Nat. 169: 323-333.

Aguilera M.A. \& Navarrete S.A. (2012) Interspecific competition for shelters in territorial and gregarious intertidal grazers: consequences for individual behaviour. Plos One 7 .

Albrecht M. \& Gotelli N.J. (2001) Spatial and temporal niche partitioning in grassland ants. Oecologia 126: 134-141.

Alford R.A. \& Wilbur H.M. (1985) Priority effects in experimental pond communities: competition between Bufo and Rana. Ecology 66: 1097-1105.

Amarasekare, P. \& Sifuentes R. (2012) Elucidating the temperature response of survivorship in insects. Funct. Ecol. 26: 959-968.

Andersen A.N. (1992) Regulation of momentary diversity by dominant species in exceptionally rich ant communities of the Australian seasonal tropics. Am. Nat. 140: 401-420. 
Andersen A.N. (1995) A classification of Australian ant communities, based on functional-groups which parallel plant life-forms in relation to stress and disturbance. J. Biogeogr. 22: 15-29.

Andersen A.N. (1997) Using ants as bioindicators: multiscale issues in ant community ecology. Conserv. Ecol. 1.

Andersen, A.N. (2008) Not enough niches: non-equilibrial processes promoting species coexistence in diverse ant communities. Austral Ecol. 33: 211-220.

Andersen A.N., Blum M.S. \& Jones T.H. (1991) Venom alkaloids in Monomorium rothsteini Forel repel other ants: is this the secret to success by Monomorium in Australian ant communities? Oecologia 88: 157-160.

Badano E.I., Regidor H.A., Núñez H.A., Acosta R. \& Gianoli E. (2005) Species richness and structure of ant communities in a dynamic archipelago: effects of island area and age. J. Biogeogr. 32: 221-227.

Barton K.E., Sanders N.J. \& Gordon D.M. (2002) The effects of proximity and colony age on interspecific interference competition between the desert ants Pogonomyrmex barbatus and Aphaenogaster cockerelli. Am. Midl. Nat. 148: 376-382.

Batchelor T.P. \& Briffa M. (2011) Fight tactics in wood ants: individuals in smaller groups fight harder but die faster. Proc. R. Soc. B-Biol. Sci. 278: 3243-3250.

Bates D., Maechler M. \& Bolker B. (2012) lme4: Linear mixed-effects models using S4 classes. $\mathrm{R}$ package version 0.999999-0. http:/CRAN.Rproject.org/package $=\operatorname{lme} 4$.

Berghoff S.M., Maschwitz U. \& Linsenmair K.E. (2003). Influence of the hypogaeic army ant Dorylus (Dichthadia) laevigatus on tropical arthropod communities. Oecologia 135: 149-157. 
Bestelmeyer B.T. (2000) The trade-off between thermal tolerance and behavioural dominance in a subtropical South American ant community. J. Anim. Ecol. 69: 998-1009.

Bestelmeyer, B.T., Agosti D., Alonso L.E., Brandão R.F., Brown Jr. W.L., Delabie J.H.C., \& Silverstre R. (2000) Field techniques for the study of ground-dwelling ants: an overview, description, and evaluation. p.122144 in Agosti D., Majer J., Alonso L.E., \& Schultz T.R., editors. Ants: standard methods for measuring and monitoring biodiversity. Smithsonian Intitution, United States of America.

Blacquiere T., Smagghe G., van Gestel C.A.M. \& Mommaerts V. (2012) Neonicotinoids in bees: a review on concentrations, side-effects and risk assessment. Ecotoxicology 21: 973-992.

Blüthgen N., Stork N.E. \& Fiedler K. (2004) Bottom-up control and cooccurrence in complex communities: honeydew and nectar determine a rainforest ant mosaic. Oikos 106: 344-358.

Brightwell R.J., Bambara S.B. \& Silverman J. (2010) Combined effect of hemipteran control and liquid bait on Argentine ant populations. $J$. Econ. Entomol. 103: 1790-1796.

Brook B.W., Sodhi N.S. \& Bradshaw C.J.A. (2008) Synergies among extinction drivers under global change. Trends Ecol. Evol. 23: 453-460.

Brown L.A., Thara M., Buckingham S.D., Matsuda K. \& Sattelle D.B. (2006) Neonicotinoid insecticides display partial and super agonist actions on native insect nicotinic acetylcholine receptors. J. Neurochem. 99: 608-615.

Brown Jr. W.L. (1958) A review of the ants of New Zealand. Acta Hymenopterologica 1: 1-50. 
Brown Jr. W.L. (2000) Diversity of ants. In: Ants: standard methods for measuring and monitoring biodiversity (eds Agosti D., Majer J., Alonso L.E. \& Schultz T.R.) pp. 45-79. Smithsonian Intitution, United States of America.

Buczkowski G., Kumar R., Suib S.L. \& Silverman J. (2005) Diet-related modification of cuticular hydrocarbon profiles of the Argentine ant, Linepithema humile, diminishes intercolony aggression. J. Chem. Ecol. 31: 829-843.

Burne A.R. (2012) The sub-lethal and density-dependent effects of an invasive wasp on an endemic ant. PhD-thesis Victoria University of Wellington, Wellington, New Zealand

Carlin N.F. \& Johnston A.B. (1984) Learned enemy specification in the defense recruitment system of an ant. Naturwissenschaften 71: 156-157.

Casewell N.R., Wuster W., Vonk F.J., Harrison R.A. \& Fry B.G. (2013) Complex cocktails: the evolutionary novelty of venoms. Trends Ecol. Evol. 28: 219-229.

Cerdá X., Arnan X. \& Retana J. (2013) Is competition a significant hallmark of ant (Hymenoptera: Formicidae) ecology? Myrmecol. Nexss 18: 131-147.

Cerdá X., Retana J., \& Cros S. (1997) Thermal disruption of transitive hierarchies in Mediterranean ant communities. J. Anim. Ecol. 66: 363-374.

Chase J.M. \& Myers J.A. (2011) Disentangling the importance of ecological niches from stochastic processes across scales. Philos. T. R. Soc. B 366: 2351-2363.

Chesson P.L. \& Case T.J. (1986) Overview: nonequilibrium community theories: chance, variability, history, and coexistence pp. 229-239 in: Diamond J.M. \& CaseT.J. (eds) Community ecology. Haper \& Row, New York.

Cole B.J. (1983a) Assembly of mangrove ant communities - colonization abilities. J. Anim. Ecol. 52: 349-355.

Cole B.J. (1983b) Assembly of mangrove ant communities - patterns of geographical distribution. J. Anim. Ecol. 52: 339-347. 
Colman N.J., Gordon C.E. Crowther M.S. \& Letnic M. (2014) Lethal control of an apex predator has unintended cascading effects on forest mammal assemblages. P. R. Soc. B 281: 20133094.

Connell J.H. (1980) Diversity and the coevolution of competitors, or the ghost of competition past. Oikos 35: 131-138.

Connor E.F. \& Simberloff D. (1979) The assembly of species communities: chance or competition? Ecology, 60: 1132-1140.

Cooling M., Hartley S., Sim D.A. \& Lester P.J. (2012) The widespread collapse of an invasive species: Argentine ants (Linepithema humile) in New Zealand. Biol. Lett. 8: 430-433.

Czechowski W. \& Marko B. (2005) Competition between Formica cinerea Mayr (Hymenoptera: Formicidae) and co-occurring ant species, with special reference to Formica rufa L.: direct and indirect interferences. Pol. J. Ecol. 53: 467-487.

Dall S.R.X., Giraldeau L.A., Olsson O., McNamara J.M. \& Stephens D.W. (2005) Information and its use by animals in evolutionary ecology. Trends Ecol. Evol. 20: 187-193.

Dahbi A., Retana J., Lenoir A. \& Cerda X. (2008). Nest-moving by the polydomous ant Cataglyphis iberica. J. Ethol. 26: 119-126.

Dante S. K., Schamp B. S. \& Aarssen L. W. (2013) Evidence of deterministic assembly according to flowering time in an old-field plant community. Funct. Ecol. 27: 555-64.

Davidson, D.W. (1997) The role of resource imbalances in the evolutionary ecology of tropical arboreal ants. Biol. J. Linn. Soc. 61: 153-181.

Decaëns T., Margerie P., Aubert M., Hedde M. \& Bureau F. (2008) Assembly rules within earthworm communities in North-Western France - a regional analysis. Appl. Soil Ecol. 39: 321-335. 
Deitloff J., Adams D.C., Olechnowski B.F.M. \& Jaeger R.G. (2008) Interspecific aggression in Ohio Plethodon: implications for competition. Herpetologica 64: 180188.

Delong J.P. \& Vasseur D.A. (2013) Linked exploitation and interference competition drives the variable behavior of a classic predator-prey system. Oikos 122: 1393-400.

Desneux N., Decourtye A. \& Delpuech J.M. (2007) The sublethal effects of pesticides on beneficial arthropods. Annu. Rev. Entomol. 52: 81-106.

Dhami, M.K., Gardner-Gee R., Van Houtte J., Villas-Boas S.G. \& Beggs J.R. (2011) Species-specific chemical signatures in scale insect honeydew. J. Chem. Ecol. 37: 1231-1241.

Diamond J.M. (1975) Assembly of Species. In: Ecology and evolution of communities (eds Cody M.L. \& Diamond J.M.) pp. 342-444. Harvard University Press, Cambridge, MA.

Diamond J.M. (1978) Niche shifts and the rediscovery of interspecific competition. Am. Sci. 66: 322-331.

Don A.W. \& Jones T.H. (1993) The stereochemistry of 3-butyl-5-(5-hexenyl)pyrrolizidine from populations of Monomorium antarcticum (Smith) (Hymenoptera: Formicidae) and its possible role as a unique taxonomic character. N. Z. Entomol. 16: 45-48.

Don W. (2007) Ants of New Zealand. Otago University Press, Dunedin, New Zealand.

Donald H. \& Fenner Jr., D.H. (2000) Is the assembly of ant communities mediated by parasitoids? Oikos 90: 79-88.

Donoso D.A. (2013) Assembly mechanisms shaping tropical litter ant communities. Ecography 37: 001-10 
Droual R. (1983). The organization of nest evacuation in Pheidole desertorum Wheeler and Pheidole hyatti Emery (Hymenoptera, Formicidae). Behas. Ecol. Sociobiol. 12: 203-208.

Dussutour A. \& Simpson S.J. (2012) Ant workers die young and colonies collapse when fed a high-protein diet. P. R. Soc. B 279: 2402-2408.

Duthie C. \& Lester P.J. (2013) Reduced densities of the invasive wasp, Vespula sulgaris (Hymenoptera: Vespidae), did not alter the invertebrate community composition of Nothofagus forests in New Zealand. Environ. Entomol. 42: 223-230.

Elton C. (1946) Competition and the structure of ecological communities. J. Anim. Ecol. 15: 54-68.

Englund G., Johansson F., Olofsson P., Salonsaari J. \& Öhman J. (2009) Predation leads to assembly rules in fragmented fish communities. Ecol. Lett. 12: 663-671.

Errard C., Le Guisquet A.M., Christides J.P., Mercier J.L., Lenoir A. \& Hefetz A. (2008) Early learning of volatile chemical cues leads to interspecific recognition between two ant species. Insect. Soc. 55: 115-122.

Feener D.H., Jr. (1986) Alarm-Recruitment Behavior in Pheidole-Militicida (Hymenoptera, Formicidae). Ecol. Entomol. 11: 67-74.

Feener D.H., Jr. (1987) Response of Pheidole morrisi to two species of enemy ants, and a general model of defensive behavior in Pheidole (Hymenoptera: Formicidae). J. Kans. Entomol. Soc. 60: 569-575.

Feener D.H., Jr. (2000) Is the assembly of ant communities mediated by parasitoids? Oikos 90: 79-88.

Fox B.J. \& Brown J.H. (1993) Assembly rules for functional groups in North American desert rodent communities. Oikos, 67: 358-370. 
Galvanho J.P., Carrera M.P., Moreira D.D.O., Erthal M., Silva C.P. \& Samuels R.I. (2013) Imidacloprid inhibits behavioral defences of the leafcutting ant Acromyrmex subterraneus subterraneus (Hymenoptera: Formicidae). J. Insect Behav. 26: 1-13.

Gaston, K.J. (2000) Global patterns in biodiversity. Nature 405:220-227.

Gaze P.D. \& Clout M.N. (1983) Honeydew and its importance to birds in beech forests of South Island, New Zealand. N. Z. J. Ecol. 6: 33-37.

Gill R.J., Ramos-Rodriguez O. \& Raine N.E. (2012) Combined pesticide exposure severely affects individual- and colony-level traits in bees. Nature 491: 105-108.

Gonzalvez F.G. \& Rodriguez-Girones M.A. (2013). Seeing is believing: information content and behavioural response to visual and chemical cues. P. R. Soc B, 280: 20130886.

Gordon D.M. (2013) The rewards of restraint in the collective regulation of foraging by harvester ant colonies. Nature 498: 91-93.

Gotelli N.J. \& Ellison A.M. (2002) Assembly rules for new England ant assemblages. Oikos 99: 591-599.

Gotelli, N.J. \& Entsminger G.L. (2004) EcoSim: null models software for ecology. Acquired Intelligence Inc. \& Kesey-Bear, Jericho, VT 05465.

Grangier J. \& Lester P.J. (2011) A novel interference behaviour: invasive wasps remove ants from resources and drop them from a height. Biol. Lett. 7: 664-667.

Grangier, J. \& Lester P.J. (2012) Behavioral plasticity mediates asymmetric competition between invasive wasps and native ants. Commun. Integr. Biol. 5: 127-129.

Gravel D., Guichard F. \& Hochberg M.E. (2011) Species coexistence in a variable world. Ecol. Lett. 14: 828-839. 
Grime J.P. (1977) Evidence for existence of three primary strategies in plants and Its relevance to ecological and evolutionary theory. Am. Nat. 111: 1169-1194.

Grime J.P. (1998) Benefits of plant diversity to ecosystems: immediate, filter and founder effects. J. Ecol. 86: 902-910.

Grover C.D., Kay A.D., Monson J.A., Marsh T.C. \& Holway D.A. (2007) Linking nutrition and behavioural dominance: carbohydrate scarcity limits aggression and activity in Argentine ants. P. R. Soc. B 274: 2951-2957.

Gurevitch, J., Morrow L.L., Wallace A. \& Walsh J.S. (1992) A meta-analysis of competition in field experiments. Am. Nat. 140: 539-572.

Harris M.R. \& Siefferman L. (2014) Interspecific competition influences fitness benefits of assortative mating for territorial aggression in Eastern bluebirds (Sialia sialis). Plos One $\mathbf{9}$.

Heuts B.A., Cornelissen P. \& Lambrechts D.Y.M. (2003) Different attack modes of formica species in interespecific one-on-one combats with other ants (Hymenoptera: Formicidae). Annales Zoologici 53: 205-216.

Højsgaard S., Halekoh U. \& Yan J. (2006) The R Package geepack for generalized estimating equations. J. Stat. Softw. 15: 1-11.

Hölldobler B. (1976) Tournaments and slavery in a desert ant (1976) Science 192: $912-914$.

Hölldobler B. (1979) Territoriality in ants. Proc. Am. Phil. Soc. 123: 211-218.

Hölldobler B. (1983) Territorial behavior in the green tree ant Oecophylla smaragdina). Biotropica 15: 241-250.

Hölldobler B. \& Carlin N.F. (1987) Anonymity and specificity in the chemical communication signals of social insects. J. Comp. Physiol. A 161: 567-581.

Hölldobler B. \& Lumsden C.J. (1980) Territorial strategies in ants. Science 210: 732-739. 
Hölldobler B. \& Wilson E.O. (1978) The multiple recruitment systems of the African weaver ant Oecophylla longinoda (Latreille) (Hymenoptera: Formicidae). Behav. Ecol. Sociobiol. 3: 19-60.

Hölldobler B. \& Wilson E.O. (1990) The ants. Harvard University Press, Cambridge, Massachusetts.

Hölldobler B. \& Wilson E.O. (1994) Journey to the ants: a story of scientific exploration. Belknap Press of Harvard University Press, Cambridge, Massachusetts.

Holway D.A., Lach L., Suarez A.V., Tsutsui N.D. \& Case T.J. (2002) The causes and consequences of ant invasions. Annu. Rev. Ecol. Syst. 33: 181-233.

Holway D.A. \& Suarez A.V. (1999) Animal behavior: an essential component of invasion biology. Trends Ecol. Eøol. 14: 328-330.

Hubbell S.P. (2001) The unified neutral theory of biodiversity and biogeography. Princeton University Press, Princeton, New Jersey.

Hutchinson G.E. (1959) Homage to Santa-Rosalia or why are there so many kinds of animals. Am. Nat. 93: 145-159.

Jervis M.A., Ellers J. \& Harvey J.A. (2008) Resource acquisition, allocation, and utilization in parasitoid reproductive strategies. Annu. Res. Entomol. 53: 361-385.

Johnson R.M., Ellis M.D., Mullin C.A. \& Frazier M. (2010) Pesticides and honey bee toxicity - USA. Apidologie 41: 312-331.

Jones T.H., Clark D.A., Edwards A.A., Davidson D.W., Spande T.F. \& Snelling R.R. (2004) The chemistry of exploding ants, Camponotus spp. (cylindricus complex). J. Chem. Ecol. 30: 1479-1492.

Kardol P., Souza L. \& Classen A.T. (2013) Resource availability mediates the importance of priority effects in plant community assembly and ecosystem function. Oikos 122: 84-94. 
Kaspari M. \& Vargo E.L. (1995) Colony size as a buffer against seasonality: Bergmann's rule in social insects. Am. Nat. 145: 610-632.

Kay A.D., Shik J.Z., Van Alst A., Miller K.A. \& Kaspari M. (2012) Diet composition does not affect ant colony tempo. Funct. Ecol. 26: 317-323.

Kay A.D., Zumbusch T., Heinen J.L., Marsh T.C. \& Holway D.A. (2010) Nutrition and interference competition have interactive effects on the behavior and performance of Argentine ants. Ecology 91: 57-64.

Kearney M., Shine R. \& Porter W.P. (2009) The potential for behavioral thermoregulation to buffer "cold-blooded" animals against climate warming. P. Natl. Acad. Sci. USA 106: 3835-3840.

Killen, S.S., Marras S., Metcalfe N.B., McKenzie D.J. \& Domenici P. (2013) Environmental stressors alter relationships between physiology and behaviour. Trends Ecol. Eøol. 28: 651-658.

Knaden M. \& Wehner R. (2003) Nest defense and conspecific enemy recognition in the desert ant Cataglyphis fortis. J. Insect Behav. 16: 717-730.

Kohler A., Raubenheimer D. \& Nicolson S. W. (2012) Regulation of nutrient intake in nectar-feeding birds: insights from the geometric framework. J. Comp. Physiol. B 182: 603-611.

Laforsch, C. \& Tollrian R. (2004) Inducible defenses in multipredator environments: cyclomorphosis in Daphnia cucullata. Ecology 85: 2302-2311.

Langkilde T. (2009) Invasive fire ants alter behavior and morphology of native lizards. Ecology 90: 208-217.

Laskowski K.L. \& Bell A.M. (2013) Competition avoidance drives individual differences in response to a changing food resource in sticklebacks. Ecol. Lett. 16: 746-753. 
Leathwick J.R. (2001) New Zealand's potential forest pattern as predicted from current species-environment relationships. N. Z. J. Bot. 39: 447-464.

Leathwick J.R. \& Whitehead D. (2001) Soil and atmospheric water deficits and the distribution of New Zealand's indigenous tree species. Funct. Ecol. 15: 233-242.

LeBrun E.G., Jones N.T. \& Gilbert L.E. (2014) Chemical warfare among invaders: a detoxification interaction facilitates an ant invasion. Science 343: 1014-1017.

Leibold M.A., Holyoak M., Mouquet N., Amarasekare P., Chase J.M., Hoopes M.F., Holt R.D., Shurin J.B., Law R., Tilman D., Loreau M. \& Gonzalez A. (2004) The metacommunity concept: a framework for multi-scale community ecology. Ecol. Lett. 7: 601-613.

Leonard J.G. \& Herbers J.M. (1986) Foraging tempo in two woodland ant species. Anim. Behav. 34: 1172-1181.

Lester P.J., Baring C.W., Longson C.G. \& Hartley S. (2003) Argentine and other ants (Hymenoptera: Formicidae) in New Zealand horticultural ecosystems: distribution, hemipteran hosts, and review. N. Z. Entomol. 26: 79-89.

Lester P.J., Abbott K.L., Sarty M. \& Burns K.C. (2009) Competitive assembly of South Pacific invasive ant communities. BMC Ecology, 9: 3

Lima S.L. \& Dill L.M. (1990) Behavioral decisions made under the risk of predation: a review and prospectus. Can. J. Zool. 68: 619-640.

Líznarová E. \& Pekár S. (2013) Dangerous prey is associated with a type 4 functional response in spiders. Anim. Behav. 85: 1183-1190.

Louette G. \& de Meester L. (2007) Predation and priority effects in experimental zooplankton communities. Oikos 116: 419-426. 
Mack R.N., Simberloff D., Lonsdale W.M., Evans H., Clout M. \& Bazzaz F.A. (2000) Biotic invasions: causes, epidemiology, global consequences, and control. Ecol. Appl. 10: 689-710.

Manson N.W.H., Bello F., Dolezal J. \& Leps J. (2011) Niche overlap reveals the effects of competition, disturbance and contrasting assembly processes in experimental grassland communities. J. Ecol. 99: 788-796

Martin S.J., Vitikainen E., Shemilt S., Drijfhout F.P. \& Sundstrom, L. (2013) Sources of variation in cuticular hydrocarbons in the ant Formica exsecta. J. Chem. Ecol. 39: 11-12.

McGrannachan C.M. \& Lester P.J. (2013) Temperature and starvation effects on food exploitation by Argentine ants and native ants in New Zealand. J. Appl. Entomol. 137: 550-559.

McPeek M.A. (1998) The consequences of changing the top predator in a food web: A comparative experimental approach. Ecol. Monogr. 68: 1-23.

Miller-Pierce M.R. \& Preisser E.L. (2012) Asymmetric priority effects influence the success of invasive forest insects. Ecol. Entomol. 37: 350-358.

Moller, H. \& Tilley J.A.V. (1989) Beech honeydew: seasonal variation and use by wasps, honey bees, and other insects. N. Z. J. Zool. 16: 289-302.

Morales, C.F., Hill M.G., \& Walker A.K. (1988) Life history of the sooty beech scale (Ultracoelostoma assimile) (Maskell), (Hemiptera: Margarodidae) in New Zealand Nothofagus forests. N. Z. Entomol. 11: 24-37.

Moritz C., Meynard C.N., Devictor V., Guizien K., Labrune C., Guarini J.M. \& Mouquet N. (2013) Disentangling the role of connectivity, environmental filtering, and spatial structure on metacommunity dynamics. Oikos 122: 1401-1410.

Murcia C. (1995) Edge effects in fragmented forests - implications for conservation. Trends Ecol. Evol. 10: 58-62. 
Oster G.F. \& Wilson E.O. (1978) Caste and ecology in the social insects. Princeton University Press, Princeton, NJ

Ozaki M., Wada-Katsumata A., Fujikawa K., Iwasaki M., Yokohari F., Satoji Y., Nisimura T. \& Yamaoka R. (2005) Ant nestmate and non-nestmate discrimination by a chemosensory sensillum. Science 309: 311-314.

Pacala S.W. \& Tilman D. (1994) Limiting similarity in mechanistic and spatial models of plant competition in heterogeneous environments. Am. Nat. 143: $222-257$.

Palmer M.J., Moffat C., Saranzewa N., Harvey J., Wright G.A. \& Connolly C.N. (2013) Cholinergic pesticides cause mushroom body neuronal inactivation in honeybees. Nat. commun. 4: 1634.

Pinheiro J., Bates D., DebRoy S., Sarkar D. \& Team R.D.C. (2013) nlme: linear and nonlinear mixed effects models.

Porter, S.D. (1988) Impact of temperature on colony growth and developmental rates of the ant, Solenopsis invicta. J. Insect Physiol. 34: 1127-1133.

Powell S. \& Dornhaus A. (2013). Soldier-based defences dynamically track resource availability and quality in ants. Anim. Behav. 85: 157-164.

Prestwich G.D. (1984) Defense-mechanisms of termites. Annu. Rev. Entomol. 29: 201-232.

Pulliam, H.R., Pyke G.H. \& Caraco T. (1982) The scanning behavior of juncos: a game-theoretical approach. J. Theor. Biol. 95: 89-103.

Puth L.M. \& Post D.M. (2005) Studying invasion: have we missed the boat? Eco.l Lett. 8: 715-721.

R Development Core Team (2013) R: A Language and Environment for Statistical Computing. R Foundation for Statistical Computing, Vienna, Austria. 
Rajakumar R., San Mauro D., Dijkstra M.B., Huang M.H., Wheeler D.E., Hiou-Tim F., Khila A., Cournoyea M., \& Abouheif E. (2012) Ancestral developmental potential facilitates parallel evolution in ants. Science 335: 79-82.

Retana J. \& Cerda X. (1995) Agonistic relationships among sympatric mediterranean ant species (Hymenoptera, Formicidae). J. Insect. Behav. 8: 365-380.

Rice E.S. \& Silverman J. (2013) Propagule pressure and climate contribute to the displacement of Linepithema humile by Pachycondyla chinensis. Plos One $\mathbf{8 .}$

Ridley A.R., Raihani N.J. \& Bell M.B.V. (2010) Experimental evidence that sentinel behaviour is affected by risk. Biol. Lett. 6: 445-448.

Riley J.R., Greggers U., Smith A.D., Reynolds D.R. \& Menzel R. (2005) The flight paths of honeybees recruited by the waggle dance. Nature 435: 205-207.

Robinson E.J.H., Richardson T.O., Sendova-Franks A.B., Feinerman O. \& Franks N.R. (2009) Radio tagging reveals the roles of corpulence, experience and social information in ant decision making. Behav. Ecol. Sociobiol. 63: 627-636.

Roulston T.H., Buczkowski G. \& Silverman J. (2003) Nestmate discrimination in ants: effect of bioassay on aggressive behavior. Insect. Soc. 50: 151-159.

Roura-Pascual N., Hui C., Ikeda T., Leday G., Richardson D. M., Carpintero S., Espadaler X., Gomez C., Guenard B., Hartley S., Krushelnycky P., Lester P.J., McGeoch M.A., Menke S.B., Pedersen J.S., Pitt J.P.W., Reyes J., Sanders N.J., Suarez A.V., Touyama Y., Ward D., Ward P.S. \& Worner S.P. (2011) Relative roles of climatic suitability and anthropogenic influence in determining the pattern of spread in a global invader. P. Natl. Acad. Sci. USA 108: 220-225.

Rust M.K., Reierson D.A. \& Klotz J.H. (2004) Delayed toxicity as a critical factor in the efficacy of aqueous baits for controlling Argentine ants (Hymenoptera : Formicidae). J. Econ. Entomol. 97: 1017-1024. 
Sagata K. \& Lester P.J. (2009) Behavioural plasticity associated with propagule size, resources, and the invasion success of the Argentine ant Linepithema humile. J. Appl. Ecol. 46: 19-27.

Sanders N.J. \& Gordon D.M. (2000) The effects of interspecific interactions on resource use and behavior in a desert ant. Oecologia 125: 436-443.

Sanders, N. J., Crutsinger, G. M., Dunn, R. R., Majer, J. D. and Delabie, J. H. C. (2007), An ant mosaic revisited: dominant ant species disassemble arboreal ant communities but co-occur randomly. Biotropica 39: 422-427.

Scharf I., Pamminger T. \& Foitzik S. (2011) Differential response of ant colonies to intruders: attack strategies correlate with potential threat. Ethology 117: 731-739.

Sih A., Cote J., Evans M., Fogarty S. \& Pruitt J. (2012) Ecological implications of behavioural syndromes. Ecol. Lett. 15: 278-289.

Silverman J. \& Brightwell R.J. (2008) The Argentine ant: challenges in managing an invasive unicolonial pest. Annu. Rev. Entomol. 53: 231-252.

Spiesman B.J. \& Cumming G.S. (2008) Communities in context: the influences of multiscale environmental variation on local ant community structure. Landscape Ecol. 23: 313-325.

Stephens D.W. (2008). Decision ecology: Foraging and the ecology of animal decision making. Cogn. Affect. Behav. Ne. 8: 475-484.

Stone, L. \& Roberts A. (1990) The checkerboard score and species distributions. Oecologia 85: 74-79.

Stringer, L.D., Haywood J. \& Lester P.J. (2007) The influence of temperature and fine-scale resource distribution on resource sharing and domination in an ant community. Ecol. Entomol. 32: 732-740. 
Southwood T.R.E. (1977) Habitat, templet for ecological strategies. J. Anim. Ecol. 46: 337-365.

Stegen J.C., Freestone A.L., Crist T.O., Anderson M.J., Chase J.M., Comita L.S., Cornell H.V., Davies K.F., Harrison S.P., Hurlbert A.H., Inouye B.D., Kraft N.J.B., Myers J.A., Sanders N.J., Swenson N.G. \& Vellend M. (2013) Stochastic and deterministic drivers of spatial and temporal turnover in breeding bird communities. Global Ecol. Biogeogr. 22: 202-212.

Suarez A.V., Tsutsui N.D., Holway D.A. \& Case T.J. (1999) Behavioral and genetic differentiation between native and introduced populations of the Argentine ant. Biol. Inv. 1: 43-53.

Svensson E.I. \& Raberg L. (2010). Resistance and tolerance in animal enemyvictim coevolution. Trends Ecol. Evol. 25: 267-274.

Taylor R.W. (1959) A note on the status of the ant species Monomorium (Notomyrmex) smithii Forel-(Hymenoptera: Formicidae). N. Z. Entomol. 2: 20-21.

Tanner C.J. (2006) Numerical assessment affects aggression and competitive ability: a team-fighting strategy for the ant Formica xerophila. P. R. Soc. B, 273: 2737-2742.

Tanner C.J. \& Adler F.R. (2009) To fight or not to fight: how context affects interspecific aggression for competing ants. Anim. Behav. 77: 297-305.

Therneau T. (2012) A Package for Survival Analysis in S. R package version 2.37-2.

Thorne B.L. \& Breisch N.L. (2001) Effects of sublethal exposure to imidacloprid on subsequent behavior of subterranean termite Reticulitermes sirginicus (Isoptera : Rhinotermitidae). J. Econ. Entomol. 94: 492-498.

Tilman D. (2004) Niche tradeoffs, neutrality, and community structure: A stochastic theory of resource competition, invasion, and community assembly. P. Natl. Acad. Sci. USA 101: 10854-10861. 
Tome H.V.V., Martins G.F., Lima M.A.P., Campos L.A.O. \& Guedes R.N.C. (2012) Imidacloprid-induced impairment of mushroom bodies and behavior of the native stingless bee Melipona quadrifasciata anthidioides. Plos One 7.

Tomizawa M. \& Casida J.E. (2005) Neonicotinoid insecticide toxicology: mechanisms of selective action. Annu. Re». Pharmacol. Toxicol. 45: 247-268.

Toms J.D. (2013) Linking behavior and community ecology: interspecific aggression provides evidence for competition between a migrant and resident warbler. Ethology 119: 1057-1066.

Vander Meer R.K. \& Morel L. (1998) Nestmate recognition in ants. In: Pheromone communication in social insects (eds Vander Meer R.K., Breed M.D., Winston M. \& Espelie K.E.) p. 368. Westview Press, Boulder, CO.

Vepsäläinen K. \& Pisarski B. (1982) Assembly of island ant communities. Ann. Zool. Fenn. 19: 327-335.

Vermeij G. J. (1982) Unsuccessful predation and evolution. Am. Nat. 120: 701-720.

Victorsson J. (2012) Semi-field experiments investigating facilitation: arrival order decides the interrelationship between two saproxylic beetle species. Ecol. Entomol. 37: 395-401.

Wagner N.D., Hillebrand H., Wacker A. \& Frost P.C. (2013) Nutritional indicators and their uses in ecology. Ecol. Lett. 16: 535-544.

Walters A.C. \& Mackay D.A. (2005) Importance of large colony size for successful invasion by Argentine ants (Hymenoptera : Formicidae): evidence for biotic resistance by native ants. Austral Ecol. 30: 395-406.

Wang X.H. \& Lester P.J. (2004) A preliminary study of the usefulness of morphometric tools for splitting the Monomorium antarcticum (Smith) complex (Hymenoptera: Formicidae), New Zealand's most common native ants. N. Z. Entomol. 27: 103-108. 
Ward D.F., Green C., Harris R.J., Hartley S., Lester P.J., Stanley M.C., Suckling D.M. \& Toft R.J. (2010) Twenty years of Argentine ants in New Zealand: past research and future priorities for applied management. N. Z. Entomol. 33: 68-78.

Wardle P. (1963) Evolution and distribution of the New Zealand flora, as affected by Quaternary climates. N. Z. J. Bot. 1: 3-17.

Warren R.J., Bahn V. \& Bradford M.A. (2012) The interaction between propagule pressure, habitat suitability and density-dependent reproduction in species invasion. Oikos 121: 874-881.

Watson G.B., Loso M.R., Babcock J.M., Hasler J.M., Letherer T.J., Young C.D., Zhu Y.M., Casida J.E. \& Sparks T.C. (2011) Novel nicotinic action of the sulfoximine insecticide sulfoxaflor. Insect Biochem. and Mol. Biol. 41: 432-439.

Weslien J., Djupstrom L.B., Schroeder M. \& Widenfalk O. (2011) Long-term priority effects among insects and fungi colonizing decaying wood. $J$. Anim. Ecol. 80: 1155-1162.

Whitehorn P.R., O'Connor S., Wackers F.L. \& Goulson D. (2012) Neonicotinoid pesticide reduces bumble bee colony growth and queen production. Science 
Wilson E.O. (1976) The organization of colony defense in the ant Pheidole dentata Mayr (Hymenoptera: Formicidae). Behav. Ecol. Sociobiol. 1: 63-81.

Wissinger S. \& McGrady J. (1993) Intraguild predation and competition between larval dragonflies: direct and indirect effects on shared prey. Ecology 74: 207-218.

Wittman S.E. \& Gotelli N.J. (2011) Predicting community structure of groundforaging ant assemblages with Markov models of behavioral dominance. Oecologia 166: 207-219.

Wolf M. \& Weissing F.J. (2012) Animal personalities: consequences for ecology and evolution. Trends Ecol. Evol. 27: 452-461.

Yu D.G. \& Davidson D.W. (1997) Experimental studies of species-specificity in cecropia-ant relatioships. Ecol. Monogr. 67: 273-294

Zavaleta E.S., Hobbs R.J. \& Mooney H.A. (2001) Viewing invasive species removal in a whole-ecosystem context. Trends Ecol. Evol. 16: 454-459.

Zhao Z.O., Davies K.A., Brenton-Rule E.C., Grangier J., Gruber M.A.M., Giblin-Davis R.M. \& Lester P.J. (2013) Diploscapter formicidae sp. n. (Rhabditida: Diploscapteridae), from the ant Prolasius advenus (Hymenoptera: Formicidae) in New Zealand. Nematology 15: 109-123. 